\title{
Street children: their social, physical and mental health : an intensive comparative field study in Eldoret, Kenya
}

Citation for published version (APA):

Ayuku, D. O. (2004). Street children: their social, physical and mental health : an intensive comparative field study in Eldoret, Kenya. [Doctoral Thesis, Maastricht University]. Datawyse / Universitaire Pers Maastricht. https://doi.org/10.26481/dis.20041104da

Document status and date:

Published: 01/01/2004

DOI:

10.26481/dis.20041104da

Document Version:

Publisher's PDF, also known as Version of record

Please check the document version of this publication:

- A submitted manuscript is the version of the article upon submission and before peer-review. There can be important differences between the submitted version and the official published version of record.

People interested in the research are advised to contact the author for the final version of the publication, or visit the DOI to the publisher's website.

- The final author version and the galley proof are versions of the publication after peer review.

- The final published version features the final layout of the paper including the volume, issue and page numbers.

Link to publication

\footnotetext{
General rights rights.

- You may freely distribute the URL identifying the publication in the public portal. please follow below link for the End User Agreement:

www.umlib.nl/taverne-license

Take down policy

If you believe that this document breaches copyright please contact us at:

repository@maastrichtuniversity.nl

providing details and we will investigate your claim.
}

Copyright and moral rights for the publications made accessible in the public portal are retained by the authors and/or other copyright owners and it is a condition of accessing publications that users recognise and abide by the legal requirements associated with these

- Users may download and print one copy of any publication from the public portal for the purpose of private study or research.

- You may not further distribute the material or use it for any profit-making activity or commercial gain

If the publication is distributed under the terms of Article $25 \mathrm{fa}$ of the Dutch Copyright Act, indicated by the "Taverne" license above, 
Street Children:

Their Social, Physical and Mental Health 


\section{A. \\ $M U N D O$}

Production: Datawyse - Universicaire Pers Maastrich

ISBN 9052784302

Copyright $\mathrm{O}$ Davici Otundo Ayukn, 2004 


\section{Street Children:}

Their Social, Physical and Mental Health

An Intensive Comparative Field Study in Eldoret, Kenya

\section{Dissertation}

to obtain the degree of Doctor at

the Universiteit Maastricht,

on the authority of the Rector,

Prof. dr. G.P.M.F. Mols,

in accordance with the decision of the board of Deans,

to be defended in public

on Thursday November 4, 2004 , at 12.00 hours a.m.

at Eldoret, Moi University

Faculty of Health Sciences, Kenya

by

David Otundo Ayuku

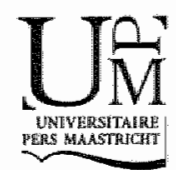




\section{SUPERVISORS}

Prof. dr. MW. deVries

Prof. dr. H.N.K Mengech, Moi University - Eldoret, Kenya

\section{CO-SUPERVISORS}

Dr. Ch. Kaplan

Dr. J. Diederiks

Dr. W. Odero, Moi University - Eldoret, Kenya

\section{DEGREE COMMITTEE}

Prof. dr. Y.Y. van Os (chairman)

Prof. dr. Y. Akonga, Moi University - Eldoret, Kenya

Dr. W.G.M. Gerver

Prof. dr. H. Philipsen 
"We must move children to the center of the world's agenda."

Nelson Mandela 



\title{
TABLE OF CONTENT
}

\author{
Y PREFACE

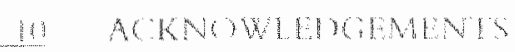 \\ 13 CHATER ।
}

Street Children: Their Social, Physical and Mental Health: An Intensive Comparative Field Study in Eldoret, Kenya

CHA'HC:

Methodological Overviews

1) CIMHLR

Street Children, Service Providers and Public Perspectives

CHAPLE

Social Network Analysis for Health and Social Interventions Among Kenyan Scavenging Street Chilldren (Published)

CUATHCS

Characteristics and Personal Social Networks of the "on" the Street, "of" the Street, Shelter and School Children in Eldoret, Kenya (Published)

Qhatilit

Psycho-Social and Nutritional Status of Street Children in Comparison to School Children: A Case of Eldoret Town (Published)

\section{MAnith}

Comparing Temperament Characteristics of Street Children and Non-Street Children in Eldoret, Kenya (Published)

H HAH $1 \mathrm{CH}$

Discussion and Conclusions 
HZ SUMMAY

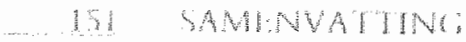

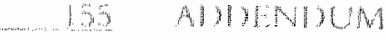

157 CURKGULUM VIHA

ISB FUBLATIONS 


\section{PREFACE}

My interest in children living under difficult circumstances dates back to 1983 when I worked for Texas Deparment of Mental Health and Mental Retardation; at Richmond State School, Texas, as a psychologist and a nember of the interdisciplinary team, monitoring self-abusive and aggressive behaviour incidents with the aim of developing behaviour therapy programs for the institutionalised children. Since then I have been intrigued with how children develop even under the most difficult conditions like street children the focus of this research.

Street children are often portrayed by the public as well as in scientific publications as a separate, socially distinct category of persons living on the fringe of society. In my research, I have tried to elacidate the social complexity that challenges this simplistic view. Taking a holistic, multi-method research perspective in this thesis, I have emphasised how street children in Eldoret, in fact, live like other Kenyans. They are embedded in similar institutions, informal work routines, cultural beliefs, and family relations.

Street children contexts are not dissimilar in many respects from others that make up the working poor in Eldoret. Still, street children do form a distinct social category both in their own minds and that of the public. In this thesis I investigate the social, physical and psychological characteristics that seem shared among street children. Throughout, however, while recognising such commonalties, I have attempted to emphasise the rich variation in experience and individual differences of these children that $J$ had the privilege of discovering as I got to know them during my daily contact as I carried out my field work.

Throughout my research and writing, 1 have been guided by research methods that include the voices of street children themselves. Their own stories concerning the events they experienced, their beliefs, and aspirations. I hope I have done them justice. 
The study was supported by an educational development grant from the Netherlands Organisation for International Cooperation in Higher Education (NUFFIC) and the Directorate General of the Dutch Ministry of International Cooperation (DGIS) to the Mastricht University Centre for International Cooperation in Academic Development (MUNDO) and Moi University, Faculty of Health Sciences. I would like to especially thank Deans Profs. H.N.K. Mengech and B.O. Khwa-Otsyula of Moi University, Faculty of Health Sciences for their support and guidance throughour the project. I wish to thank Mundo and its personnel Han Aarts, Director, Margreet te Wierik, Geraldine van Kasteren and Mike Robertson for their logistical support and friendship. I thank Rene de Bruyn for his assistance in the field with the MSNA instrument modification and later with coding the data in Maastricht. The assistance and support of the Eldoret Municipal Council Social Services Department in particle Fred Shisia and the Shelters Directors, Rescue Centre Michael, Nieswand, Benjamin Andama, Muly of Muly's Family Home and Albina Aluda of TEMAC. Moi Teaching and Referral Hospital Staff, Morris Aswani and Indiana University Doctors, Joe Mamlin, John Sidle and David Mathews were essential for the project.

I am also indebted to my Mastricht University Promoters Prof. Dr. Marten deVries and Prof. Dr. Charles Kaplan and Moi University Prof. Dr. H.N.K. Mengech and Prof. Dr. Wilson Odero for their assistance with conceptualisation of the study, fieldwork, analysis and the completion of the manuscript. Their trust in the importance of my work was instrumental in keeping the fieldwork and study alive during its prolonged and complex history. My thanks is also extend to Assoc. Prof. Dr. Jos Diederiks, the Third Promotor, for his guidance and support with the final review aspects of the manuscript. I also want to thank the Letten F. Saugtad Foundation for their support in assisting the presentation of my research at Norwegian Acadeny of Science in Oslo, IPSER for logistical and conceptual support at the inception of the project and the Stichting Wetenschaps Beoefening UM for supporting my last visit to Marstricht to finish the thesis. 
My most profound thanks of course goes to the children of Eldoret and the street children themselves to which this study is dedicated, for accepting my presence among them and participating in the study. This thanks also extends to the Shelters Directors and School Head Teachers for allowing their students to participate in the study and the Faculty of Health Sciences students for assisting in data collection. Last but certainly not least, my wife Anne and our children Lusiana, Billian, Ombisi and Brenda for their support, encouragement and patience with my often-long absences while finishing the research and writing. 


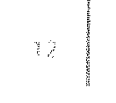


CHAPTER 1

STREET CHILDREN: THEIR SOCIAL, PHYSICAL AND MENTAL HEALTH: AN INTENSIVE COMPARATIVE FIELD STUDY IN ELDORET, KENYA 


\section{INTRODUCTION}

\section{Stret Children: Children at Risk in Developing Countries}

One of the growing and most serious child welfare problems in the world is that of street children (Ebrahim, 1984). The streets of cities in most developing countries have become homes for children unaccompanied by adults and leading an amless existence. They live by what they can obtain from handouts, recycling of waste, doing menial jobs, or by stealing. Substance abuse, commercial sex, and other forms of illegal and anti-social activities are common, resulting in regular contact with the law. Living in an unprotected and insecure environment, exploitation by drug cartels, prostitution rings, and similar illegal networks is common (Martins, et al 1993). The problem of street children today has reached a magnitude where children in such difficult circumstances have been listed among the priorities for global action at the world summit for children (Martins, et al 1995).

Despite the public attention and awareness of the social problems, plight and suffering of these children, little is actually known about their daily experience and psycho-social health. They are a "hidden population" to which most approaches are anchored in charity concerns, stigma or fear with much of current policy being ill informed by facts and systematic research. This study aims at contributing to developing a more rational approach and policy toward this social phenomenon, by employing a multi-method research methodology that takes both the qualitative voice and quantitative measures of street children's lives into account.

\section{Clildren of the Street}

The United Nations defines a street-child as "any minor for whom the street has become his or ther abode and/or source of livelihood and who is inadequntely protected, supervised or directed by responsible adults" (Veale, 1992). Cosgrave (1990) defined, "a street child is any individual under the age of majority whose behaviour is predominantly at variance with communty norms for behaviour and whose primary support for his/her development needs is not a family or family substitute". Glasser (1994) in a worldwide overview of street children concludes that, "the words used for street children often reflect the jobs they do". For example, the khate in Kathmandu, Nepal, who live by collecting trish for sale and in Kenya, where street children are known as chokon, roughly translated from Kisuahili as digging in garbage or dustbins in search of food and other valuables. An earlier generation of street boys in Kenya was known as 
parking boys (Wanaina, 1981, Dallepe, 1988) mamed for their assistance in parking and guarding cars in urban centers.

There are striking similarities between street children worldwide lending support to this study's generalizations. Le Rouxis's (1996) and Rosa's (1992) conclude based on research in South Africa and Brazil that "street children represent a world-wide phenomenon despite cultural differences". The international literature also indicates that the backgrounds of street children are also remarkably similar. They come from single parent households, out of poverty and are currently often HIV/AIDS orphans living in urban environments. These social problems have all contributed to the influx of children to the streets. The phenomenal and rapid growth of the international economy with its demanding competitive pricing has exerted pressure on local markets for cheap labour that often include children as labourers. Scheper-Hughes and Sargent (1998) and Trubilin (1995) have observed that children who once "worked" in the context of the home or community now labour in industrial and global capialist enterprises such as coffee, tea plantations and sisal estates. Children often ran away to the streets after exploitation by industrial plantations owners (Wainaina, 1981).

\section{Street Children in Africa}

Street children in Africa are a relatively recent development that reflects pattems of urbanisation and the advent of a capital economy introduced in the early $20^{\text {th }}$ century. In Dar es Salaam, Tanzania, for example, there wete between 200 and 300 street children in 1991, but by 1995 there were 3,500 (Bamurange, 1998). In 1984, in Khartoum, Sudan, street children were limited to only a few boys, but by 1990, "street boys were a predictable part of the landscape" (Dodge \& Raundalen, 1991). In South Africa, all street children ane of African origin, with no white children on the streets, a fact reflective of South Africa's history of racial segregation and apartheid (LeRowx, 1996). Kenya too has no Asian or European street children, a reflection of racist doctrine during collonial period up to the early 1960 s. Throughout Africa, street boys greatly outnumber stret girls becatise girls are generally expected to stay at home to care for young chil dren (LeRoux, 1996), are placed in homes as servants or are severely punished if they move to the streets (Dodge \& Raundalen, 1991).

\section{Background: Kenyan Research Setting}

The current study took place in the Republic of Kenya, East Africa. Kenya covers a total area of 582,646 square km with a population estimated at 33.3 million and projected to reach 34.6 million by mid 2005. More than half of the 
population comprises young people below 18 years of age. Kenya's economy relics heavily on agriculture and over $80 \%$ of the people leave in rural areas, of which about $23 \%$ of the land is arable, the rest is arid and semi arid. The man economic challenges are poverty alleviation, public health and unemployment. Half of the population liwes below poverty line, with majority living on less than 1 USD a day (Shimoli, 1999). The HIV/AIDS pandemic has killed over 1.5 million people, and left over 1.2 million children as orphans, an estimated 2.5 million Kenyan are currenty infected by the wirus. The Kenya government is a democratic multi-party system that in collaboration with the private sector and development partners has set short, medium and long term strategies to address these challenges (NACC, 2000).

The phenomenon of street children in Kenya emanates from the European experience between 1890 and 1963. With the emergence of new cities and towns, such as Nairobi, Mombassa, Eldoret, Nakuru and Kisumu, street children became part of this new landscape. By independence, street children had increased dramatically in number and the problem has grown ever since requiring govemmental as well as voluntary and non-govemmental organisations (NGOs) responses. In 1997, the Child Welfare Society of Kenya (CWSK) estimated that there were about 625,000 children in especially difficult circumstances with over 100,000 of these chidren on the streets (Kilonzo, 1997). Already in the following year, the total number of strect children in Kenya was estimated at 135,000. This figure may be higher since there are inadequate census data for street children. For example by 1998, Nairobi had the largest number $(40,000)$ of street children, with their numbers increasingly becoming a major issue in virtually all towns in Kenya. Mombassa had an estimated number of 5000, Kisumu 4000, Kitale 2000, Nakuru 2000, Eldoret 1000 , Nyeri 450 and "Thika 520 street children (Kilonzo, 1997).

In response to the poor living conditions and the serious threat posed by street children, 56 Kenyan-based organisation responsible for children issues formed the National Children in Need Network (NCNN), under the African Network of Prevention and Protection of Child Abuse and Neglect (ANPPCAN). The NCNN cnables the concerned bodies to co-ordinate their activities, all amed at improving the living conditions of children including those that live on the strects as well as those who spend most of their time away from home. Despite the fret that the NCNN is in place, problems related to poverty and AIDS orphans (estimated at 1.2 million) continue to plague Kenyan families. Kenya is loosing an estimated 700 people per day on ADS epidemic (NACC, 2000). 
The numbers of children moving from home on to the streets of large and small towms continue to grow.

\section{STIGMA AND PUBLIC OPINION}

While fear, prejudice as well as sympathy abound the personal and social lives of street children, they have remained largely hidden from main stream life, systematic investigation and understanding. Fear of these children is rampant in the press and public mind. For example, street children are frequently observed sniffing glue in the streets. The glue bottle in the public mind has come to symbolise the defining characteristic of street children: in Kenya, that is, children are troublemakers and a threat to society. Hecht (1998) points out that, street children are occupants of a prohibited public space. Street children challenge the hierarchical worlds of home and school, and threaten the commercialised space such as stores and shopping centres. They subvert their country's social apartheid that keeps the poor out of view, they are a public nuisance. Street children, especially boys, frequently encounter violence from members of the public that sometimes result to injury or death.

A Daily Nation newspaper article (Reporter, 1998) described a fight between watchmen, taxi drivers and about 65 street children on Moi Avenue in Nairobi city centre, in which six people were injured and required hospitalisation. The fight started after a child grabbed a purse from a pedestrian, after which the fleeing boy was knocked down by a taxi. The public response to this incident characterises the growing sense of fear and apprehension about street children. For example, in the same article, the chair-lady of the Federation of Women Lawyers said, "these people pose dangers not only to security in various towns but also could disconrage tourists visiting our various towns" "In response, a spokesperson for a street children relief organisation indicated in the same article that a change of atritude was needed because "there has been a lot of stigmatisation of the street children to a point where they feel the whole world is against them", and called for public sympathy for street children's rights (Reporter, 1998). A respondent interviewed for the article chatacterised current public opinion as "many of us turn and change direction when we see these children coming, warn our children about the chokon (stret children) or pull up our windows preferring to roast in the heat of our own cars" rather than make contact.

Kenyan street children have a stigmatised social status and are constandy harassed by the police and the public fears them. They seem to lead an aimless existence 
and are involved in illegal and anti-social activities. They live apart from the legitimate social context for children: with adult guardians in school, family, and community (Suda, 1994, Human Rights Watch/Africa, Juvenile Injustice, 1997. Martins, et a1, 1993). The Kenyan street child by and large symbolises a criminal element.

\section{MULTI-METHOD DESIGN FOR GUIDING A SOCIAL RESPONSE}

It is currenty agreed upot that street children as a phenomenon of modernisation are a social problem that requires urgent public attention in Kenya. Although street children in Kenya live in an exceptionally high-risk environment, little effort has gone into improving our understating of this problem. A] thongh there are today urgent calls to lift the street child ouc of the shadow of his hidden environment, very little empirical data exist about the social networks, nutritional status, health and psychological well-being of these children. This study contributes to an emerging research priority in Kenya, as well as the international theoretical interest in developing developmental models of children under difficult circumstances.

The investigation of street children in Eldoret, a city of about 300,000 , compared 400 children from different walks of life, focusing on 2 types of street children and their sheltered or school peers. The UNICEF classification of street children served as the basis for typing children with different street experiences. "On" the stree children are those who maintain strong family ties and go home in the evening to sleep, have a well established support network but often engage in illegal activities. The "of" the street children, children who have no meaningtul functional family ties and are on the streets day and night, live in a world of decreased adult presence, increased importance of the peer group, drug and alcohol abuse.

The study was inspired by the comparative research conducted on South Arican street children (Richter, 1993). These studies combined Psychological and Anthropological comparative research designs. Specifically, defined subgroups of street children (Western society "runaways" ws. African street children; glue using strect children vs. non-glue using) were compared and contrasted to yield a better understanding of street children.

The comparative methodological approach used in this study required not only multiple group designs, but also the use of multi-methods to render a comprehensive understanding of the phenomenon of street children as well as to 
generate specific explanations of street children's behaviour biology and enviromment. Such an approach systematically integrates qualitative and quantitative strategies. This design was a cornerstone of the social psychiatric approach, "Cascade" developed in Mastricht over the last two decades (deVries, 1996 and deVries and Kaplan, 1997). This "Cascade" approach was adopted by Aptekar (1991) and his associates for investigating street children in Colombia.

Qualitative methods such as focus groups and participant observation were used in order to provide contextual information from which the walidation and interpretations of the empirical data were evaluated. Empirical research instruments were the Revised Dimensions of Temperament (DOTS-R), Maastricht Social Nework Analysis (MSNA), as well as psycho-\$ocial, physical and nutritional measures. These were added to ethnographic research methods in an attempt to understand street children phenomenon in relation to comparative groups of children. Using the "best" research practice developed in Africa and Latin America for the street children problem, I have not only gained confidence in the validity and generalisability of our results but see this multi-method and comparative approach as a model for transfer to other settings in Africa, where causal knowledge of the emerging street children phenomenon is vitally needed.

\section{STUDY OBJECTIVES}

The first intention of the study was to provide profiles of street boys and girls, to testify to the complexities of their social lives from their own perspective, as they sought to make sense of their lives, and as they endure stressful circumstances. Generalisations are expected to enterge from these detaled descriptions of the children's experiences. Following a Methodological Overview in Chapter 2, Chapter 3 reports on the stree children's own perspectives on becoming a street child, ther activities on the streets, and futwre expectations. Public perspectives and atritudes as to the canses of street children are also described.

Although the isolated and unprotected nature of the street child is often emphasised, their actual social newworks have not often been investigated. Studies have shown that given their living situations, street children seck contact with others who create stability in their existence on the streets. Once on the streets, they join peer groups that give them friendshp and support. Some have benefactors, who were ex-street children, or a friendly restaurant owner who gives them food in exchange for some minor work. (Aptekar, 1991). Campos (1994) uncovered in her study differential patterns in the social network of street 
children. Other studies demonstrate the many strengths that, street children display as they struggle to survive on the streets (Aptekar, 1988). Hence streetbased children that do not have adults to turn to in times of trouble, instead they seek out and rely on peers, institution or strangers for help (Campos, 1994).

Given the importance of social support and personal social networks in child development, this study included an in-depth analysis of the nature, extent and function of the street children ties. Current evidence pertaining to the social wulnerability and personal coping capability of street children is contradictory. For example, peer relationships are reported as erratic and unstable by some and mutual caring in others. (Aptekar, 1998, Ebrahim, 1984, Veale, 1992).

Describing the characteristics of their social networks is viewed as vital for policy and planning interventions and has therefore been given a central place in this thesis.

In addition to lacking stable adult persons in their life, street children are exposed to a variety of major life events (e.g. leaving home, arrest and violence) and minor hassles during their daily struggle to survive. Continued exposure to multiple life stresses has been linked to negative long-term outcomes such as malnutrition and high levels of psychological disturbances. Investigating the psycho-social and nutritional status of street children in comparison to their peers living at home is then an important feature to evaluate in gaining a comprehensive understanding of life on the street.

Literature review of childhood stress indicate that there are three factors that most consistently predict childhood adjustment in response to stressfull life events: temperament (a person's in born character shown in the way he/she thinks, feels and behaves), family and external support (Garmezy, 1983). DeVries (1994) described temperament as the outward manifestation of internal bio-psychological events related to arousal, vigilance, and generation of effect, social bonding and mobility. Children with a difficult temperament profile have been reported more likely to have negative social interactions with significant others such as parents, teachers and peers with resultant increased risk for adverse psychosocial development and maladjustment, while "easy" children have fewer problems (Thomas and Chess, 1977). Among the Maasai of East Africa (deVries, 1984), however, difficult children were shown to have a developmental advantage under harsh conditions. These differing results under different cultural and physical circumstances suggest that the study of street chil- 
dren's temperament may yield useful insights into their character, coping style as well as providing psychological guidelines for working with them.

Chapter 4,5,6 and 7 therefore investigate and disass social, plysical and wental heallh aspects of the street child. These chapters describe the personal social netwons of stree chil dren, their case profiles (4-5), evaluate the mutritonal status of the stret dildren (6) and weaswe the temperament of the stree dildren(7), while comparing all street children findings with reference grotps.

\section{REMARKS}

Street children are a world-wide phenomenon with similar characteristics world over. The food scavenging behaviour, substance abuse, commercial sex, and other forms of illegal and anti-social activities are shared by Kenyan street children with street children around the world. Our attempt to understand street children in Eldoret, took the perspective of viewing them as an aspect of the growing numbers of the world's homeless population often hidden from social life and scientific investigation.

Street children are historically not a new urban phenomenon. They have been present at least since the time of the Roman Empire associated with processes of modernisation and social change (Martins and Ebrahim, 1993, Aptekar, 1994). Today, the problem seems to have worsened due to changing family and social dynamics that seem to selectively expel and push some children into the street while educating others. To this is added, the public's fear and consequent hostility as well as confusion as to who street children actually are and who is ultimately responsible for them.

The intention of this work is to bring order into this confusion by suggesting more infomed, evidenced-based and practical recommendations for policy makers that take the children's characteristics and perspectives more fully into account. Policy recommendations concerning street children will not get very far if we do not first learn directy from the children themselves as to how best they can be assisted. This is something street children have thought about, and about which they hold strong opinions. I hope that in my research and writing I have been able to bring the voice of these young citizens forward. 


\section{REFERENCE}

Aptekar. L. (1988) Strect children of Cail. Durham, NC Duke University Press.

Aptekar, L. (1991) Are Colombian street children neglected? The contributions of ethographic and ethonistorical approaches to the study of children, Awthropology E Edwation Quarterly, $22,326-349$.

Aptekar, L. (1994) Street children in the developing world: A review of their condition, Cross-Culfural Restarch, $28,195-224$.

Bamurange, V. (1998) Relationships for survival - young mothers and Street youths. In Magodalena Rwebangira \& Rica Liljestrom (Eds), Haraka look before you leap: yow h a the cossroad of custom and modernity. Stotkholm: Nordiska Afrikanstitutet. Pp 221-247.

Campos, R., Marcela, R., Ude, W. \& Greco, M., Ruff, A. \& Rolf, J. Antunes, C.M., Halsey, N., Greco, D. (1994). Social Networks and Daly Activities of street youth in Belo Horizonte, Brazil. Child Development. $65319-330$.

Cosgrowe, J.G. (1990) Towards a working defintion of street children. International social work, 33 , $185-192$

Dallepe, F (1988) An Experience with street children. Undugu Society of Keny, Nairobi

DeVries, M. (1997) Recontextuatizing Psychatry, Thansultural Psychatry, Vol. 34 (2) : 185-218

DeVries, M., Kaplan, Ch., Delaspaul, Ph. (1997), Naturalistic Assessment in Psychiatry, Acta Psychiaria, VOL. 9, (2) 61-63

DeVries, M. (1984) Temperament and Infant Mortaliry among the Masai of East Africa, American Journal of Pychiarry, $141: 1189-1194$.

De Vries, M. W. (1994) Kids in context: temperament in cross-culturall perspective In Prewention and Early Intervention (Eds, Carey, W. B. and McDewit, S. C.) Brunner/Mazel, New York, pp. $126-139$.

Dodge, C.P. \& Raundnen, M. (1991) Reaching children in war Sudan, Uganda and Mozambique. Norway: Signat Forlag.

Ebrahm, G.J. (1984). Stree children. A paediantic concen of eroung proportions J Trop Pediat 30: 130-1.

Garmezy, N. (1983) Stressors in Childhood: In Stress, Coping and Derelopment in Children (Eds, Garnezy, N and Rutter, M.) McGraw-Hill, New York.

Glasser, 1. (1994) Homelessness in global perspective. New York: G. K. Hall.

I-Hunan Rights Watch/Africa (1997) Juvenile Injustice Police abuse and Detention of Street Children in Kenya, New York.

Hecht, T. (1998) At home in the street: street diblen of Northeras Bazil. New York: Cambridge University Press.

Kilonzo, O. (1997) Daily Nation Special Report (A festering menace whit power to rock developrnent: urgent action called for on street children). Nairobi. Friday, Feb. 7 pp 22-23.

Le Roux, J. (1.996) Street children in South Africa. Findings from interwews on the background of stret children in Pretoria, South Africa. Adolsame 31, 122, 423-431.

Martins, S.13. Ebrahim, G.J. (1993) Street children. Jourwal of Tropinal Paedowros 39 264-268.

Martins, S. B., Ebrahim. G.J. (1995) The female street children of Riode Jnciro: A Qualitative study of their Backurounds. J. Trop pediat Vol, $41 ; 41: 43-46$

National Aids Control Council (NACC), (2000) The Kenya National HIV/AIDS Strategic plan 2000 - 2005: populat version. Nairobi.

Reporter, (1998) The Daly Nation, April 13, Narobi.

Reporter. (1996) The People, Auguse 3, Nairobi.

Rosa, C. S. de Sontsa, R. E., Borba, R... Ebrahim, G.J. (1992) The street children of Recife a study of their background. Jum of Tropiat Pediatric $3834-40$. 
Scheper-Hughes, N. \& Sargent, C. (1998). Snall wars: In N. Scheper-Hughes \& C. Sargent (Eds).

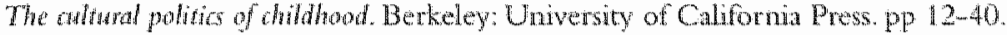

Scheper-Hughes, N. \& Hofman, D. (1998). Brazilian apartheid: streer hills and the struggle for

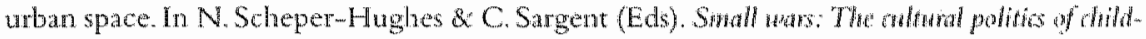
hood. Berkeley: University of Californa Press. pp 352-389

Suda $\mathrm{C}$. (1994) Report of a baseline survey on street children in Natrobi. Kenya Child Weltare Society of Kenya, Nairobi.

Thomas, A and Chess, S. (1977) Temperawest and Developmen, New York.

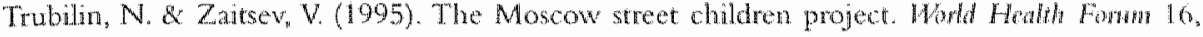
$135-137$.

Veale, A. (1992) Towards a conceptualisation of street-children: the case from Sudan and Lretand. Troatre Dewe. Rew 107.

Wainaina, J. (1981) The 'Parking boys' of Nairobi. African Joumal of Sociology, 1, 7 -45. 
4 
CHAPTER 2

METHODOLOGICAL OVERVIEWS 


\section{INTRODUCTION}

The study was a co-operative effort of the Moi University Faculty of Health Sciences, Mastricht Universicy, Departments of Hunan Biology and Social Psychiatry, The Eldoret Municipal Council Department of Social Services and an Eldoret NGO providing food, shelter, education and other services to street children. These collaborating organisations were brought into the planning and design of the study from the beginning. They were consulted for their opinions regarding the objectives, methods and contents. A thorough review of the literature was conducted while designing the study. The literature review at the time indicated that there was litte controlled, comparative research of African street children. What did exist compared African street children with other groups outside of Africa.

\section{STUDY GROUPS AND METHODS}

This research was carried out entirely in Eldoret, Kenya, embraced both quantitative and qualitative research approaches.

\section{Study Participants}

The study was a crosssectional, balanced multiple case/control design, conducted in a single Western Kenyan town of about 300,000 people. One hundred (100) children in each group, with a total of four hundred (400) children representing "on" the street children, "of" the street children, shelter (abandoned) children and a reference group of one hundred (100) primary school children from poor Eldoret neighbourhoods were recruited for the study.

Group selection was based on several meetings with stakeholders for example Municipal Council Department of Social Services). The target group of the study was the children living on the street, however, after several meetings and discussions with stakeholders and shelter directors, we learned that $70 \%$ of the street children thad been at one time or another residents of shelters, but had eventually returned to the strects. This group was given special attention in the study design to enable us to understand why some children in shelters are willing to be rehabilitated and yet others in the shelter return to the streets, refusing help. School children. were the ideal control group, demonstrating normal Kenyan school and family life. 


\section{Sindy Site}

Eldoret was an early centre for services to the faming community. In addition, soon after World War 1, Eldoret received a new impetus to its growth potential. for after 1928 a major railway line linked Mombassa directy to Uganda via Eldoret and Torono, while a branch line trawersed the Trans Naon farmlands to Kitale. One of Eldoret's greatest resources is its physical setting and climate. For set on a high plateau at about $6000 \mathrm{ft}(1800 \mathrm{~m})$ above mean sea level. Eldoret has a healthy, cool and brazing climate, with fresh winds and moderate humidity all year. Eldoret is $350 \mathrm{~km}$ West of Nairobi and $400 \mathrm{~km}$ East of Kampala.

The town acts as service centre for the hinterland by providing such services as retail and wholesale trade, sale and repair of farm implements, storage facilities for farm produce at the railway terminal, banking facilities, admmistiative services, educational (Moi University and Moi Teaching and Referral Hospital) services, entertainment facilities and a new international amport.

Central to this study, Eldoret town recorded its first street children in 1989, since then the town has experienced an influx of street children especially during the 1991-1993 ethnic clashes that erupted mainly in the Rift Valley and parts of Nyanza and Western provinces of Kenya. In 1992, after the govermment was forced to introduce a multiparty system, it is thought that the government instigated "ethnic" violence in order to punish those ethnic groups, which supported the opposition, and to reward its own supporters with illegally obtained land (Human Right Watch/Africa, 1997). Most of those displaced by the "ethnic" violence were subsistence farmers with little formal education. These people have been rendered virtually destitute following their displacement and loss of property. Many members of the internally displaced Kiknyu, Luo and Luhya ethric groups have drifted to the urban sum areas. The United Nations estinates that, as much as 75 percent of the estimated 300,000 displaced persons in the country are children (Human Right Watch/Africa, 1993). Thus, it should be emplasised here that the problem of children living in difficult conditions, in this case street children in Kenyan towns, in particular Eldoret, is real and can no longer be underestimated.

\section{RECRUITMENT OF SUBJECTS}

\section{Definition of Subjects}

The United Nations International Children's Emergency Fund (UNICEF) created a landmark report 25 years ago that is scill considered the standard defnition framework to handle the heterogeneity of the street children population 
(UNICEF, 1986). This framework inspired by the need to raise global awareness, frst signalled by United Nations 1979 Year of the Child, aimed at providing scientific rigor to the term street children which had entered the literature a century and half ago (Scanlon et al., 1998). Social network criteriare explicitly or implicitly fundamental in the defintion (Campos et al., 1994). Children "on" the street who form the majority (about two thirds in most studies) maintain strong family ties and have a sense of belonging to household. They are on the street to eam money to contribute to the household income (Ebrahim, 1984, Martins, 1993). In some studies, these children are contributing as much as 70 per cent of the total family income (Taylor and Veale, 1996). These children spend their time begging, selling woodcarwings, snacks, paper bags and other wares to the public. The significant feature of these children is that they usually return to the family home to sleep at night.

Children "of" the street are children who, for whatever reason, fully participate in street life at an economic and social level. In some cases, these children have a home too and a family available to them, but they do not go home with any degree of regularity or consistency. A large number of these children have come to Eldoret to earn money; some of them take their saving to their families once in a while. Others have no functional family ties; in some cases these children have decided to sever all ties with their families. These children beg, steal, scavenge, work in informal sector, and abuse drugs. They are completely on their own, although sone have peer (gang) support. They face stark realities of life day after day, being hemmed in by exploitative older street children and adults. School children, the control group, came from the same neighbourhood as street children. Most of the school children's parents are employed in the informal sector. And some come from single parent households (mainly headed by woment these mothers are self-employed selling fam produce in the market and streets of Eldoret. The abandoned (shelter) children are in the shelter because of the death of their parents and unavalability of appropriate extended family to take them in. Others thave been rejected or abandoned by their parents. Thus, shelter children are orphans, former street children, abandoned children and children who have been brought to the shelter by their parents because they are unable to feed and educate them.

As it has been recommended for studies of street children populations else where, we chose multiple assessment approaches (Aptekar, 1994, Campos et al. 1994). Our methods relied heavily on the nse of qualitative ethrographic techniques combined with standardised sociometric and psychometric tests (Aptekar, 1991). 


\section{Spot Observation and Key Informants}

It all began in 1996 by conduct spot observations of street children as they interacted among themselves and with the wider society employing an Anthropological fieldwork methodology (Bernard, 1994). We learned from the spot observation that Eldoret's street children were concentrated in two main "congregation sites", next to the post office and near the way to Moi University Faculty Health Sciences (Shick and Wiebel, 1981). Compared to Nairobi, these sites were not characterised by aggressive and criminal behaviour. This simplified the extension of the Geldwork to other areas. Six catchment areas were finally identified which included new congregation sites (the open air market, banking street, bus stage, and Ukwala supermarket).

A focused key informant interview guide was constructed of nine general topics with specific probes including:- causes of street children; estimated size of street children population in the city; geographic areas of origin; future prospects; names the street children are called (e g. chokom); perception of street children; what will happen to them when they grow old; hope of reducing their numbers and helping them; and possibility of rehabilitation. Recruitment of the key informant street children was on the basis of the spot observations and willing ness to participate. It was noticed that they were children that seemed more prominent in street leadership roles although these roles were quite fluid. Research assistants and the principal investigator approached these leaders and asked for their participation in the study. We then went on to other street children that did not seem to be leaders. By the time we approached them, word had spread that the University was starting a project to help street children. A small incentive of $K$ shs. 20 , was given to each street child for participating in the interview. In total, 18 key informant interviews were conducted with leader and non-leades stree children in the University research office. There were no refusals. Interviews were recorded by paper and pencil notes.

\section{Recruiment for Focus Groups}

Recruitment of the street children for the focus groups occurred after the key informant interwiews were completed. In selecting the participants for the focus groups, we again controlled for the bias toward leaders and tried to constitute each group with some non-leaders (Valdez and Kaplan, 1999). Otherwise, the groups were kept homogenous for gender although we did include both "on" the street and "of" the street children in each group (Morgan, 1997a, Morgan, $1997 \mathrm{~b}$ ). Three street children focus groups (2 male, $N=16,1$ femalle, $N=9$ ) with age range of $10-14$ were recruited. 
The focus group guide included the following general themes with specific probe items: - daily activities (where do you sleep, what do you eat, etc.); contact with parents (when, stay with them); friends'alcohol and drug use; future aspirations (work, other plans, etc); how to improve your lives (education, work, etc.); areas of town do you spend time; earnings; reasons for you becoming a street child; siblings; problems encountered on the streets; gang membership (initiation, recruitment, etc.); first initiation in the streets (age, community reaction, etc.).

To obtain the shelter children sample, we contacted three shelter programs, that of schooled and housed orphans and abandoned children. In one of the shelter programs, we recruited 1 male $(N=10)$ and 1 female $(N=5)$ in the age range 10-14 for the focus group. We adopted the same focus group guide stating the themes in a way consistent with their perception. To recruit the reference sample, we contacted two primary schools located in the poorer suburbs of Eldoret and organised 1 malle $(N=9)$ and 1 female $(N=7)$ focus group in one of these schools.

The same focus group guide was used in an adapted form. No material incentives were given to the school children. The directors of the shelter and schools' headmasters were provided the ideal incentive that their institution would be involved in an important and innovative study involving the University and the Municipal Council Department of Social Services.

The focus group discussion technique followed similar procedures that had been employed in a study of AIDS perspectives of street children in South Africa, but with some modifications (Richter and Swart-Kruger, 1993). Assurance of confidentiality was given to the participants. The focus group sessions were tape recorded and transcribed. Nicknames and initials were coded and used in the transcripts to protect the identities of the participants. The facilitator led the discussion and encouraged an open exchange of viewpoints among the participants. All participants were encouraged to speak freely.

The topics that freely emerged in the discussion were checked against the guide by the facilitator and further probed. No attempt was made to force the group participants to address a guide topic if it had not somehow emerged naturally in the discussion. Once the topics were covered, each participant was asked if he or she endorsed categories that came up in the discussion. The facilitator recorded the endorsements and went on to the next topic. For the street and shelter groups only, the facilitator specifically directed the discussion to the additional 
topics of future aspirations and policy measures to be taken in assisting street based children. Eact focus group took 1 to $1 / 2$ hours. The observational data provided detailed information on the social context in which the children interacted among themselves, with service providers and the general public. In order to collect data on the children's service providers and general public perspectives on the causes, activities, future aspirations and policy measures of the street children problem, we employed both focused key informant interviews and focus group discussions, as has been used for some time in public opinion research (Merton, 1987).

Administering the same interview guide to a convenience sample of 30 females and 25 males (with age range from 21 to 56 years) the public data was collected. The key informants were approached on the streets and in shelter programs in two main areas in the city, where street children congregated. The purpose of the study and its affiliation with the University was explained. Five of these key informants were mothers of street children and two were shelter directors. The interviews took place on the streets, at the workplace, and six were held in the homes of the key informants. We adopted the children's focus group guide, stating the themes in a way consistent with their perception of street children phenomenon. We also adopted the children focus group guide to conduct 1 focus session with 6 male service providers (mean age 26 years) working at the shelter. No material incentives were given for the interviews.

\section{Rechitment for Mastricht Social Network Analysis (MSNA)}

An adaptive, snowball sampling strategy was then applied to recruit representative "on" and "of" the street children samples (Spreen, 1992, Kaplan et al. 1987, Thompson, 1997). This sampling strategy was employed because of the non-existence of a sampling frame for the "on" the street and "of" the street children samples. Since these street children constituted the "experimental" groups in our research design, we wanted to go beyond a convenience smple that was used for our key informant and focus group interviews to draw the most representative sample that was possible. We allowed the street children to "drive" the sampling process oflering ideal and material incentives for then participation (Heckathorm, 1997).

The street based children preferred money, Kshs. 20 (USD =0.25), instead of milk and bread, because those who go home can take something to their families and others felt that githeri (a cooked mixture of maize and beans) is a better deal for them at the cost of Kshs. 5 . 
As is the standard practice, initial focal persons we knew from our focus groups were invited to nominate other street children they knew and to provide the names (mostly nicknames which were kept secure and confidential in the office file boxes), age, and self-defining characteristics of these children. These children knew a lot about others like themselves in different areas of town, whether they went home or styyed on streets at night and where we could find them.

While the focus groups with the street children leaders was critical in building trust in the population, getting the sampling moving required the engagement of an older, respected former street child leader as has been documented by other street studies (Wiebel, 1993, Whyte, 1949, Wiebal, 1990). One of the student interviewers knew Manny, a man of about 30 years old, who was still acting as a trusted leader of a large group of street children, who congregated near the Faculty. Manny was asked to help us. This was not an easy thing to ask because police were then routinely beating and detaining street children. However, after much anxiety, the ice was finally broken. The first day we succeeded in recruiting and interviewing five street children with Manny's help. Because of the concentration and time required to complete the data collection, the office in the University hospital was transformed into a "field station" (Goldstein et al., 1990). After the initial chill, the street children became increasingly eager to bring in new nominees. Street children from the other areas started appearing. When the recruitment process slowed in about two months, due to saturation of the population, the added incentive of a free medical circumcision procedure allowed us to reach the most marginalized segments of the population.

Medical students were trained and supervised by a Faculty surgeon to perform the procedure. These stibgroups were largely new migrants from ethnic groups that did not practice circumcision. The children wanted circumcision in order to gain accetance from the Eldoret street children. Another persistent logistical problon was aficiently scheduling the traned students for the interviews, given the waves of strect children that came in. Imagine entering the office at 8 am and within 10 minutes a large group of street children walks in waiting to be interviewed and, of course, to get paid.

We had to quickly go to the library, to the hospital and to the student hostel to tind our interviewers, usually wh success. The biggest obstacle came not from the students, but rather from sone sceptical colleagues (others were most supportive) who felt the mass presence of dirty street children was not appro-
priate in the University Hospital setting. 


\section{A Sub-sample of 204 Children Were Selected for a Revised Dimensions of Temperament (DOTS-R), Nutrition and Health}

Sub-samples of 204 children from the cohort of 400 children were randomly selected and further assessed. with psychometric test. None of these children had any physical or observable mental disability and their mean age was 13.97 (SD $=$ 1.63) with no significant differences between the groups. The difficulty of using standardised psychometric tests in cross-cultural research has been long documented, but the accepted opinion is that they are of some value especially wher making group comparisons (Holtzman, 1980). We used the Revised Dimensions of Temperament Survey (DOTS-R), a 54-item, factor-analycically developed self-report instrument that measures nine temperament dimensions, fol the measure of temperament (Windle and Lerner, 1986).

The DOTS- $\mathbb{R}$ measures nine independent dimensions reported as follows witl number of items and Cronbach alphas for the American elementary schoo normed sample: (1) activity level-general ( $\mathrm{N}$ of items 7 ; alpha $=.75$; high score: are characterised by high levels of energy, vigour and overt motor activity); ( 2 , activity level-sleep $(\mathrm{N}$ of items $=4$; alpha $=.81$; high scores are characterised by high level of motor activity during sleep, e.g., tossing and turning); ( 3 , approach-withdrawal $(\mathbb{N}$ of items $=7 ;$ alpha $=.77$; high scores tend to approach or move toward new persons, objects, situations, or events); (4) flexibility-rigidity $(\mathbb{N}$ of items $=5 ;$ alpha $=.62$; high scores tend to respond flexibl) to changes in the environment).; (5) Mood quality ( $\mathrm{N}$ of items $=7 ;$ alpha $=.80$ high scores are characterised by high levels of positive effect, e.g. smiling cheerful); (6) rhythmicity-sleep ( $\mathrm{N}$ of items $=6$; alpha $=.69$; high level score: are characterised by timing of daily sleep-wake cycle to be highly regular, that is varying little from day to day); (7) rhythmicity-eating $(\mathrm{N}$ of items $=5$; alpha $=$ .75; high scores are characterised by regularity of eating habits pertinent to appetite and quantity consumed); (8) rhythmicity-daily habits ( $\mathbb{N}$ of items $=5$ alpha $=.54$; high scores are characterised by regularity of diurnal activities suct: as toileting, peak period of feeling full of pep and energy and taking a rest on break in daily activities); (9) task orientation ( $\mathrm{N}$ of items $=8$; alpha $=.70$; higl: scores tend to be able to concentrate and maintain perceptual focus despite extraneous stimuli).

Scoring the DOTS-R corresponds to the subject's ratings of all items along the continuum (1) usually false, (2) more false than true, (3) more true than false. and (4) usually true. In order to limit the influence of some response set tendencies 15 randomly dispersed items were reversed in terms of directionality of scoring On the basis of the number of items per attribute on the DOTS-R the ranges of 
scores for each dimension were 7-28 for activity level-general; 4-16 for activity level-sleep; $7-28$ for approach-withdrawal; $5-20$ for flexibility-rigidity; $7-28$ for mood quality; 6-24 for thythmicity-sleep; 5-20 for thythmicity-eating; 5-20 for rhythmicity-daily habits; $5-20$ and $8-32$ for task orientation.

We chose DOTS- $R$ measure of temperament because the infant version, the Infant Temperament Questionmaire, a standardised instrument originally developed for clinical paediatrics, had been validated in several studies in Kenya (de Vries and Sameroff, 1984, deVries, 1984). The infant version, in contrast, to the DOTS-R, uses parental reports for the assessment. Parental reports using other instruments have been found to be sensitive to cultural and social differences between Kenyan and American societies (Weisz et al, 1993). Kenyan parents (of the Embu ethnic group) tend to rate particularly high levels of "over-controlled" problems (fears, feeling guilty, somatic problems) while white American parents rate their children as high in "under-controlled" problems (arguing disobedient, cruel). We expected these differences to be even more pronounced in a self-reported Kenyan primary school-aged sample where no norms exist for the DOTS-R. Both qualitative and quantitative techniques were therefore employed to evaluate the validity and reliability of the measure.

Two different translators translated the DOTS-R into Kiswahili then back into English. The accuracy of the translation was compared with the original version. No major differences were found between the original and the translated questionnaire. We then piloted the instrument with some of our school children sample and found no major difficulties in comprehension among the school children sample. We then computed the Cronbach alphas for each dimension. Our results showed in comparison to the American norms a moderate to low reliability. The rhythmicity-sleep dimension compared most closely to the American norm (alpha $=63$ ). Moderate reliabilities were found for the activity level-general $(a l p h a=.59)$, rhythmicity-eating (alpha $=.65)$ and task orientation (alphat $=.58$ ).

The rhythmicity-daily habits dimension that showed the relatively low reliability in the American normed sample also performed extremely poor in our school sample (alpha $=.13)$. Flexibility/rigidity (alpha $=.47)$ and mood (alpha $=.47)$ dimensions approached moderate reliability while activity level-sleep $($ alpha $=.34)$ and approach/withdrawal (alpha $=.47)$ were clearly low. Although these reliabilities show a worse pattern than the high to moderate scores of the American norms, we found this not surprising since the American norms were based on a sample of $100 \%$ white middle class students from a north west Penn- 
sylvania school district. Since our school sample was drawn from disadvantaged neighbourhoods with a relatively heterogeneous ethnic composition, it is not surprising that reliabilities were lower apart from the obvious cultural differences.

We continued with the administration of DOTS-R on the other three groups; taking into account the advice of cross-cultural methodologists that multiple comparison groups are desirable when standardised test norms might not be appropriate. As expected, among the shelter group the reliability was generally lower than the school children, but moderate levels were found on the activity level-general (alpha $=.57$ ) and rhythmicity-sleep $($ alpha $=.51)$ dimensions. Both groups of street children showed consistence with two notable exceptions. The "on" the street group showed a remarkably high reliability on the mood dimension (alpha $=.83$ ) that even exceeded the American norm. The "of" the street group had a moderate reliability for the rhytmicity-sleep dimension (alpha $=.51)$, for more detail see addendum table 1 .

\section{Collection of Nutritional Status}

Weight was taken using SECA model 770 digital weighing scale (SECA, Hamburg, Germany) with a unit precision of $0.1 \mathrm{~kg}(100 \mathrm{~g})$. Body weight was measured to the nearest $0.1 \mathrm{~kg}$ with the child lightly clothed.

Height was taken using a Microtoise with a unit precision of $0.1 \mathrm{~cm}(1 \mathrm{~mm})$ the standing body height (stature) was measured to the nearest $0.1 \mathrm{~cm}$ using a microtoise fixed to the wall. The subjects stood (without shoes) on a horizontal platform with his or her heels together and with the Frankfurt plane horizontal. The subjects were asked to draw themselves to full height without raising the shoulders, with hands and arms hanging relaxed, and with the feet hat on the ground [A 1]. Body mass index (BMI): antonatically calculated by weiglt:

$$
\frac{\text { (height) }}{(\text { weight) }} \quad \frac{\mathrm{kg}}{\mathrm{m}^{2}}
$$

Mid-upper-arm circumference (MUAC) was taken with non-stretch measurements tape with marker with a unt precision of $0.1 \mathrm{~cm}(1 \mathrm{~mm})$. The circumference of the left upper arm was measured at its midpoint. The midpoint was located after bending the left arm to a 90 -degree angle at the elbow. The upper arm was approximately parallel to the trunk. Using an insertion tape, the examiner identified and marked the midpoint of the arm, halfway between the tip of the acromial process and the tip of the olecranon process. The skin was marked at this point before the arm was repositioned for the circunference measure- 
ment. The left arm was used and measurement was recorded to the nearest 0.1 cm.

Skinfold thickness were measured by a Holtain skinfold thickness caliper (UK). Quadruple measurements of biceps, triceps, suprailiac and subscapular skinfold thickness was done. These measurements were taken with the children standing with the feet spread about $15 \mathrm{~cm}$ apart and the weight equally distributed between the two feet [A2] (Gibson, 1990). One investigator made all the measurements. Total skinfold: Skinfolds $(\mathrm{mm})=$ triceps + biceps + subscapular + supraliac skinfolds. Body density (BD) was estimated from the log of the total skinfold using the age $(c)$ gender $(m)$ regtession equation $B D=c-m \times \log s$ skinfolds (mm). The mid-upper-arm muscle area (M) results from the mid-upper-arm circumference (MUAC) and the triceps skinfold thickness (TSK) is used widely as an indicator of the total body muscle mass. The following equation was used: $M(m m 2)=[M U A C-(p \times T S K)] 2 / 4 p$ (Gibson, 1990 ).

Percentage of body fat (\%BF): The predication formulas developed by Deurenberg $(1991) \% \mathrm{BF}=1.51 \times \mathrm{BMl}-0.70 \times$ age $-3.6 \times 1+1.4\left(\mathrm{R}^{2} 0.38\right)$ was used to determine body fat percent on children aged $<15$ years. And prediction formula $\% \mathrm{BF}=1.20 \times \mathrm{BMI}+0.23 \mathrm{X}$ age $-10.8 \times 1-5.4\left(\mathbb{R}^{2} 0.79\right)$ was used for children aged $>16$ years

Total body fat (TBF); was calculated as TBF $(\mathrm{kg})=\% \mathrm{BF} \times$ weight $(\mathrm{kg})$

Lean body mass (LBM): or fat-free mass was calculated as LBM $(\mathrm{kg})=$ weight (kg) - TBF (kg).

\section{Health and Drug Abuse}

A structured questionnaire with questions on general. symptoms, skin symptoms, drug use and sexually infections was used. Past medical history, followed by plysical examination. The results were first published by: Ayaya, S.O. and Esamai, FO. (2001) Health Problems of Street Children in Eldoret, Kenya. East Africa Medical Jonmal, $78624-629$.

\section{Data Analysis}

One-way Analysis of Variance (ANOVA) statistical procedures were performed with the aid of the SPSS Version 10.0 to calculate the F-test values (all tests had $\mathrm{df}=3$ ) to determine significant differences between the children in extremely difficult circumstances groups. And the school children controls of means on 
each of the DOTS-R and the difficulty of temperament construct Each dimension and the difficulty of temperament construct were tested for homogeneity of variance among the groups and no significant differences were found satisfying the assumption of our ANOVA procedures. Post Hoc group companisons between the means were conducted with the help of the Scheffe test. Plots were made representing significant mean differences among groups on the DOTS-R dimensions. The mean differences among the groups on the difficulty of temperament construct representing the positioning of each group in the property space circumscribed by the difficult/easy child distinction were also plotted. For MSNA we aggregated the size and composition of the network, family sector, friendly relations, social services, frequency of contact with parents, chusters (father and mother) and the variable for affective needs, comnection needs, preference and the need for help.

For more detaled information about the instrument used and results are reported in the sulsequent chapters of the thesis and for master table see addendum 2.

\section{CONCLUSION}

Research was carried out in Eldoret town, our area of study. Multi-methods were used for data collection, which included key informant interviews, focus group discussions, temperament assessment and health/nutrition tests plus the MSNA data. Specifically, children interviewed as key informants and tested for temperament assessment and health/nutrition tests included, "on" and "of" the street children (selected by way of snowball sampling on the streets). Primary school children (as a reference group) came from poor Eldoret neighbourhoods (selected by random sampling in the schools). To obtain our sheter (abandoned) children sample (based on random sampling), we contacted three shelter programs that of schooled and housed orphans and other abandoned children. Other key informants as noted in the chapter included five mothers of street children, two shelter directors and participants of focus groups.

The interviews took place at a number of locations: for street children on the streets and at the researcher's workplace and for school children at their respective schools. In the case of shelter directors, at shelter homes; and mothers of street children were interviewed at the work place. Furthermore, temperament assessment and health/nutrition tests on sampled "on" and "of" the street chilldren took place at the researcher's work place; and for the others at the shelter or 
Table 1. Schema

\begin{tabular}{|c|c|c|c|c|}
\hline Mervberes of Pulblic & 48 & - & - & - \\
\hline Service providers & 2 & 6 & - & - \\
\hline Mother of stredt chiddren & 5 & - & - & - \\
\hline Street children (on-the and of -the street) & 18 & 25 & 200 & 102 \\
\hline Street childen boys only & $\left(14^{*}\right.$ & $16^{\star}$ & $176 *$ & $102 \times$ \\
\hline Sheter children & - & 15 & 100 & 51 \\
\hline Sebool children & - & 16 & 100 & 51 \\
\hline Total & 73 & 62 & 400 & 204 \\
\hline
\end{tabular}

* Boys on the street based groups for information only.

- KI-key informant interviews

- FGD - focus group discussion

- MSNA - Marastricht Social Network Analysis

- DOTS R - Revised Dimensions of Temperament

- Nutrition and Health

schools. Generally, interviews were recorded by note taking; while focus group discussions were tape-recorded and later transcribed by the researcher. Table I summarizes the methods used and the numbers of participants.

\section{Ethical Consideration}

Moi University institutional research ethical committee approved this study prior to commencement of data collection. The issue of informed consent is especially difficult when studying street children. Conventional procedures in child research of obtaining permission by using parents and/or institutional authorities to explain the purpose of the study was neicher practical nor suitable in samples of street children recruited outside of institutional or family settings. Consent and co-operation with a research protocol involving long psychometric assessment also increased the ethical burden. A large amount of preparatory fieldwork that would not have been necessary in a study of Western children began a process of collectively informing groups of street children the objectives, risks and benefits of the study. The social organisations of street children groups have some form of leadership. Leaders were identified and in informal conversations informed of the study and asked to "spread the word" in their groups. The leaders tended to be slightly older than the average age of the group and were capable of understanding the study purpose and translating consent information to the younger children. Material benefits were provided in the form of having immediate access to the medical services of the University 
Teaching Hospital and a subject fee of Kshs. 20 (about 0.25 US cents). The interviews were conducted in a spectal research office at the teaching hospital, which had an "open door" policy to all street children. An office located at the hospital was preferred over a street-based field station in onder to provide a non-distracting, sate and secure setting for the street child subjects. The street children samples usually appeared for the assessment in a group. The principal investigator and research assistants specially trained in informed consent principles repeated risks and benefits of the study to the assembled groups reinforcing the leaders. At the individual interview situation, the informed consent protocols were again introduced at the beginning of the session in onder to ensure understanding. Signed forms were seen as inappropriate and in some way intrusive to individuals who may be functionally illiterate. For the school and shelter samples, the heads of the orgamisation were contacted and explained the objectives of the study using conventional child research procedures. The interviewers were brought into the class or meeting room of the school and shelter, talked to the teachers or staff and given the opportunity to explain the study to the assembled children. Refusals by the children were allowed, but there was no individual child who took this option. In general, the reception of the study by the children was very enthusiastic.

\section{REFERENCES}

Aptekar, I. (1994) Street children in the developing world: A review of their condition. Cross-Cultural Research, 28, 195-224.

Aptekar, L (1991) Are Colombian street children neglected? The contributions of ethnographic and ethno historical approaches to the study of children, Anthropology \& Education Quarterly, 22, 326-349

Bemard, R.H. (1994) Research Methods in Antloropology: Qualitative and Quantiative Approaches, Sage Publications, London.

Campos, R., Antunes, C.M., Ratfali, M., Halsey, N., Ude, W., Greco, M., Groco, D. Ruf, A. Rolf, and Group, S.YS. (1994) Social Networks and daily Activities of strecte youth in Belo Horizonte, Brazil., Child Development, 65, 319-330.

Deurenberg, P., Westrstrate, J.A., Seidel, J.C. (1991) Body mass index as a measure of Body Gatness age and sex specific prediction formalary. Br. N. NMt 65, 105-114.

deVries, M. W. (1984) Temperanent and infant mortality among the Masai of East Africa, Anerican Journal of Psychatry, 141, 1189-1194.

deVries, M. W. and Sameroff, A.J. (1984) Culure and temperament: Intuences on infant temperament in three East African societies, Amorian Journat of Onthopsphiatry. 54, 83-96.

Ebrahin, G.J. (1984) Street Children: A Pediatric Concern of Growing Proportions. Jownal of Tropiacal Pediatrics 30: 130-1.

Gibson, R. (1990) Principles of nutritional status assesment. Oxford University l'ess.

Giel, R., Arango, M. V. Clinent, C.E., Harding, T.W. Ibrahim, H.A., Ladrido, I.L. and Yunis, Y. (1981) Chilhood mental disorders in prinary health care in 4 developing countries, Pediatrics, 68,677 . 
Goldstein, PJ., Spunt, B.., Miller, T, and Bellucci, B. (1990) Ethnographic feld stations In The Collection and Interpretation of Data from Hidden Populations, Vol. 98 (Ed, Lambert, E. Y) USCPO, Washington, DC, pp. 80-95.

Heckathorn, DD. (1997) Respondent-driven sampling: A new approach to the study of hidden populations, Social Problems, 44, 174-199.

Human Rights Watch/Africa (1993) Divite and Rule. State-sponsored Ethic Volence in Kenyat. New York, Washington, DC, London and Brussels: Human Rights Wach.

Human Rights Watch/Africa (1997) Jwernte Ininstice Police abuse and Derestinn of Street Children in Kerrya. New York. Washingtor, DC. London and Brusses. Muman Rights Watch.

Holman, W. (1980) Projective techniques in Handbook of Cross-cultural Methodlogy, Vol. 2 (Eds, Triandis, H. and Berry, J) Allyn \&Bacon, New York, pp. 245-278.

Kaphan, C.D., Korf, D and Sterk, C. (1987) Temporal and sacial contexes of heroin-using populations: An illustration of the snowball sampling technique, Joumal of Nerrows and Mevtal Disorders, $175,566-574$.

Martins, S and Ebrahim, G.J. (1993) Street children, fournal of Tropical Pediatrics, 39, 264-268.

Merton, R. K. (1987) The focused interview and focus groups Continuties and discontinuities. Pulvic Opinion Quarterly, 51,550-556.

Morgan, D.L. (1997a) The Focus Group Guidebook, Sage Editions, London.

Morgan, D.L. (1997b) Planning Focus Croups, Sage Editions, London.

Richter, L.M. (1990) South African "street children": Comparisons with Anglo-Annerican rumawass. In Contemporary Issues in Cross-Cultural Psychology (Eds, Bleichrodt, $\mathbb{N}$. Drenth, P.) Swets \& Zeitlinger; Ansterdatn, pp. 96-109.

Richter L. M. and Swart-Kruger, J. (1993) Knowledge, Atritudes, Beliefs and Behaviour Patterns of Stree Children in South Africa with regard to A.JDS. Department of National Health and Poputation Development, Pretoria.

Scanlon, T.J., Tomkins, A., Lynch. M.A. and Scanlon, F. (1998) Street children in Latin Anerica, British Medical Journal, 316, 1596-1600.

Shick, J. and Wiebel, W. (1981) Congregation sites for youthful multiple drug abusers: Locations for epidemiological research and intervention..., Drug and Alcohol Dependence., 7, 63-79.

Spreen, M. (1992) Rare populations, hidden populations, and link-tracing designs; what and why?, Bulletin de Methodologie Sociologique, 36, 59-70.

Taylor; M. and Veale, A. (1996) Rethinking the problem of street children: Parallel catuses and interventions In Psychology and the Developing Word(Eds, Carr, S. C. and Schumaker, J. F) Priteger, London, pp. 90-91.

Thonapson, \$.K. (1997) Adaptive sumpling in behavioral surveys In The Validity of Self-Reported Drug Use: Improving the Accuracy of Survey Estimates, Vol 167 (Eds, Harrison, L. and Hughes, A.) USGPO, Washingron, D. C., pp. 296-319.

UNICEF (1986) Children in especially difficult circumstances, UNICEF, New York.

Vulder, A and Kaplan, C.D. (1999) Reducing selection bias in the use of focus groups to inwestigate hidden populations: The case of Mexican American gang members from South Texas, Drug and Society, 14, 209-224.

Weisz, J.R., Sigrinan, M. Weiss, B. and Mosk, J. (1993) Parental reponts of behavioral and emotional problens amongetildren in Kenya, Thailand and the United States, Child Development, 64, $98-109$

Whyte, W.F (1949) Street Corner Society: The Social Stmoture of an Ltaliat Slum. University of Chicago Press., Chicago.

Wicbl, W. (1993) The Indigenous Leader Ontreach Model Intervention Manual, National Institute on Drugg Abuse, Rockville, MD. 
Wiebel, W. W. (1990) Identifying and gaining access to hidden populations In the Collection and Interpretation of Data from Hidden Populations, Vol, 98 (Ed, Lambert, E. Y) USGPO Washington, DC, pp. 4-11.

Windle, M. and Lerner, R.M. (1986) Reassessing the Dimensions of Temperamental Individuality Across the Life Span: The Revised Dimensions of Temperament Survey, Journal of Adolescen Research, 1, 213-230. 
12 


\section{CHAPTER 3}

STREET CHILDREN, SERVICE PROVIDERS AND PUBLIC PERSPECTIVES 


\section{WTRODUCTION}

The problem of street children is often considered in Eldoret as much a political issue as a public health and welfare matter. Since the 1991-1993 ethnic clashes, street children in Eldoret have increased drastically. A considerably number of street children in Eldoret are victims of the early 1991-1993 ethnic clashes that affected parts of the Rift Valley, Western and Nyanza provinces of Kenya. The clashes were mainly between Kallenjin speakers, on one hand, against Kikuyu, Luhya, and Luo ethnic groups on the other. Ethnic clashes affected various areas around Eldoret; for example Turbo, Burnt Forest, Timboroa and Kapsabet among others (Human Rights Watch/Africa (1993).

The affected families, mainly from the Kikuyu, Luhya, and Luo ethnic groups, were displaced from their homes and farms, and moved into the slum areas in Eldoret in search of safety and accommodation. These slum areas included Langas, Huruma, Kidiwa, Kamukunji and Munyaka. Most of these groups of displaced subsistence farmers found themselves in Eldoret in destitution. Given the circumstances, most of them were in no position to sustain their families. As. a result, most children of the ethnic victims have been pushed by poverty onto the streets of Eldoret (Human Rights/Africa, 1993). It is our intention to document street children's perspectives and the public's understanding of the causes of becoming a street child, their activities on the streets and their potential for rehabilitation so that policy makers such as the Eldoret Municipal Council Department of Social Services, Child Welfare Society of Kenya, and other voluntary and non-governmental organizations (NGOs) can act more effectively. In this chapter, we use key informant interviews of the public and focus group discussions with street children and the school children reference group.

\section{METHODS AND STUDY SUBJECTS}

\section{Spot Obsermation and Key Informants}

Spot observations, an Anthropological field work method (Bernard, 1994), were conducted in Eldoret town at different times of the day and night to get a picture of children's activicies on the streets as they interacted among themselves and with the wider society. We learned from the spot observation that, Eldoret's street children were concentrated in two main "congregation sites", next to the post-office and near the way to Moi University Faculty of Health Sciences (Shick and Wiebel, 1981). Later six more areas were identified which included new congregation sites at the open air market, banking street, bus stage, and Ukwala supermarket. 
It was noticed that some children semed more prominent in street leadership roles although these roles were quite fuid. The research assistants and the author approached these leaders and asked for their participation in the study. We then went on to other street children that did not seem to be leaders. By the time we approached them word had spread that the Unversity was starting a project to help street children. As a small incentive Kshs. 20 was given each street child for participating in the interview.

\section{Focus Group Intervieus}

In recruiting street children participants for the focus groups we controlled for the bias toward leaders and tried to constitute each group with some non-leaders (Valdez and Kaplan, 1999). Otherwise, the groups were kept homogenous for gender (boys/girls) although we did include both "on" the street and "of" the street children in each group. The shelter children were included because they had resided in the streets between 1 - 3 years before joining the shelters in Eldoret (Morgan, 1997a, Morgan, 1997b). Three street children focus groups were held (2 male, $N=16,1$ female, $N=9$ ) with age range of 10-14. The focus group guide included the following general themes with specific probe items: daily activities (where do you sleep, what do you eat, etc.); contact with parents (when, stay with them); friends' alcohol and drug use; future aspirations (work, other plans, etc); how to improve your lives (education, work, etc.); areas of town you spend time; earnings; reasons for you becoming a street child; siblings; problems encountered on the streets; gang membership (initiation, recruitment, etc.); first initiation in the streets (age, community reaction, etc.). To obtain the shelter children sample, we contacted three shelter programs, that of schooled and housed orphans and abandoned children. In one of the shelter programs, we recruted 1 male $(N=10)$ group and 1 female $(N=$ 5) group in the age range 10-14 for the focus group. We adopted the same focus group guide stating the themes in a way consistent with their new life in the shelter. To recruit the reference group, we contacted two primary schools located in the poorer suburbs of Eldoret and organized 1 male $(\mathbb{N}=9)$ and 1 female $(\mathrm{N}=7$ ) focus group in one of these schools.

The same focus group guide was used in an adapted form. No material incentives were given to the shelter and school children. The directors of the shelter and schools headmasters were provided with the ideal incentive that their insttution would be involved in an important and innovative study involving the University and the Municipal Council, Department of Social Services. The focus group discussion technique followed similar procedures that had been employed in a study of AIDS perspectives of street children in South Africa, but 
with some modifications (Richter and Swart-Kruger, 1993). Assurance of confidentiality was given to the participants. The focus group sessions were tape recorded and transcribed. Nicknames and initials were coded and used in the transcripts to protect the identities of the participants. The facilitator led the discussion and encouraged an open exchange of viewpoints among the participants. All participants were encouraged to speak freely. This technique was well within the social tendencies of street children to be on the whole verbal and conversational, especially with questions concerning their own experiences with life on the streets. We found that street children, by drawing on their own experiences, frequently had stories of their own to be told concerning solutions for the street children problem, the subject of one of our questions. Questions were asked in conversational format so as to encourage the informality desired in focus group techniques and spontaneous expression of individual ideas, the exchange of ideas between group members was encouraged (Irwin, et al, 1991). The topics that freely emerged in the discussion were checked against the guide by the facilitator and a research assistant and further probed. No attempt was made to force the group participants to address a guide topic if it had not somehow emerged naturally in the discussion. Once the topic was covered, each participant was asked if he or she endorsed categories that came up in the discussion. The facilitator recorded the endorsements and went on to the next topic. For the street and shelter groups only, the facilitator specifically directed the discussion to the additional topics of future aspirations and policy measures to be taken in assisting streer based children. Each focus group took 1 to $11 / 2$ hours. The data provided detailed information on the social context in which the children interacted among themselves, with service providers and the general public.

In order to collect data on the children's service providers and general public's perspectives on the causes, activities, future aspirations and policy measures of the street children problen, we employed both the key informant and focus group interview guides as has been used for some time in public opinion research (Merton, 1987). Administering the same key informant interview guide to a convenience sample of 30 females and 25 males (with age range from 21 to 56 years), the public data was collected. The key informants were approached on the streets and in shelter programs in two main areas in the city where street children congregated. The purpose of the study and its affiliation with the University were explained. Five of these key informants were mothers of street children and two were shelter directors. The interviews took place on the streets, at the workplace and in the homes of the key informants. We adopted the children's key informant interview guide, stating the themes in a 
way consistent with their perception of street children phenomenom. We also, adopted the children focus group guide to conduct 1 focus group session with 6 male service providers (mean age 26 years) working at the shelter. No material incentives were given for the interviews.

\section{ANALYSIS}

The focus group analyses were kept at the most concrete level. Counts of each subcategory endorsements were made for each focus group session and broken down by gender. The frequency distributions were compared across the groups for convergences and divergences. These distributions provided a quantitative summary overview of the qualitative findings. A grounded theory analysis was conducted of the qualitative material (Strauss and Corbin 1990). The core category of solving the street children problem by policy measures to be taken emerged in the analysis. Important strategies conditioning the solutions to the problem were perception of the causes and activities of the street children. The group's discussions were facilitated with the PI assisted with research assistants to take notes and assist in the coding and interpretation of the data.

The public key informant ( 25 men and 30 women) interviews were put under the same scrutiny. The transcriptions were read line-by-line and immediately coded for themes related to the causes, activities, future aspirations and pollicy themes. Interesting statements were highlighted and used in the interpretation of the core category of solwing the street children problens. The variation in this core category was further elaborated into a set of subcategories that represented properties of the emergent core category.

\section{RESULTS}

\section{Perspectives: Perceived Causes of Becoming a Street Child}

A wide variety of factors were explained by the street children in the focus groups as to why they were living the substantial part of their lives on the streets. They reported being on the streets because of lack of an alternative way of life, poverty at home, desire to help their families, and lack of school fees. A twelve year old boy stated that: "I am on the streets because my father and mother are dead". He further noted that, his paternal uncle, the one expected to take care of him and his siblings, was not ready to accommodate them. A similar testimony was obtained from a girl who is on the streets because both her parents are dead as a result of violence in her region. In addition, her district suffers from recur- 
ring droughts. Therefore, she says street life is a little bit more manageable than life in her home area. She argues that, "there is food, water and even security in the streets."

Poverty and family quartels were cited as reasons to why some of the children are on the streets. For instance, one boy mentioned the fights between his parents on one hand and the general misunderstanding in the family on the other, as why he is on the street. He further noted that most of family misunderstandings were due to poverty. Table $1 \mathrm{a}, 1 \mathrm{~b}$ and $1 \mathrm{c}$ causes, 2 activities and 3 policy measures combine the result of street children with shelter children because they uniformly endorsed the same items. All of the boys and three of the girls were on the street (between 1-3 years) before admission in the shelter. However, at the time of the focus group discussion, they had been at the shelter for a period of between 6 months for the majority to 4 years. Most of them kept a regular contact with their peers on the streets. We considered the shelter group to be at risk of going back to the streets if conditions at the shelter changed to worse.

Tables: la through $c$ present the summary overview of the count distribution of endorsements on the core subcategory of the perceived causes of street children for the street and shelter children focus groups, the school children reference group and the shelter service providers. The endorsements are broken down, by male and female when appropriate. For the street based and shelters children, they concurred in their most frequent endorsements such as the subcategories of poverty, lack of food and love and lack of school fees. These three subcategom ries all express the sense of physical and emotional neglect of some kind. Ethnic clashes and abuse in the family occupy the second ranking in importance for these children. There are no gender differences in the first rankings and all participants endorsed the subcategory. Gender differences can be seen, however, in the second order rankings where most of the boys endorse ethnic clashes while only a third of the girls do. In contrast, all the girls endorse family abuse and only half of the boys. It seems that, family abuse is a cause that specifically affects girls more than boys and all of them experienced it before moving to the streets. For the school children group, less than half the numbers of subcategories of causes (4/7) were mentioned compared to the street and shelter groups, Table 1 b. The highest ranked subcategories were lack of school fees and stealing from the home. Slightly fewer endorsements were made for poverty and peer pressure (non-street children intuenced by street children to become streets children). Compared to the street and shelter children, the distribution among 
Table 1a. Count Distribution of Perceived Causes of Becoming a Street Child for Male (N) $=16)$ and Female $(\mathrm{N}=9)$ Street Children and Male $(\mathrm{N}=10)$ and Female $(\mathrm{N}=5)$ Shelter Children

\begin{tabular}{lccc}
\hline & 26 & 14 & 40 \\
Poverty & 26 & 14 & 40 \\
Lack of food and love & 26 & 14 & 40 \\
Lack of school fees & 20 & 6 & 26 \\
Clashes & 13 & 14 & 27 \\
Abuse by parents and relatives & 12 & 6 & 18 \\
Death of a parent & 11 & 6 & 17 \\
Sent by parents to get money & 6 & 2 & 8 \\
Drought: & 3 & 1 & 4 \\
Addiction to street life & & & \\
\hline
\end{tabular}

Table 1b. Count Distribution of Perceived Causes of Becoming a Street Child fot Male (M $=9)$ and Female $(\mathrm{N}=7)$ School Children

\begin{tabular}{|c|c|c|c|}
\hline Lack of school fees & 9 & 7 & 16 \\
\hline Stole from home & 9 & 7 & 16 \\
\hline Poverty & 8 & 6 & 1.4 \\
\hline Peer pressute & 6 & 6 & 12 \\
\hline
\end{tabular}

Table 1c. Count Distribution of Perceived Causes of Becoming a Street Child by Service Providers $(\mathrm{N}=6)$

\begin{tabular}{lccc}
\hline Poverty & 6 \\
Family breaks-up & 6 \\
Single motherhood & 6 \\
Rural-urban migration & 6 \\
Peer pressure & 4 \\
Alcoholic parens & 3 \\
Lack of lowe & 2 \\
Abusc by parcurs and relatives & 2 \\
\hline
\end{tabular}


subcategories was not as large for the reference group indicating a more thomogenous perspective on causes.

The main divergence of the group was on the category stole from the home. All school children endorsed this subcategory while this cause was not even mentioned by the street and shelter groups. Peer pressure is another divergence only mentioned by the school children. The lack of school fees was endorsed at a high ranking for the street and shelter as well as the reference groups. All school children endorsed this cause too. Poverty was endorsed by both groups, but at a slightly higher rank for the street and shelter groups. Another noticeable divergence is that for the reference groups there are no observable gender differences in the endorsement patterns. The school children perspective on causes was especially sensitive to the school fee issue, which along with poverty touches their daily life. Theft from the home suggests a perspective where the school children distance themselves from their street age-mates. The street children have caused their own situation through bad behaviour resulting in being chased from their own homes.

The adult service provider group has the same number of subcategories of causes as the street and shelter groups, see Table $1 \mathrm{c}$. All service providers endorsed the causes of clashes, poverty, family break-up, single motherhood and rural-urban migration. Peer pressure, alcoholic parents, lack of love and neglect/abuse has a secondary ranking. These adults mention new subcategories that did not come up in the children's focus group discussions as causes including family break-up, single motherhood, rural-urban migration and alcoholic parents. The lack of school fees subcategory is completely absent from service provides perspective. Emotional neglect (lack of love) is mentioned, but it is of less importance as a cause for the service providers compared to the street and shelter children. Their endorsements of specific subcategories not mentioned by the children such as family break-up, expressed through descriptions of increasing levels of divorce in Kenyan society, were clearly informed by a social science analysis reflecting their own professional status and aspirations.

\section{Perspectives: Children's Activities on the Streets}

To be able to stay on the streets, street children reported to behave and respond in different ways. The majority of them reported that, they were able to stay on the streets due to their dedication to their activities on the streets. Others reported to have managed to stay on the streets due to lack of alternative way of life. Patience and toughness was another aspect that was cited by some of the strect children. Generally, as noted by street children, their daily activities are 
Table 2. Count Distribution of Perceived Children's Activities on the Strets Subctegory Endorsement for Male $(\mathrm{N}=16)$ and Female $(\mathrm{N}=9)$ street Children and $\mathrm{Male}(\mathrm{N}=10)$ and Female $(\mathrm{N}=5)$ Shelter Children

\begin{tabular}{lccc}
\hline & 26 & 9 & 35 \\
Begging, scavenging & 26 & 9 & 35 \\
Saxually accing & 26 & 9 & 35 \\
Being anrested & 26 & 9 & 35 \\
Bribing authorities & 26 & 9 & 35 \\
Socialising with friends & 25 & 9 & 34 \\
Being harassed and beaten & 26 & 6 & 32 \\
Sniffing giue/using drugs & 20 & 4 & 24 \\
Stealing & 15 & 0 & 15 \\
Working & 10 & 3 & 13 \\
Supporting fanily & 8 & 0 & 8 \\
Collecting paper to sell & & &
\end{tabular}

centred on scavenging for food, begging for food and money, stealing, in search of friendship with their peers to avoid fights, and sniffing glue (and taking any other available drugs) among other activities as survival techniques while on the streets. The shelter children endorsed the same activities as the street based groups because most of them have lived on the street before they moved into the shelter.

On the other hand, the school children focus group described the street children activities as "fierce". From time to time, they see them sniff glue, fight, and steal from members of the public, and at times, beaten (even to death) by way of mob justice. In the adult service providers focus group, the emphasis is that street children spend most of their time on the streets scavenging for food. In the words of one of the service provider participant, "these boys and girls scavenge in dust bins, eat whatever food they can find, whether good or bad". He further noted that, "they also go to Eldoret open market to eat thrown away (mostly half rotten) mangoes, bananas, carrots and just anything they lay their hands on". Besides scavenging for food, the service provider focus group reports that a considerable number of street children are also sniffing glue all day long, while others are engaged in begging, stealing, exchanging sex for money (mainly girls) and collecting paper to sell (mainly boys) as a way of survival. Furthermore, the adult group consensus much like the school children reference group, perceive 
the street children basically as a delinquent population who are in the process of turning into hard-core criminals.

Table 2 presents the summary overview of the count distribution of endorsements on the core subcategory of the activities of street children and shelter children focus group. As with the causes' tables, male and femalle participants break down the endorsements. There are a large variety of activities mentioned in the group unevenly distributed. For the street children, begging and scavenging along with sexually acting, being arrested, bribing authorities, socialising with friends and being harassed and beaten are the first ranked activities. The participants elaborate being harassed and beaten as largely a victimisation experience perpetrated by the police and the public, but also by other street children. In contrast, the school children reference focus group had fairly small variety of activities (4) they perceive the street children to be doing. These could be classified as socially negative, deviant behaviour. Also, there were no differences in distribution across the endorsement. This finding supports the monolithic and stigmatised view the school children expressed in the discussion. Gender makes no difterence in this pattern.

Somewhere in between the street and schoolchildren are the adult service providers. Like the school children they had a uniform endorsement pattern. Different from the school children are noticeably more items (7), although not as many as the street and shelter children groups. They also introduced a new endorsement, peddling drugs, which neither the street and shelter children nor the school children mentioned. Although they tend towards a monolithic and deviant view of the activities of street children, they do not seem to be stigmatising them in their perspective. They do mention working as an item although they emphasise the demeaning character of the work (e.g. "petty" traders with "some" work).

\section{Porspectives: The Cone Category of Soluing the Problem by Policy Mearures}

The street and shelter children focus groups concur that despite leading a hard life if given a chance, for example to go to school or attain some training, in driving, masonry or carpentry they would lead a better life and also help others in the same situation. In response to the discussion of what society can do to help them come out of the street life, specifically, both older and younger street children said that, individual members of sociery, the government or any willing organizations should step in to help them leave the streets. They should first be given basic necessities - shelter, food and clothing and then be provided the opportunity of school and training. This would instil hope of getting a job and 
Table 3. Count Distribution of Solwing the Street Children Problen by Policy Measures for Male $(\mathrm{N}=16)$ and Female $(\mathrm{N}=9)$ Streec Children and Male $(\mathrm{N}=10)$ and Female $(\mathrm{N}=5)$ Shelter Children

\begin{tabular}{lccc}
\hline Provided with food, clothing and shelter & 26 & 14 & 40 \\
Provided with identity cards & 26 & 14 & 40 \\
Provided with employment & 26 & 14 & 40 \\
Proviaged with free education & 12 & 9 & 21 \\
Provided with training & 10 & 9 & 19 \\
\hline
\end{tabular}

then being able to quit the street and forge a new and respectable livelihood. On the other hand, the participants who are on the street because their parents are too poor to support them, noted that, if their parents could get support then they would be willing to go back home. Whatever help offered to them by members of society, and where need be extended to their families, would be greatly appreciated by the participants. In the course of the group discussions, the street children repeatedly emphasized that help offered by members of society should first be directed to their most urgent needs - food, shelter and clothing.

Table 3 presents the summary overview of the count distribution of endorsements on the core category. All the policy measures mentioned involve some sort of provision of services. Food, clothing and shelter, and employment I have already referred to, but a first ranking subcategory was also the provision of an identity card. An identity card is a basic bureaucratic requirement in Kenyan society in order to obtain employment and other services as a bona fide citizen. Many of the street children have not been able to obtain one because they could not come up with the necessary documents from their fanilies proving that they are Kenyan citizens. Without this card, their status as citizen is undermined and they could be treated as an "undocumented" refugee. It is therefore casy to understand why the children unanimously endorsed this measure across both genders along with the other two subcategories. Free education and training were both considered being a secondary ranking measure. Girls tend to slightly favor training/education (64\%) measures, while boys endorsed more for education $(46 \%)$. The kind of training that was most wanted was for the occupations of drivers, carpenters and tailors. 
Table 4. Count Distribution of Perceved Causes of Becoming a Street Child Subcategory Endorsement by Male $(\mathrm{N}=25)$ and Female $(N=30)$ Mernbers of the Public Key Informants

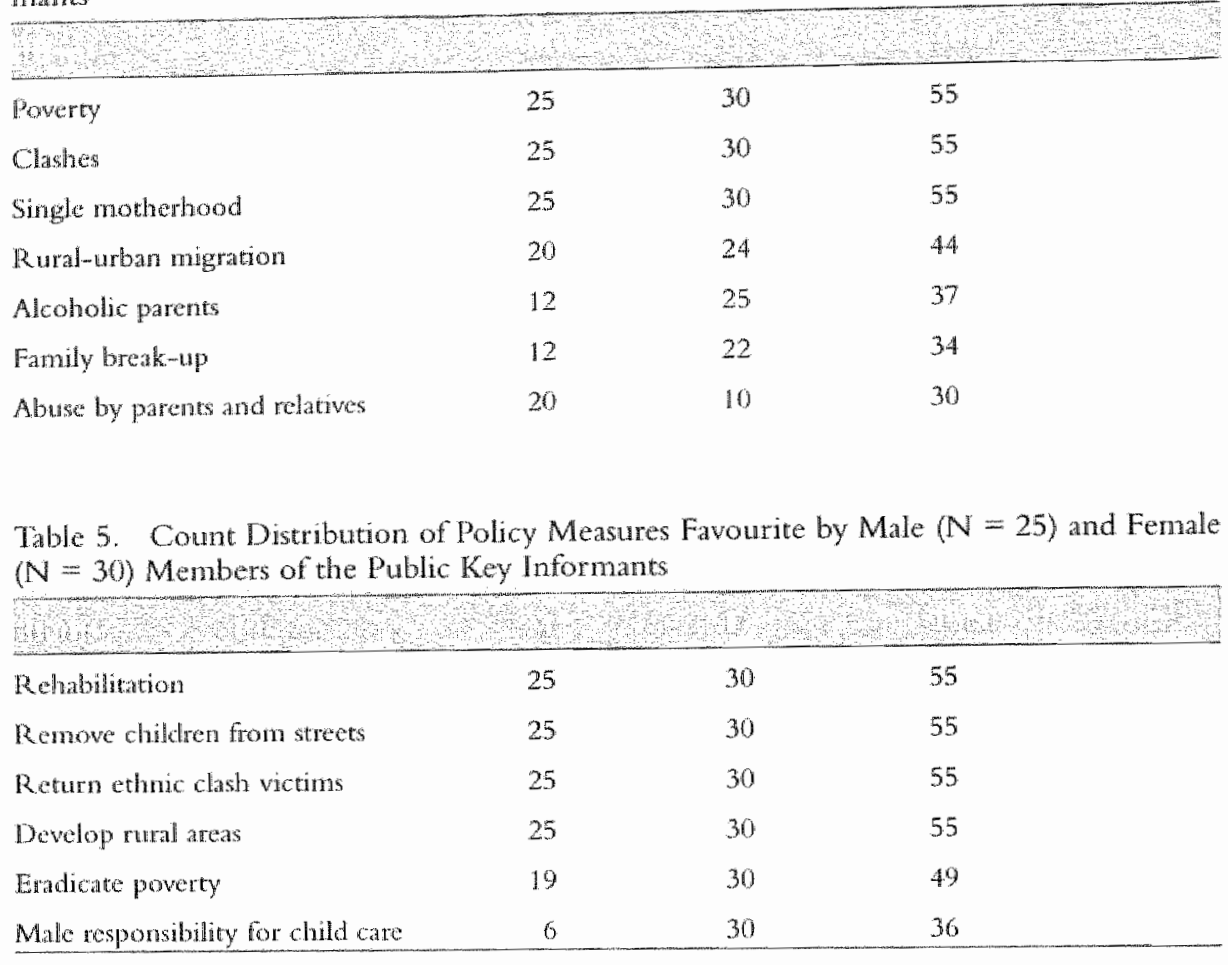

\section{Public Perspectives: Perceived Canses of Becowing a Street Child}

Public key informant interviews results of the causes of beconing street children. A mother of two street children, and a victim of 1991-1993 ethnic clashes noted that, poverty, divorce, single parenthood (especially homes headed by women), alcoholic parents, and orphan-hood are some of the main causes of street children in Eldoret. Another ethic clash victim emphasized how the chashes have almost totally alone created the phenomenon of street children in Eldoret since the early 1990 s.

The summary overview of the count distribution of perceived causes mentioned in the public key informant interviews is seen in Table 4 . Of first ranking were the endorsement of ethnic clashes and poverty. Equal in ranking was for single motherhood. There were no notable gender differences in these frest ranking causes. The second ranking of rural-urban migration in the public's opinion indicates another instance of the general tendency of the public to see 
macro-sociological causes as prinary with the exception of single motherhood. Of third ranking were, endorsements having to do with dystunctional tamily causes of alcoholic parents, family break-up and abuse. Here gender differences can be detected. Women tend to mention alcohol and family break-up reflecting a special critical sensitivity to the problems associated with Kenyan husbands of which they, as well as their children, are victims. In contrast, men blame women for child abuse and prostitution.

The summary overview of the count distribution of policy measures that the government and NGOs should take into consideration what is mentioned in the interviews, presented in Table 5. Of furst ranking were the subcategories, rehabilitation, remove the children from the streets, return the ethnic clash victims to their homes and develop rural areas. This ranking fits well with the strong feeling of a considerable number of Kenyans that, as a matter of high priority, street children should forcefully be removed from the streets and be taken to government or non-governmental/charitable organisations for rehabilitation.

\section{DISCUSSION}

The street children in the focus groups reported a wide range of factors as to why they were living on the streets. At the individual level, the reason oftered by the children for leaving home were poverty, lack of food, school fee, and love, physical abuse from parents and relatives, desire to be independent and a need to earn money to assist the family (Wainaina, 1981, Dallape, 1988). Although the street children expressed physical and emotional neglect in their focus group discussion as the reasons, they did not blame their parents. In fact, there was an expressed sadness that they are on the streets and are there without their parents" consent. Furthermore, most of them expressed the fact that they do not want to be on the streets. A few of them felt however that, "it is better to be independent where nobody bothers about you and hence the street is the only place". Related to poverty is the cause of alcohol abuse. Often mentioned in the group discussions was the complex of causal factors including poverty, unemployment and alcoholism in families that makes life unbearable at home. In one boy"s words, "my parents did not go to school and therefore they do not have regular jobs. Once in a while they find odd jobs, and the little money they get they spend on busa (a local brew) and nothing remains for food or family necessitics in general". Generally, most children on the streets are there due to circumstances beyond their control. School children however, mentioned school fee and poverty as some of the reasons that force children to the streets. In addition. 
they felt that, street children caused their own situation by stealing in their homes. Street children in the discussions did admit that they stole food and other necessities from their neighbours and that their parents did not support this act, so they ran away. Peer pressure is another divergence mentioned by school children and service providers as a cause of becoming a street child. The service providers went further and mentioned family break-up, single motherhood, and migration to the urban centres.

The public endorsed without gender differences four causes for becoming a street child: poverty, clashes, single parenthood, and rural urban migration as the first ranking causes for becoming a street child. Female participants see the second ranking of alcohol and divorce initiated by the men as the principle mechanism of family break-up. One of the professionals in the sample, a male director of a shelter program, supported this women's perspective by noting that, he has four children (ages five to eleven years), who were brought to the home after they were abandoned by their parents. The father of the children deserting the family after marrying a second wife caused the abandonment. The mother soon realising that she was not financially capable of taking care of the children alone also deserted them, taking off to an unknown place. In contrast, men tend towards mentioning abuse of the child by parents and relatives as a cause without any expressed awareness of male gender role behaviour. There is even a tendency among the male public to blame the females. Thus, the lowest ranking cause, mentioned by nine male members of the public and no females was prostitution, especially among single and poor mothers. Three of the males insisted that, single mothers in slum housing, in particular those who practice prostitution, lack space to accommodate children in the same room as they entertain their clients. Therefore, "they have to send their children out of the house (mainly on the streets/alleys of slum housing) whenever a client shows up, consequendy, children slowly adapts to street life". Single and poor mothers have to turn to prostitution to support their children, but, in a vicious circle, the practices involved in commercial sex work out of the home interfere with the care of children and force them into the streets. In this case, it can also be argued that, single parenthood and prostitution are not causes in themselves but the underlying cause is poverty that has forced these women to exchange sex for money (Wainaina, 1981).

On the street, the children mentioned variety of activities they are involved in. Scavenged for food from dustbins and begging for money was frequently discussed. On the other hand, sexual activities of all sorts including commercial sex work also came up frequently in the discussions. Sexually acting is not in the 
first ranked items. Slight gender differences among the street and shelter chil dren groups can be seen with all of the boys endorsing the activities and 9 of the 14 girl participants. The most noticeable gender difference emerges in work item where a substantial majority of the boys endorse this activity and none of the girls. Also, only 3 of the girls endorsed supporting a family as an activity. In addition, less than haif $(6 / 14)$ of the girls endorses sniffing glue and using drugs and stealing (4/14) as activities. This indicates that the girls see relatively nuch of the victimization, sexual activities and socializing activities of street children life, but are excluded from the two extremes (drug abuse and stealing) of anti-social delinquency and pro-social working behaviors (Campos et al, 1994, Martins and Ebrathim, 1993). One girl participant as a matter of act stated that, "I earn my living through prostitution". She went on to explain that she knew prostitution has its own social evils and can lead to death (for example if she contracted HIV/AIDS), but since it enables her to survive on the streets, she must accept it. Other studies have noted that, HIV is not one of the children's main concerns; as their lives are dominated by more pressing survival issues such as food and shelter (Richter and Swart-Kruger, 1993).

The frequent engagements in commercial and non-commercial sexual activities include both heterosexuality and homosexuality. The group discussions leave the impression that street children are much more sexually active than one would expect of their age group. They have sex among themselves and also exchange sex for money (mainly girls) with members of the public, but also are victimized by their peers as well as nembers of the public through rape and sexual assault. Commercial sex. work by street girls may provide relatively higher levels of material and emotional support to the street girl than they could get by begging and hawking in competition with the boys. Commercial sex work of children is widespread in Kenya with low estimates of between 10,000 to 30,000 (Reporter, 2002). That commercial sex work has become an attractive option for street girls testifies to the gender-determined coping mechanisms that preval on the street. Hawking of groundnuts and sweets, nost of the time for survival not proft was also mentioned, but not as frequently as the above activities. Summing up the street economy for these children on a daily basis means begging for money to buy food and other necessities, scavenging for food, hawking small items to raise money for survival, stealing from members of the public, (money and food and whatever items of use to them or what could be sold for money), and intermittently snifong glue and other drugs available on the streets to keep them going. The reason given by Eldoret street children for sniffing glue were similar to what street children reported in Brazil including making life better by dulling hunger, by helping to forget problems, and by 
giving courage to face dangers (Campos et al, 1994., Scharf et al, 1986., Jansen et al, 1992., Scanlon et al, 1998., Berry et al, 1997). It should also be noted here that, these are the same reasons that keep children on the streets such as availability of varying daily activities that generate money and freedom from parents to abuse of drugs. This confirms the observation that the problems of street children are a reflection of both social and economic problems in Kenya.

Moreover, the street children focus groups emphasised that what they acquire from the above-mentioned activities is not enough to sustain them in their already poor living conditions. Hunger and lack of shelter (housing and proper clothing) are major problems. As far as eating as a basic necessity, street children claim that they are in no position to have breakfast, lunch and supper as required for basic health and nutrition. As one male participant explained, "on the streets there is nothing like breakfast or lunch time, you just eat whenever you are lucky to find food from dustbins, begging, stealing or whatever you can buy". Because of their daily activities to find food, they have earned a name chokora roughly translated from Kiswahili as digging in garbage or dustbins in search of food and other valuables (Dallepe, 1988). Very few children cited food donations from well wishers. Besides, almost all the street children focus groups noted that, life on the streets is tough. On daily basis, members of the public and the police harass them. As reported in one group, "here on the streets people beat us for no reason". "The group further noted that, members of the public and police regard street children as a nuisance. Therefore, as noted by them, "the police also arrests us from time to time for no apparent reason, just because we are street children". Some of the children, particularly those found in the act of stealing, are arrested by police or even can be stoned to death by the public. Some of those detained are taken to court and end up in juvenile homes. Others are locked up in police cells for days, weeks and even months, and are then released back on the streets without a proper trial (Human Right Watch/Africa: Juvenile Injustice in Kenya, 1997). Frequent beatings while in police custody were also described in the groups. The groups reported that the police tend to view street children as hardened criminals, who must be treated with severity. The children have to bribe to avoid arrest. They also must bribe the watchmen who guard various shops and other business premises in order to sleep on the veranda.

Furthermore, the activities that strect children are involved in have a negative, deviant behavioral meaning that somewhat supports the perception of the reference group and the adult service providers that street children are largely a delinquent population. The reference group thinks of themselves as the good children, while the street children are bad ones. This is evidenced in their 
descriptions of the fighting activity of street children that are perpetrated by "dirty looking boys". Also the "badness" of street children in the eyes of the school children can be seen in their accounting of mob justice anger and beating elicited by their stealing activities. There were no gender differences in the school children endorsements of street children"s activities on the streets. Somewhere in between the street and school children are the adult service providers. Their descriptions of fighting among street children were favoured by a delinquency perspective that sees street children more as perpetrators of violence than victims. This fits with their perception that drug peddling is as common an activity as begging in this population. In addition, their view of street children's sexual activities is limited to prostitution further indicating a tendency to view deviant behaviour in this street children population as essentially delinquent activities.

The street children were in favour of rehabilitation policies from society to lead a better life. However, most admitted that they are not ready to let go of street life. For instance, in the discussions, it emerged that some of the children had been admitted into the shelter programs in town and soon after were back on the streets. One of the participants accounted for the paradox in these words: "there is a lot of work (for example cleaning and farming). You are shouted at and even beaten day in day out, and you are given very little food, that is why I ran away, despite the fact that there was free education there". A large majority (about 70\%) of the street children in our focus groups who once were in a shelter, ran away because they were not ready to do farm work (among other chores), said they were offered too little food and harassed by the staff. Interestingly, this paradox was also addressed in the service providers focus group to a lesser degree. The service providers maintained that most street children are not willing to be rehabilitated or trained to be responsible citizens. They are not ready to change their bad habits for example, sniffing glue and stealing. At the same time, some of the children in the focus group discussion expressed their wish to go to school if given a chance. They argued that, after schooling, they could be in a position to get employment and lead a nomal life like other members of society. Accordingly, schooling emerged as the dominant wish of most street children. Although when it came to endorsement, only $46 \%$ of boys and $64 \%$ of girls supported education as best option. This wish is consistent with the predominant age of these children (10-1.4 years). They are school age children, and therefore their wish is quite realistic. However, the opportunity that street life offers to them is too attractive to let go of it (intemalized strect life). They would rather have provision of their basic needs such food, shelter, and also be given identity cards so that they can excise their rights as citizen to have 
access to employment, education and training. It should also be noted here that, most street children did not favour the solution to the problem of removing them from the street to rehabilitation centres, which was advocated by various authorities and members of the public. Also, both male and female members of the public see street children as a nuisance that should be forcefully removed from the streets. For instance, a University student summarized this view: "they are rude, cunning, rowdy, disrespectful, a nuisance, poor and prone to diseases. When they grow up, the men end up as criminals, car washers and watchmen; and women as prostitutes and barmaids". She further noted that, on the street, these children are arrested by the police for loitering and at times beaten or even killed by members of the public and the police. They are seen in public sniffing glue and looking intoxicated, they have created a drug subculture that the public hates. The public felt that the government should take a leading role by rehabilitating these children. First, they should be removed from the streets. Ethnic clash victims should be resettled. Rural areas should be developed and poverty eradicated. Men should take responsibility in the care of their offspring. In these rehabilitation centres, the children should be provided with education, especially technical training from which they can acquire skills as mechanics, carpenters, masons, tailors and drivers among other trades. With a trade, they can seek employment and gradually be incorporated into mainstream community life. Other children, after undergoing a rehabilitation stage, can be employed in the country's agricultural sector. Divergences in perspective between the genders can be seen in the second ranking item. Females less than males mention the eradication of poverty as a policy measures although the majority of males find this important. In contrast, only a small minority of the males mentioned the need for policies oriented towards giving more male responsibility for childcare, while all of the femalles found this important. In fact, the females uniformly mentioned all of the measures as necessary for solving the street children problem. While mentioning these policies, the members of the public also recognised that a lot more needs to be done, if the stage of rehabilitation and integration of street children in Kenya's mainstream community life can ever be reached.

The government was blamed for not caring about the clash victim's plight; this has partly contributed to the problem of street children in Eldoret. They suggested that, the government ought to resettle ethnic clash victims and this could partly encourage children affected by clashes to go back home. They also warned that, unless street children are rehabilitated, their future is bleak and most of them will end up as criminals or dead. The pessimistic feeling in the public about the chances for rehabilitation of the street children was articulated 
strongly by the director of a shetter program, "so far I have not seen any hope of them living a normal life". He further noted that, this is mainly because, there seems to be an increase in poverty stricken families, which are compelled to move to urban areas in search of jobs. But, with limited employment opportunites in Kenya, a good number of then end up as the urban poor. In most of these families, the children end up on the street. It should be also noted here that 65 percent of Kenyans are living on less than a dollar per day (World Bank, 1995). Besides, the feels, the Kenyan govermment has not addressed the problem of street children seriously. The Kenyan public has left the problem of street children to a few churches, volunteers and non-governmental organizations (NGOs). These groups have responded to the problem of street children by giving some help in form of food, clothing and, at times, shelter. The director stressed that the problem of street children should be treated as an urgent problem by the Kenya government and members of the Kenyan society. In other words, rehabilitation of street children, and their eventual integration in the mainstream of community life should not be left to the limited capacities of charity organizations, but should be treated as a collective responsibility. The alternative of treating street children as outcasts in society is no solution. Indeed, in the current situation, emphasized the director, street children are a danger to the community since most of them end up as criminals. Others who shaned this critical and professional viewpoint in our sample were a potato seller, a fruit seller, and a saloon owner at Eldoret municipal market. They noted that, the government, charitable organizations (for example churches and NGOs), and members of the Kenyan society should work together towards rehabilitation of street children.

\section{CONCLUSION}

In summary, the public blames the govermment for instigating ethnic clashes that forced the poor and subsistence farmers to migrate to the slums of Eldoret town, in search of safety and accommodation. Most of these displlaced farmers found themselves in destitution. Given these circumstances, most of them were in no position to sustain their families. As a result, most of children of the ethnic clash victims have been pushed by poverty onto the streets. On the other hand, street children recognize poverty, lack of food, school fee and love as the main cause of their present situation. They do not blame their parents for being unable to provide for their physical and emotional needs. Instead they are sympathetic to their parents circumstances. Gender differences were noted in girls endorsing being more abused by family members than boys. Girls were more sensitive to family abuse and boys to clashes. Boys know that they are the rightful inheritors of the family land and ethnic conflict has nobbed them of their cultural right. It 
should be also stressed here that the public blamed family discord as the second cause of street children. Gender differences were noted. More females endorsed alcohol abuse (most men in Kenya spent their money more on drinking than are providing for their families) and divorce. There is no functional law in Kenya that forces a man to take care of their children (in case of separation or divorce), even though customarily children belong to the men. On the other hand, the males blamed females for abusing children and for prostitution. The public want rehabilitation by removing children from the streets to institutions and resettling the ethnic clash victims. But, the children themselves were advocating for their present need fulfilment such as food, clothing, and a place to stay, identity cards, employment and assisting their parents. Gender differences were noted in public endorsements such as female favouring eradication of poverty as policy measures and having males to take more responsibility in childcare. On the other hand, long term relabilitation was not highly endorsed by street children. For instance, 12 of the 26 boys endorsed education while 9 of the 14 girls did, and for prefering training boys (10/26) and girls $(9 / 14)$. It appears that their preference for immediate needs fulfilment might feed a reluctance to abandon the streets even when better alternatives are provided. Other minor factors cited to explain the sustained interest in a street life included the availability of varying daily occupations that generated money and freedom from parents. Gender differences are quite evident in the perspectives where distinctive male and female differences could be detected on causes, activities and policy measures across street children and the public. It can be argued that, among the numerous socio-economic factors that have contributed to the problem of street children are poverty and the increasingly difficult circumstances of women as head of single-parent households. Kenyan women as in most parts of the developing world have comparatively less access to education and formal employment (World Bank, 1995). The majority of these women are in the informal sector and earn very little to support their larger fanilies. While there is shelter help available in Eldoret, those street children who are neither ready nor suitable for the religiously inspired and disciplined help available are completely left without services. Also, the perspectives of the care providers in the shelter are pessimistic and highly judgmental on the moral character of the children and the public also supported this cynicism. Indeed, the overall impression offered by the sample is that the problem of street children in Eldoret is a challenge yet to be tackled.

The main strengths of my methodology were the rapport and interaction I had with the children through spot observation and focus group discussions. These methods systematically sought to discover any social similarities and differences 
among street children by age, residence, and gender. Ethnographic techniques served as an informative way to understand street children from their own perspective through focus group discussions and the unannounced spot observation of their daily activities that emphasised observed behaviours, and shared experiences arising from social life in the streets. Specifically, the methodology sought to provide a variety of opportunities for street children and others closely involved with their lives such as service providers to speak directly to me about my own understanding of their observed belhaviour and to speak their own views on matters related to their lives. It should be noted here, that the participants in each focus group discussions showed signs of intimate knowledge of each others behaviour. When the participants were not pleased with what one of the other participants said, they told him/her to stop lying and tell the truth. I also realised that a serious limitation of the methodological design for generating causal explanation is its cross-sectional nature. Stronger results will be possible with longitudinal designs. My future plans in Eldoret start with the construction of a registry and database of the cohort used in this study for the purpose of planming longitudinal studies of family relations and related social and psychological pathologies as the children mature.

\section{REFERENCES}

Bernard, R.H. (1994) Researd Methods in Anthopology: Qudtitative and Qrantitatine Approadros, Sage Publications, London.

Berry, G.J., Heaton, R.K \& Kirby, M.W. (1997) Neuropsychological deicits of chronic inhalant abusers. In B. M. Rumack \& A.R. Temple (Eds) Management of poisoned parient. Pp 9-29. Princeton: Science Press.

Campos, R., Antunes, C.M., Rafreli, M., Halsey, N., Ude, W. Greco, M., Greco, D., Run, A. Rolf, J and Group, S.YS. (1994) Socha networks and daily activitics of street youth in Bello Horizonte, Brazil., Chid Dewlopnen, 65, 319-..330.

Dallape, F. (1988) An Experience with street children. Undugu Society Nairobi.

Human Rights Watch/Africa (1993) Dinde and Rule: start spansored atho wolence in Kanga. Now York.

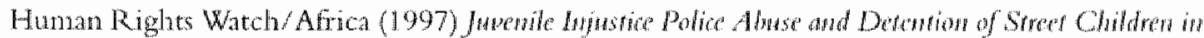
Kenya, New York.

Irwin, K., Bartrand, J, and Ndilu, M. (1991) Knowledge, Attrudes and Beliefs about HIV lnfoction and ADDs Armong Health Factory Workers and their Wives in Kinshasa, Zaire, Sonal Science and Mediciwe, Vol 32 No8, pp. $917-930$.

Jansen, 1. Richter, R and Griesel, R. (1992) Glue sniffing A comparison study of sniffers and non sniffers, Jownal of Adolescren, 15, 29-37.

Martins, S. and Ebrahim, G.I. (1993) Street children, Joumal of Tropical Pardianrs, 39, 264-268.

Merton, R.K. (1987) The focused interview and focus groups: Continuties and discontinuitics., Public Opinion Quartorly, 51,550-556.

Morgan, D.L. (1997a) The Fous Group Guidebok, Sage Edirions, London.

Morgan, D.L. (1997b) Phonnuye Forus Growps, Sage Editions, London. 
Reporter (2002) In Daly Nation, Nairobi, Kenya, pp. 19.

Richter. L.M and Swart-Kruger, J. (1953) Knowledge, Attitudes, Bedigefs and Behaviour Pateress of Stret Children in south Afrat with regard to AlDS, Deparment of National Health and Popuarion Development, Pretoria.

Scandon, T., Tomkins, A., Lynch, M.A. and Scanlon, F. (1998) Street children in Latin America, British Medical Journal, 316, 1596-1600.

Scharf, W, Powell, M. Thomas, E. (1986) Strollers-Street chidren of Cape Town. In S. Burman \& P. Reynolds (Eds), Growing up in a divided society: The contexts of childhood in South Africa. Johannesburg Ravan Press. Pp 352-389.

Shick, I. and W/ibel, W (1981) Congregation sites for youthful multple drug abusers: Locations for epidemiological research and intervention, Drug and Alcohol Dependence, $7,63-79$.

Strauss, A and Cobin, J. (1990) Baselines of Qualitative Research: Grounded Theroy Procedure and Techniques. Newbury park, CA. Sage Publications.

Valdez, A. and Kaplan, C.D. (1999) Reducing selection bias in the use of focus groups to investigate lidden populations: The case of Mexican American gang members from South Texas, Drugs and Society, 14,209-224.

Wainainat, J. (1981) The "parking boys" of Nairobi, African Journal of Sociology, 1, 7-45.

World Bank (1995) Kenya Potery Assessmen 1995, World Bank, Washington. 
CHAPTER 4

SOCIAL NETWORK ANALYSIS FOR HEALTH AND SOCIAL INTERVENTIONS AMONG KENYAN SCAVENGING STREET CHILDREN 


\section{NTROTUCTION}

More than a decade ago, UNICEF estimated approximately 100 million children and adolescents are growing up on the streets of large cities (UNICEF, 1989). Increasing poverty, war, famine and disease occurring singly or in combination has substantially increased this number. The phenomenon of street children is quite prevalent in Kenya as throughout Africa. The adverse situation posed by economic deterioration has resulted in increasing family disintegration triggering off a much greater exodus of children from the rural areas to the streets of large towns. Other children are born on the streets; some come from poverty stricken families in the peri-urban slums. In Kenya alone, it has been estimated that there will be 1 million children orphaned by AIDS in the beginning of this century, and that most of them will end up in the streets (World Bank, 1995). Following the national trend, the number of street children in Eldoret, a city with about 300,000 inhabitants in the western Kenya and the subject of this report, is also increasing.

There is an urgent need for health policy and planning in Africa and globally to develop a methodology that can systematically measure the nature and extent of the street children population and its service needs. In this chapter, we report upon how we implemented a personal social network methodology to this end. It is generally accepted that what a child does, with whom, and where, has far-reaching implications for that child's development. An analysis of the daily life social environment and context can provide significant information about child developmental trajectories. Interpersonal relationships, which constitute the social enviromment, give children the opportunity to engage in joint activities, provide information about resources (a job, a grood place to get free food, a place to sleep), and form affective thes. In most economically developed, Westem societies, parents (or parent substitutes) protect and guide children until they reach late adolescence (Bronfenbrenner, 1979). The lack of stable parental figures has been linked to a variety of negative outcomes (Kranzler, 1990, Damon, 1983). Additionally, social support from family and non-family members may alleviate the negative impact of stressful events in childhood (Roberts, 1974). Children's ties to their families and their compensatory relationships with significant others are of developmental significance (Kimchi and Schaffiner, 1990). In order to ensure those children's social ties promote and stupport mental and physical healthy development; a practical way of obtaining an assessment of the available social network is required. This information is vital in order to detect individual vulnerabilities and to design suitable individual and collective treatment intervention plans and policies. 
Given the importance of personal social networks to chid development, it is surprising that few studies offer an in-depth analysis of the nature, extent and functions of street children ties (Campos et al. 1994). Part of the problem is methodological, a practical way of assessing street chidren's social networks for the purposes of diagnosis and intervention planning is lacking. These data are vital in onder to better understand certain paradoxes in current research that inhibit policy and planning. Evidence pertaining to the vulnerability and coping of street children, for example, is contradictory; peer relationships are reported as erratic and unstable in some publications and mutual caring in others (Donald and Swart-Kruger, 1994).

\section{OBJECTIVE}

The goal of this chapter is to adapt/develop and test the Mastricht Social Network Analysis instrument for the purpose of measuring the social environment of street children. We designed a cross-sectional factorial study of 400 children in Eldoret town. Like the national trend, the number of street children in the city is increasing and the problem has become a policy priority. Our study utilized a balanced design of 100 children in three groups reflecting the UNICEF definition along with a matching school child control group drawn from similarly disadvantaged urban areas. A methodological limitation of most of the prior studies of street children in the developing world has been the lack of control groups. Therefore, the extra effort of implementing a controlled comparison research design should pay off in stronger scientific results for intervention planning and policy development.

In the situation of street children interviewing, a methodology inspired by the practicality of psychosocial medical science seems most useful (Guenther, 1992). Such a methodology should be "diagnostic" relying on not only in-depth cross-sectional data on cases, but also assembling collateral and context information. Such a multiple assessment approach has been shown to be especially appropriate for the investigation of street children as well as other "hichen populations" (wan de Coor et al., 1994, Campos et al., 1994). We measured the total sample with the Mastricht Social Network Analysis (MSNA) instrument in order to obtain a social diagnosis of the strect child's environment (Baars and Kaplan, 1996). A sub-sample $(N=204$ with $51 \mathrm{~m}$ ach group) were also measured with a general health and mutrition questionnaire and the Revised Dimensions of Temperment Survey (DOTS-R). A standardised psychometric instrument for cross-cultural assessment of children's temperament vallidated for Kenyan samples (Windle and Lemer, 1986, deVries, 1984). The sub-sample was 
also given a thorough medical physical examination. Collateral data sources came from spot observations, key informant interviews and focus groups. These data provided rich information on the context, community and service provider attitudes and the street children's own self-perception.

\section{What is Maastricht Social Network Analysis?}

A personal social network can be defined as "all persons and groups, expressed in terms of actual persons, with whom one maintains direct and more or less lasting ties that satisfy the daily requirements of life" of a given "key person" (Hammer, 1978). The structure of this collective consists of the other persons ("network members") and ties that give shape and substance to the fulfilment of the key person's ("focal person") basic psychosocial needs. This structure can be divided into various "plexus groups" (Pattison, 1981). The MSNA model subdivides the network into family, friendly relations and service provider groupings referred to as "sectors". These sectors can be subdivided further into smaller units called "clusters" varying depending on the goal and population of the study. Additional structural elements of the network are included. "Variety" is measured by selected socio-demographic characteristics of network members and "accessibility" by their geographical distance from the focal person. The characteristics of the ties between the focal person and the network nembers provide additional information and include: contact frequency; contact initiative; contact length and contact weight. Contact weight is especially important because it measures the degree to which a tie satisfies the focal person's basic psychosocial needs, i.e. "social support" (Coyne et al., 1988, Roberts, 1988, Kaplan, 1977). Four basic needs are distinguished:- affective needs, to be loved, appreciated, trusted, and emotionally supported; connection needs, to belong, to be safe, to be supported by others based on common interests, values and backgrounds; stability needs, to have enduring, evenly distributed preferential and habitual ties and material and instrumental needs, for housing, food, information and practical assistance. These MSNA categories fit well with the personal and physical support dimensions of the Envirommental Context scale developed for psychosocial studies of Latin American street children (Tyler et al., 1991).

The MSNA instrument is a semi-structured interview lasting for about one hour in which subjects are systematically guided in describing their available personal networks. The MSNA is designed primarily as a diagnostic tool for the purpose of creating an effective intervention plan to establish a social equilibrium. The methodology proceeds in distinct steps: (1) diagnosis of the structure of a person's social newwork, (2) Interpretation of the diagnosis in order to provide an understanding of both the deficiencies and resources in the social 
network, (3) Creation of an intervention plan, (4) Implementation intervention, monitoring and evaluation phases. The instrmment was developed in Dutch social psychiatry in the 1970 s for planning the social integration of chronically ill parients (Baars et al., 1997. Bolwin et al., 1996, Baars and Verschuren-Schoutissen, 1998). It followed an international trend of expanding the scope of family therapy to kinship structures and beyond (Pattison et al., 1979). In recent years, the MSNA has been applied and validated outside the Netherlands in European forensic and drug dependent populations (Kaplan et al., 2001 , Baars et al. 1997). The Kenyan study posed new challenges of testing the applicability of the MSNA to African children populations.

\section{Implementing the MSNA}

In implementing the MSNA, a large amount of preparatory fieldwork was required that would not have been necessary in a study as well-defned in European population. Our research began by observing and recording activities of Eldoret street children as they interacted among themselves and with the wider community. We employed an Anthropological fieldwork methodology (Bernard, 1994). We learned that street children were organized in loose groups or more organized gangs that were rooted in one particular area. These social organisations had some form of leadership. Leaders were identified and selected as key informants and, later, focus group participants. In some cases, we were unable to pick a single leader because leadership was shared depending upon different circumstances. We also observed that leadership was also quite fluid in the sense that each child aspired to the role. Similar findings are reported in earlier cross-cultural research (Whiting and Whiting, 1975).

We then began systematically social mapping the areas where the street children could usually be found in Eldoret town. Two main "congregation sites" are publicly known, one next to the post office and one not far away from the Faculty of Health Sciences (Shick and Wiebel, 1981). There the children beg for money, sell plastic bags, sniff solvents, loiter and sleep. Compared to Nairobi, for example, these sites are not particularly characterised by aggressive and criminal behaviour. A total six catchment areas were identified which included new congregation sites (e.g. bars and the open-air market) unknown to the public. Observations of the street children continued, but we expanded our methodology to focus groups. We needed to know more about the context before implementing the MSNA, specifically the community attitudes and perception toward street children and the children's perception of their situation. The identified street children key informants were recruited for two focus groups to explore perceptions of their social enviromment, their health and social prob- 
lems, what they ate and the attitudes they felt the wider community had about them. Each group consisted of $8-10$ participants. Parallel to these focus groups, we organised 5 separate focus groups with school children, shelter children and shelter service providers to provide us with collateral data on the same issues.

Before administering the study instruments, a SPSS Date Entry file was made so that the raw data from the interviews could efficiently be processed into the computer. An English-language version of a standard MSNA interview form of three pages, one for each sector, was brought from the Netherlands. An instrument with the least amount of paper was highly desirable given high reproduction costs. With some adjustments, the form became an essential tool in the MSNA protocol package. But even with such streamlining we faced considerable logistic problems in the course of data collection producing enough forms to keep up with the tempo of recruitment. Sometimes there was no paper, sometimes electricity and, above this photocopying and printing required extensive bureaucratic approval. Nevertheless, we were able to supply the interviewers with instruments generally within the schedule.

A special manual was then written for the MSNA Kenyan project and the interview form was translated and back translated in English and Kiswahili by a bilingual native speaker behavioural scientist. No substantive changes were needed in the instrument as a result of the back translation procedure. Two students of the Moi University Faculty of Health Sciences were trained in the administration of the MSNA and other instruments by the researcher. The training consisted of wo sessions. In the first session the background of the MSNA methodology was explained and then the students were instructed on how to do the interviewing. In the second session they were asked to conduct an MSNA interview with a fellow student. After the interview, the two students discussed their experience and results with the trainer.

Pilot interviews with four primary school students on the outskirts of Eldoret were then conducted. We found two heads of primary schools that gave us permission. In one of the schools we conducted the pilat interviews. We were brought to selected classrooms, talked to the teachers and were introduced to the school children. The children were very enthusiastic and, although they were rather shy, co-operated. Two of the students did the MSNA interviews. The students answered the questions very seriously, with a very soft voice and moved about the room as well as sat on a chair when answering the questions. Each pilot interview lasted for about 45 minutes. After these first interviews we were convinced of the face validity of the MSNA for the general Kenyan 
culture and the general population of school children. Our main concern was then that, in case of the special population of street chidren, things would be much more difficult given their reputation as being both restless and impudent.

\section{Modifying the MSNA Protocol}

The pilot phase generally demonstrated that Kenyan school children could rather easily understand the MSNA questions. There were, however, excepcions and some questions were eliminated. For instance, children's understanding of initiative was very similar to their understanding of accessibility. Both items could be reduced in meaning to "the place where the contact takes place". "The question about the way of communication ("Is it mainly by telephone, by mail or face-to-face?") showed no variation because among the Kenyan lower social classes, there is hardly any contace by telephone or mail for children. Finally, variety in the Kenyan social enviromment was modified to measure primarily ethnic variation. This had not been the case in the onginal Maastricht studies conducted in a relatively ethically homogenous small Dutch city.

Other modifications were necessary because of the translated version was too abstract for the children to understand. After extensive discussion, we decided to transform these questions into more concrete formulations. Thus, the "affection need" was changed in "to what extent can you talk to your network nember about things you love or hate and to what extent can you cry and laugh together". The "connection need" became "to what extent do you like to play games or talk about the same interests". The "stability need" translated "to what extent will you miss your network member when he or she will move to a place far away". Finally, the "material and instrumental need" was described "as "to what extent can you go to your network membet and get help if you are hungry, hurt, seek a place to sleep, protection or need money".

Table 1 presents our final model of a personal social network adapted to Kenyan street children. As indicated, some clusters of the European adult MSNA had to be eliminated and new clusters had to be added. For example, the European friendly relations cluster "neighbour" did not apply. In Kenya, a neighbour can be a person that lives in the same village or area, and most of the times there is nothing like a "neighbour-contact" in Europe, somebody one can "borrow sugar, drink a cup of coffee together or look after the house". The MSNA friendly sector also needed to be modified. The cluster" gang mates" was added. Street children who were gang members told us that all their mates were also their friends. This strong bonding of gang membership and friendship has been extensively described in the literature and therefore, in this subgroup, no distinc- 
Table 1. Modifed MSNA Sectors Subdivided into Clusters for Eldoret Street Children

\begin{tabular}{|c|c|c|}
\hline Partiectí & Friends & Colleagues \\
\hline Children & Gang mates & Schoolmates \\
\hline Father & Acquantances & Health professionals \\
\hline Mother & Club members & Church members \\
\hline Brothers/sisters & & Private helpers \\
\hline Brothers/sisters in-law & & Private institutions \\
\hline Parents-in-law & & Goverment institutions \\
\hline Grandparents & & Religious institutions \\
\hline \multirow[t]{2}{*}{ Relatwes/'sn-laws } & & Lawyer/police \\
\hline & & Teachers \\
\hline
\end{tabular}

tion was made between the gang mates and friends clusters (Baron and Tindall, 1998, Decker and Van Winkle, 1996). Another age-specific modification was related to the contact duration. Street children normally have friends they know only for a short time, a pattern of fluidity reported also among Western school children (Cairns et al., 1995). The "silent criterion" found among European adults of calling somebody a friend only when known for a relatively long time was not relevant.

The family cluster of parents in the European MSNA also needed modifying. Street children hardly could make a distinction between "brothers -or- sisters -in-law" and "other family members" clusters. They only mentioned them if personally important and often did not know their names. We also found large differences in street children contact with fathers and mothers. Although we did not split the Family menbers into father and nother clusters, we came to appreciate that when one of these parents was completely absent from the network, the family members related to that parent were also completely absent. In the Kenya context, a profound modification of the MSNA for "lost and forgotten" fanily nembers was a necessity.

We also tound that the social weltare institution cluster needed extensive modification. Social welfare in Kenya is not organized, as in northern Europe, through strong welfare state policies. Institutions (and individuals) other than the government are extensively involved in providing health and welfare services. We found, for instance, that most of the services for children in Eldorer 
are provided by religious institutions or self-identified members of religions communities and needed to be reflected as a distinct chuster. Also, a distinct cluster for individuals that regularly gave street children food or money ("private helper") had to be added.

\section{Recruiting}

After these final modifications in the instrument were made, MSNA training was expanded to more health science students $(\mathrm{N}=14$ ). Most of the students responded very well to the training and the few difficulties in comprehension were resolved by more intensive individualized attention by the researcher. When the training was completed, three shelters that serviced street children and orphans were selected to draw the "abandoned" children sample. During the visits to the shelters, the principal investigator accompanied the students and supervised the interviewers. Each interview was reviewed with the principal investigate and problems addressed.

At the first shelter, 300 children were provided with food, a place to sleep and had the opportunity to attend classes. The German director was a very religious man and he very much supported our study. Things went well because of the high discipline of the children and we obtained our MSNA and other data from a randomly selected sub-sample. The other two shelters had strong Christian beliefs too a "children's home" directed by a Kenyan couple, a section of a Roman Catholic Church in a slum area. At first, the priest was reluctant to enrol "his" children in the study, but convinced of our good moral intentions, he eventually co-operated.

An adaptive, snowball sampling strategy was then applied to recruit representam tive "on" and "of" the street children samples (Spreen, 1992, Kaplan et al., 1987, Thompson, 1997). This sampling strategy was employed because of the non-existence of a sampling frame for the street based children samples. Since these street children constituted the "experimental" groups in our research design, we wanted to go beyond a convenience sample that we had used for our key informant and focus group interviews to draw the most representative sample that was possible. We allowed the strect children to "drive" the sannling process offering material incentives for their participation (Heckathorn, 1997). They preferred money, Kshs. 20 (USD $=0.25$ ), instead of milk and bread because, those who go home can take something to their families and others felt that githeri (a cooked mixture of maize and beans) is better deal for them at the cost of Kshs. 5 . 
As is the standard practice, initial focal persons we knew from our focus groups were invited to nominate other street children they knew and to provide the names (mostly nicknames which were kept secure and confidential in the office file boxes), age, and self-defining characteristics of these children. These children knew a lot about others like themselves in different areas of town, whether they went home or stayed on streets at night and where we could find them. While the focus groups with the street children leaders was critical in building trust in the population, getting the sampling moving required the engagement of an older, respected former street child leader as has been documented by other street studies (Wiebel, 1993, Whyte, 1949, Wiebel, 1990). One of the student interviewers knew Manny, a man of about 30 years old, who was still acting as a trusted leader of a large group of street children who congregated near a bar and restaurant in the city centre. Manny was asked to help us. This was not an easy thing to ask because pollice were then routinely beating and detaining street children. However, after much anxiety, the ice was finally broken. The first day we succeeded in recruiting and interviewing five street children with Manny's help. Because of the concentration and time required to complete the data collection, our office in the academic hospital was transformed into a "field station"(Goldstein et al., 1990). After the initial chill, the street children became increasingly eager to bring in new nominees. Street children from the other areas started appearing.

\section{Analysing and Interpreting}

In a surprising short time, we had collected our data and were ready to clean and begin analysis. Our analytical approach was comparative and comprehensive going beyond exclusive qualitative and quantitative strategies (Ragin, 1987). For the purposes of this chapter we will present onlly a brief summary overview of some descriptive statistical results across our four study groups. This analysis is intended as illustrative requiring further testing and elaboration. We have purposely kept the analysis as concrete as possible describing the frequencies distributions of counts, percentages in some of the main categories of key variables.

\section{Gains}

The social diagnosis of the following series of three cases is illustrative of the scientific gains in understanding street children. With this description and interpretation accomplished (along with our other statistical analyses), we will be able to create an intervention plan targeting specific subgroups of the Eldoret street children population. Table 2 presents a summary overview of some of the structural and functional elements of the MSNA model for three Eldoret street 
Table 2. Profiling Personal Social Network Characteristic for "on" the Street Male, "of" the Street Male and "of" the Street Female Cases

\begin{tabular}{|c|c|c|c|}
\hline \multicolumn{4}{|l|}{ Structure (Coumts) } \\
\hline Size & 14 & 15 & 7 \\
\hline Family & 7 & 8 & 3 \\
\hline Friendly relation & 7 & 7 & 4 \\
\hline Service providers & 0 & 0 & 0 \\
\hline Variety & 3 & 3 & 2 \\
\hline Access family & 5 & 1 & 1 \\
\hline Access friends & 7 & 7 & 4 \\
\hline \multicolumn{4}{|l|}{ Function (Means) } \\
\hline Affection & 4.4 & 3 & 4.5 \\
\hline Comnection & 5 & 2.5 & 3.5 \\
\hline Stability & 1 & 2.5 & 3.2 \\
\hline Material resources & 2.7 & 3.8 & 4.2 \\
\hline
\end{tabular}

children. The case series represents many of the distinguishing characteristics found among the total population including age, ethnicity, gender, type of work, contact with parents and place of residence.

\section{Case 1: Jimmy}

The MSNA indicates that the total size of Jimmy's personal social network is 14 members. Jimmy's friendly sector at 7 members is equal to 7 members in his family sector. This indicated that jimmy has a healthy balance of these sectors. However, what is clearly out of balance is an absolute deficiency $(N=0)$ in service providers in the network. The question that obviously rises is that if, as Jimmy says, his mother, brother and two sisters are dependent on him for material support then who is supporting Jimmy's needs? Obviously, it is not the service provider sector.

In Jimmy's friendly sector, a good variety of ethnic groups are represented. It is clear that Jimmy does not stick only to his ethnic group for friendly support, but counts among his friends three ethnic groups, Kikuyu, Luhya and Luo. Jimmy has good access to his family and friends. All his friends live in Eldoret and 5 of 
his 7 family members are also living in the same town. This is also a healthy condition and indicates a good balance in access between these two sectors.

Jimmy has no problems in his social network in satisfyng his needs for connection and affection with mean values of 5 and 4.4 respectively. The problems in social support lie somewhat in the fulfilment of material resource needs (2.7) and most glaringly in stability (1). On the face of it, Jimmy has a well-balanced social network with the exception of the deficiency of service providers. However, the extremely low level of stability indicates a serious deficiency in the social support of Jimmy. This perception of Jimmy of an almost total lack of stability seems to be derived from two factors. On the one hand, although Jimmy is not alone on the street, his friends are also his street business competitors. This fact of life does not make for a sense of enduring friendship in the relationship. Because competition is intense, it is not unlikely that today's close friend, can be tonorrow's worst rival. On the other hand, Jimmy, as chief breadwinner of his family at 12 years old, has been allotted a strong responsibility and a commitment to his family that is out of balance with the commitment he should have to his friends. With all of this pressure to support a family instead of the family supporting him as does, for instance, school children, it is not surprising that Jimmy feels his personal social network is extremely unstable.

\section{Case 2: Mara}

Mara, a 12 -year old Luhya boy left home in Mbale district when his parents separated after the father lost a job as a cleaner for the Chavakali Municipal Council. At the time of our interview he had been on the street for 3 years. He noted: "I run away from home because my father could not afford to feed and educate the five of us". Abuse from the father and brother was another factor. On his arrival on the streets of Eldoret from his rural home, $99 \mathrm{~km}$ away, life became hard. The older boys who clamed to be initiating him into street life abused him. He was sidelined and begging could not earn him a living because the older street boys snatched all that he had earned he could only scavenge for food from garbage bins to have a meal.

Mara has been admitted twice at the Moi University Teaching and Referral Hospital because of a leg injury. On the first admission in mid-June 1997, he said that he fell down while playing with his friends and sustained an injury to his right limb. Thereafter, he was not able to walk or bear weight on the injured limb. His medical history recorded that he had a recurrence of cough and fever. Mawa admitted to the history of sniffing glue and smoking cigarettes. On further medical examination, there was a swelling on the right hip with destructed 
range of movement. After a blood test and $X$-rays, a diagnosis of tuberculosis of the hip was made, and subsequently a treatment of pankillers and skin traction was prescribed. He defaulted after one month of treatment. Three months later, he was readmitted and the earlier treatment re-stanted. Again he defaulted after two weeks and returned to the streets.

Mara's personal social network is similar in size (15) to Jimmy's and is rather representative of male street children. Similar to Jimmy, the network displays the same structural pattern of a healthy balance of the number of friendly relations and family. Like Jimmy, however, there is a complete deficiency in service providers. Mara's network, like Jimmy's, also has a good variety of ethnic group members consisting of friendly relations. However, there is one glaring defciency in the access to family members. A brother living in Langas, a slum area on the outskirts of Eldoret, is the only family member accessible to Mara. In terms of social support, Mara has a farly evenly distributed and midding level of satisfaction of his basic needs. His network does not provide him with any great satisfaction in any of his needs, but a diagnosis of a functional deficiency as was seen with Jimmy has to be ruled out.

The case of Mara clearly represents the poor health and social backgrounds, states and conditions of many scavenging street children. The case also provides a rather typical dilemma faced by medical care providers. Although treatment plans are deweloped and good medical diagnoses obtained, the scavenging street child is often not in the social or mental condition to comply with staudard clinical treatment practices. The case of Mara indicates that compliance with a treatment plan, especially for a child, seems to have the structural requirement of accessible family members to act as primary care providers. Mara only has a brother living in a slum area who obviously is not in a position to really halp Mara with his medical problens. A second factor may be the lack of a primary care physician in Mara's network. While treatment of a high quality is available at the academic hospital, this seems to be delivered in Mara's case in an impersonal way as indicated by the absence of any mention of a physician in the service provider sector.

\section{Case 3: Thru}

In contrast to Jimmy and Mara, Turu represents a case of a girl from which gender diferences among street children can be detected. An 11-year-old comes from Turkana district, a remote and wild district in Nortlwwest Kenya characterised by the odd mixture of natural beaty and violent social conflict. Her parents were killed in banditry raids, which are frequent in the area. She 
seems content with the street life, as for her, she said: "life in the streets is better then home".

Compared to Jimmy and Mara, Turu's network is small, about half the size of the two boys. Although small she has a well balance of familly and friendly relations. Like the boys, there are no service providers in her network. She also presents a network with some degree of variety in ethicity. While access to friends is good, access to family is not. This, of course, is not surprising given that she is an orphan and has migrated from a remote and unsafe area. Her main structural. deficiencies clearly lie in the absence of service providers and little access to her existing family relations.

In terns of social support, she seems to be doing somewhat better than the boys. In terms of material and emotional needs she is receiving in ther view a very high level of social support. This indeed seems related to her closeness to her friends in the streets. Turu's relatively small friendly relations sector is all girls. They have highly supportive emotional and material ties. This contrasts greatly with the male competitiveness of the boys. The bonding between these girls is especially strong in the absence of living parents and accessible family relations. Where protection is necessary, alliances with older street boys are possible. Her perception that life is better for ther now in Eldoret town streets then as an orphan in strife-torn Turkana is not unrealistic.

\section{SUMMARY}

These cases are illustrative of the substantive gains in applying the street-based MSNA methodology. Linking the MSNA to a snowball sampling as a recruitment strategy proved to be an efficient and effective way of obtaining a relatively large sample of street children that was representative of the variation in areas in the town. In a relatively short period of time (approximately 3 months) 250 street children were enrolled in the scudy and interviewed. In addition, a control group of primary school students were also recruited and interviewed as well as focus groups organised to clarify the context of the MSNA social diagnosis and to provide validating collateral data. This allowed us to start planning a case registry and database for street children in Eldoret as we move to the intervention stinge. 


\section{DISCUSSION}

This chapter has attempted to describe how we were able to transfer a social network-based assessment methodology developed in a European social psychiatric context to the situation of street children in Africa. This process involved a true collaborative learning and relearning of the foundations of social network analysis (Tenkasi and Mohrman, 1995). While the case-specific interpretations offered in this article are limited by their small numbers, it should be clear that how we implemented the MSNA methodology allowed us to gain insight into both the deficiencies and strengths in scavenging street children's social networks that otherwise would never have been possible.

Our findings support the current opinion that street children do not present a highly homogeneous population. It is necessary to make structural distinctions within the population and work with the planning and policy most suitable for specific subgroups. Primarily, the currently accepted classification of "on" the street, "of" and "abandoned" street children authorised by UNICEF is supported by our findings as it has been in previous studies (UNICEF, 1986 , Taylor and Veale, 1996, Rosa et al., 1992). Holding gender constant, we have been able to see clearly the similarities and differences in social network patterns between Jimmy who represents an "on" the street child (living with a parent at night and working the streets in the day) and Mara who represents an "of" the street child. In the African context, because of strong and large kinship relations, true "abandoned" children might be a rare phenomenon. More case studies need to be analyzed, however, to increase the confidence that the UNICEF classification is valid in contemporary Eldoret in particular and in Africa in general.

Creating an intervention plan in the next step of the MSNA application will take such differences into consideration. "On" the stree children seem to especially need social support that targets their needs for stability. The highly competitive male world is not easy for Kenyan fathers and it seems virtually impossible for a child to bear. It is hard to see what kind of social programmes could address this deficiency given the basic condition of poverty. However, something could be done to target the increasingly difficult circumstances of women as head of single parent such as Jimmy's mother. These mothers are forced to rely on their sons to solve the deficiency of not having a supportive husband or another arrangement. The survival strategy of relying on one son to act as the surrogate adult male breadwinner is in the long run counterproductive. The stress and instability of this arrangement will likely have mental and physical health consequences and undermine even further the scant family 
resources. The MSNA provided social diagnoses of "on" the street children specifyng a social network mechanism that mediates the disruptive effect of poverty on the family. Kenyan female single parents, as in most parts of the world, have comparatively less access to economic resources, education and formal employment. The case of Jimmy illustrates that the meagre earning his mother can make in the informal economic sector are not sufficient to relieve him of stress of an adult family breadwinner role. Instead of having the opportunity for education that would in the long term benefit his family, Jimmy must opt for short-term economic survival strategies.

The case of Mara is a good example of the typical "of "the street child who is quite likely not to have any daily contact with his parents and low access to family relations. In general, factors such as alcoholism, drug abuse, violence and physical or sexual abuse in the home, acting singly or in different combinations, have contributed to pushing otherwise intelligent and functioning children into the streets. At the individual level, the reasons offered by the children in our study for leaving home were family conflict, being unloved, physical or sexual abuse from a parent or relative, a desire for independence and the need to earn money. In the case of Mara the physical abuse within the family and the need to earn money seem paramount and once into the streets the situation only marginally improved if we are to accept his existing moderate levels of social support. But without more access to his family, we clearly see how vulnerable Mara is to illness and injury and his prospects for recovery.

From the focus group discussions, the public is looking to the government and NGO's to provide solutions to the street children problems and to the deficiency in access to their families. As Jill Swart found in her study of street children in South Africa, that street children network provided a high enough degree of social support to be characterised as "pseudo-families" (Swart, 1990). As the case of Mara illustrates, however, this support can never be the same as a family especially when illness strikes. Creating an intervention plan for "of " the street children would have to go beyond simple family therapy as was discovered in the origins of the network paradigm in sociall psychiatry mentioned in the beginning of this chapter. The deeper consideration of network therapy as it has been applied to substance abusers in the United States deserves further consideration (Galanter, 1990).

Our findings also illustrate the necessity to take a gender perspective when especially looking at "of" the street children. "The case of Turu shows how different the social support functions and the size of the network are. There are far fewer 
girls pushed into the streets than boys for a number of reasons and this makes for smaller network sizes since children are socialised at an early age into gender-specific groupings. What adwantages these girls may have in social support as described in the case of Turu can be oftset by the small network size. Compared to American street population norms. Turu's personall social network is about the same size as the extremely low crisis cases presenting in American drug programs (mean 6.7) (Westemeyer and Neider, 1988). The American heroin addicts in treatment had social nerworks that were about the same as our male cases (mean 14.5) who were significanty less in number than the normal American adult subjects (mean 22.4). Despite the high social support, the small network of "of" the street girls makes them vulnerable. One or two friends lost could have disastrous effects on the social support of these girls. Interventions need to be developed that are gender specific and aim at increasing the size of these street girls' networks.

Despite these subgroup differences, one finding is consistent across all cases and related to the deficiency in the size and overall balance of street children personal social networks is the total lack of service providers. While there is shelter help available in Eldoret, those street children who are neither ready nor suitable for the religiously inspired and disciplined help awailable are completely left without services. Obviously more outreach work and "drop in" center programs are warranted to try to insert at least one service provider in these street children's personal social network. It needs to be emphasized that the service needs to be personalized so that the child has a feeling of a real tie with the service provider. In the case of Mara, we saw that a health crisis could provide the opportunity for the introduction of such a relationship. From our findings, it is clear that street children must start lending for themselves at a very young age. Besides, their lifestyle exposes them to a greater than averuge risk of health problems. There is high risk of infections, skin disorders, injuries caused by violence and trafic accidents, substance abuse, sexully transmitted disesses, nutritional deficiencies and gastrointestinal disorders. Obtaining treatment is difficult because of the cost-sharing user-fees introduced in government hospials. However, given chance, of being provided with a personalised caseworker (for instance, a psychiatric social worker) most would choose to live like any other children and take dignified family life as a mater of routine.

The MSNA diagnosis provides a strongly contrasting evidence-based view opposed to the public stereotypes of the morally defective character of street children. Their personal social networks have many indications of a healthy balance in structure berween the friendly relations and family sectors. If there is 
one possible deficiency other than in the service provider sector, it lies in size, especially for the girls. On the positive side, the street children networks seem to show a healthy structural variety of ethnicity in their friendly sector. Street children of different ethnic backgrounds socialise together and do not show the same degree of ethnic exclusiveness and animosity found among adults in many segments of Kenyan society. We observed even when playing, joking and fighting there were no expressions of ethnic animosity that would be common with adults in similar situations. Street children networks should not be primarily viewed as supporting gang and organised criminal behaviour as is often implied in the public discourse. Rather street children networks can be seen as political resource for developing a modern, democratic and ethnically diverse society in Kenya.

The MSNA provided us with a core social diagnostic instrument upon which we could integrate psychiatric and general health instruments as well as supplementary qualitative information. The qualitative research approaches applied in this study were also especially appropriate in highlighting the various causes of the increasing phenomenon of street children in Kenya. Perceptions of the public, government officials and NGO representatives towards street children. though divergent, provided valuable insights that can help in developing solutions to the growing problem. The MSNA protocol is currently being developed as the framework for cases register and database for future health policy development, planning and monitoring. With the registry in place, we will be in a position to form alliances with church and private institutions in Eldoret to take the next step of intervention planning.

\section{CONCLUSION}

Our research supports the theory that "social network" is a universal concept and therefore is a good basis for developing a methodology to diagnose, interpret and intervene in health and social problems in hidden and special street children populations. Everybody in the world has family members and some kind of friends and therefore it is possible to ask certain things about the social network members of a focal person that can be compared across groups and populations. We found that most of the questions in the MSNA interview are rather easy to understand and not difficult to answer for children and provided a valid and reliable instrument in the Kenyan context. Basically, only the questions about the functions of the network (i.e. "weight") had to be modified. This may be more an issure of age than culture. However, in the Kenyan socio-cultural context, some concepts, like family, neighbours and acquaintances will have a 
slightly different meaning. Future work with the MSNA in other African cultures must first employ intensive and continuing Anthropological fieldwork in order to determine what the local people mean wirh words like friends and neighbours. It can be expected that one category will be larger across cultures. but that is, instead of being a problem of validity, an interesting fact Our results also suggest that in the African context, because of the issue of "lost and forgoten" parents, that future applications of the MSNA are especially sensivive to whether family relations are linked to the father or mother.

Finally, organisationally and politically, the MSNA methodology demonstrated that the University could effectively function as an institution to provide health and social services research capacities to the most disadvantiged segments of Kenyan society (Ayuku, 2001). Policy makers were provided with thealth and social data and policy-relevant evidence. On a hidden and special population where not even, census data had existed before. A continuing perspective that sustains this methodology is the plan of erecting a case register of strea children in Eldoret that should provide an essential policy resource for the community.

\section{REFERENCES}

Ayuku, D. (2001) A case srudy of street children in Kenya In Univesities and the Heath of the Disadwantaged(Eds, Blumenthal, D. S. and Boelen, World Heath Organization, Geneva, pp. 81 - 82.

Bars, H. and Verschuren-Schoutissen, M. (1998) Sociale-nerwerkanalyse cen diagnostiek van de matschappelijke inpassing (social network analysis: a diagnostic of social integration) in Handbock Dagbesteding (Handbook of Dodily Lifo Structuring), Vol. April Staflue Van Loghum, Houten/Antwerpen.

Baars, H.M.J, de Bruyn, R.G.M. and van den Bergh, W.M. (1997) Die Wiedereingliederung von

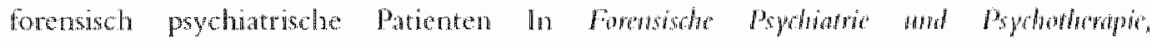

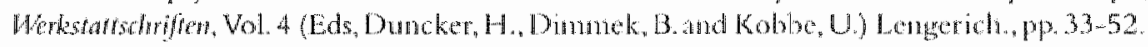

Baars, H.M.J. and Kaplan, C.D (1996) Marstrich University Department of Soc ial Psychintry. Maastricht.

Baron, S. W and Tindall, D.B. (1998) Network structure and delinquent atcitudes within a juwenile gang, Social Neruotes, 15,255-273.

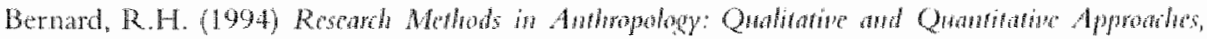
Sage Publications, London.

Bolwijn, P.H. van Santen-Hoeuft, H.M.S. Baars, H.M. Kaplan, C.D. and wan der Lindern, S. (1996) The social network characteristics of fibromyalgia patients: a controlled comporison, Arthrits Care and Resard, 9, 18-26.

Bromfenbrenner, U. (1979) The rology of Haman diwdoment, Harvard University Press. Cambridge, MA.

Cairns, R. B., Leung, M..C., Buchanan, L. and Cairns, B.D. (1995) Friendships and social networks in childrood and adolescence: Fuidiry, reliability and interchations., Child Drephyphen, 66, $1330-1345$. 
Campos, R., Antunes, C.M, Raffieli, M. Halsey, N., Ude, W., Greco, M., Greco, D., Ruft, A. Rolf, J and Group, S.YS. (1994) Social Newworks and daly Activites of strest youth in Belo Horizonte, Brazil., Child Deselopment, 65,319-330.

Coyne, J C, Wortman, $\mathrm{C}$ and Lehman, D. (1988) Marstuilling social stpport: Formats, processes, and efferts, Sage, Beverly Hills, CA.

Damon, W. (1983) Social and personality development, Norton, New York.

Decker, S.H. and Van Winkle, B. (1996) Life wh the Gang. Fantly, Frends, and Violence, Cambridge Uniwersity Press, Cambridge.

deVries, M.W. (1984) Temperament and infant mortality among the Masai of East Africa, Amer. ican Jourval of Psychiarty, 141,1189-1194.

Donald, D. and Swart-Kruger, I. (1994) The South African street child: Developmental implications, Sowth African Jourvial of Psydiology, 24, 169-174.

Galanter, M. (1990) Network Therapy for Alchol atd Drag Abuse, The Guilford Press, London.

Goldstein, PJ, Spunt, B.J., Miller, T. and Bellucc, P. (1990) Ethographic field stations In. The Colledion and Interpretation of Dan fron Hidden Popularions, Vol. 98 (Ed, Lambert, E. Y.) USGPO, Washington, DC, pp. $80-95$.

Guenther. H. (1992) Interwiewing street children in a Brazilian city, The Joumal of Social Psycholog, $132,359-367$.

Hanmer, M. (1978) Social Nerworks and schizophrenia, Schizophenia Bullevin, 4, 522-545.

Heckathorn, D.D. (1997) Respondent-driven sampling: A new approach to the study of hidden populations, Sorial Problewrs, 44,174-199.

Kaplan, B.H., Cassel,J.C. and Gore, S. (1977) Social support and health., Medical Care, 15, 47-58.

Kaplan, C.D., Broekaert, E. and Morival, M. (2001) limproving social psychiatric treatment in residential progrannes for emerging dependence groups in Europe cross-border networking, methodological innovations and substantive discoveries, huternational found of Social Welfare, $10.127-133$.

Kaplan, C.D. Korf, D and Sterk, C. (1987) Temporal and social contexts of heroin-using populations: An illustration of the snowball sampling technique, Jourwal of Nervous and Mental Disor ders, $175,566-574$.

Kinchi, J. and Schatfner, B. (1990) Childhood protective factors and stress risk In Chithood stros (Ed, Arnold , L. E.) Wiley, New York, pp. 475-500

Kranzler, E.M. (1.990) Parent deata in childhood In Chidhood stress(Ed, Arnold, L. E) Wiley. New York, pp. 405-421.

Pattison, E.M. (1981) Introduction: The social network paradigm, International joumal of Fastily Thropy $3,241-245$.

Pattison, E.M. De Francisco, D. Wood, P. Frazier, H. and Crowder, J. A. (1979) A psychosocial kinship model for fanily therapy, Anctian formal of Psydratry, 132, 1246-1251.

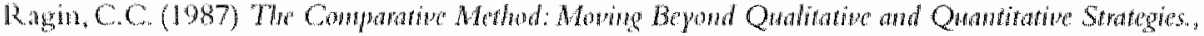
University of Califomia Press, Los Angeles.

Roberts, A.R. (Ed.) (1974) Childrod duprivan, Thomas, Springfield, ll.

Raberts, S.J. (1988) Social stpport and help-secking: Review of the literature, Adones in Nursing Situce, $10,1-11$.

Rosa, C.S.A. de Sousa, R.E.,Borba, R, and Ebrahim, G.J. (1992) The street children of recife: A study of their background, foumal of Thapiad Pedatrics, 38, 34-40.

Shick. J and Wiebed, W. (1981) Congregation sites for youthful multiple drug abusers: Locations for epidemological resemch and intervention., Dnig and tllohol Depewdene, 7, 63-79.

Spreen, M. (1992) Rate populations, hidden poptlations, and link-macing designs; what and why?

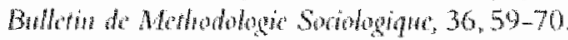




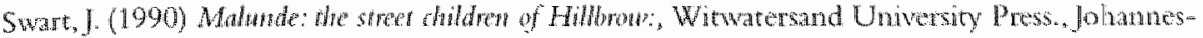
burg.

Taylor, M. and Veale, A. (1996) Rethinking the problem of street children: Barallel cauces and interventions In Psyhology and he Dereloping Wold (Eds, Carr, S. C. and Schunaker, J. F) Praeger, London, pp. 90-91.

Tenkasi, R.V., Mohrman, SA. (1995). Technology ransfar as collaborative leaming. In: Backer T

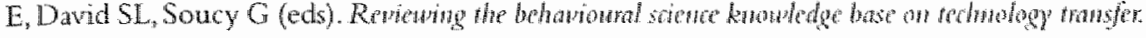
National hstitute on Drug Abuse Research. Monogmph 155. Washingron, DC: USCPO pp. $147-168$

Thompson, S.K. (1997) Adaptive sampling in behavional surveys In The Volding of Silf-Regroted

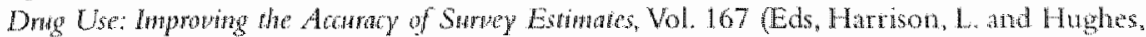
A.) USGPO, Washington, D. C., pp. 296-319

Tyler, FB., Tyler, S.L. Echeverry, J) and Zea, M.C. (1991) Making it on the streets in Bogata: A

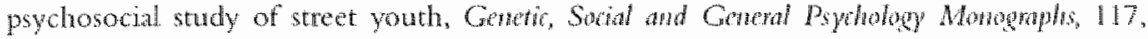
$397-417$

UNICEF (1986) Chldren in epecially diffoult cirrmsinnces, UNICEF New York.

UNICEF (1989) Ammal Repori, UNICEF, New York.

van de Goor L.A.M. Garretsen, H.FL, Kaplan, C., Kort, D. Sprui, I.P and deZwart, WM. (1994) Research methods for illegal drug use in hidden popularions, fournith of Psychathir Drugs, $26,33,40$.

Westermeyer, J. and Neider, J. (1988) Social networks and psychopathology among substance abusers, American Jounal of Pspchiatry, 145, 1265-1269

Whiting, J. and Whiting, B. (1975) Childen in Six Cuthres, Harvard University Ptess, Cambridge, MA.

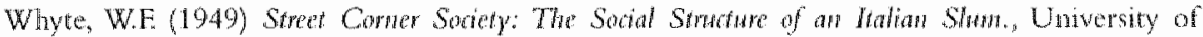
Chicago Press. Chicago.

Wiebel, W. (1993) The Indigenows Leader Outrend Modd: Inrenention Mamal, National Institute on Drug Abuse, Rockville, MD.

Wiebel, W.W. (1990) Identifying and gaining access to hidden populations In The Colwotion aw Interpredation of Dawa from Hidden Population, Vol. 98 (Ed, Lambert, E. Y.) USGPO, Washington, $\mathrm{DC}, \mathrm{pp}, 4-11$.

Windle, M. and Lemer, R.M. (1986) Reassessing the Dimensions of Temperamental Individuality Across the Life Span: The Revised Dinensions of Temperament Survey, formal af Adotercen Rerseach, 1, 21,3230

WorldBank, (1995) Kenyal Ponvty Assessuen 1995, World Bank, Washington. 


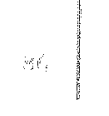




\section{CHAPTER 5}

CHARACTERISTICS AND PERSONAL SOCIAL NETWORKS OF THE 'ON' THE STREET, 'OF' 'THE STREET, 'SHELTER AND SCHOOL' CHILDREN IN ELDORET, KENYA 


\section{INTRODUCTION}

The phenomenon of street children in Kenya dates back to the colonial period (between 1890s and 1963). With the emergence of new towns, Nairobi, Mombassa, Eldoret, Nakuru, and Kisumu among others, street children become part of the new development. At independence, street children had increased in number and ever since have become a problem not only for the Kenya government, but also for voluntary and non-government organisations (NGOs). For instance, in 1997, the Child Welfare Society of Kenya (CWSK) estimated that there were about 625,000 children in especially difficult circumstances in the country (Kilonzo, 1997). In the following year, the total number of street children in Kenya was estimated at 135,000. However, this figure might be higher since there are no census data about street children. Although Nairobi has the latgest number of street children, the problems are not confined there alone. It is increasingly becoming a major issue in virtually all towns in Kenya. For example, by 1998 Mombassa had an estimated number of 5,000 street children, Kisumu 4,000, Kitale 2,000 Nakuru 2,000, Eldoret 1,000 , Nyeri 450 and Thika 520 (Killonzo, 1997).

Recognising the poor living conditions and the serious threat posed by street children, 56 - Kenyan based organisations dealing with children issues formed the National Children in Need Network (NCNN), under the African Nerwork of Prevention and Protection of Child Abuse and Neglect (ANPPCAN). The NCNN enables the concerned bodies to co-ordinate their activities all amed at improving the living conditions of children found in difficult circumstances (for example those "on" and "of" the street children). Despite the fact that the NCNN is in place, problems related to poverty continue to plague a considerable number of Kenyan families, and the children moving from homes onto the streets of big and small towns continue to grow.

Central to this study. Eldoret town recorded its first street children in 1989, since then the town has experienced an influx of street children especially during the $1991-1993$ ethnic clashes that eruped mainly in the Rift Valley and parts of Nyanza and Western provinces of Kenya. In 1992, after the government was forced to introduce a multiparty system. The government was suspected of instigating "ethnic" violence in order to punish those ethnic groups, which supported the opposition, and to reward its own supporters with illegally obtained land (Human Rights Watch/Africa, 1997). Most of those displaced by the "ethnic" violence were subsistence farmers with little formal education. 
These people have been rendered virtually destitute following their displacement and loss of property.

Many nembers of the internally displaced Kikuyu, Luo and Luhya ethnic groups have drifted to the urban slum areas. The United Nations estimates that, as much as 75 percent of the estimated 300,000 displaced persons in the country are children (Human Rights Watch/Africa, 1993). Thus, it should be emphasised here that the problem of children living in difficult conditions, in this case street children in Kenyan towns, in particular Eldoret, is real and can no longer be underestimated.

\section{METHODS}

\section{Sudy Design and Subjects}

We employed cross-sectional, multiple group case, control study design. The study design allowed for comparison within and between cases and control groups. We had two case study groups, "on" the street children, "of" the street children and two control groups, school children and children in the shelter. Street children are not a homogenous group. Recognition of this heterogeneity in the concept of the street children is incorporated into the principal. United Nations International Children's Fund (UNICEF) defmition of street children (Veale, 1992). UNICEF identifies three broad categories of street children. These are children "on" the street, children "of" the street, and children who have been "abandorned".

Children "on" the street, who form the majority (about two-thirds in most studies) maintain strong family ties and have a sense of belonging to a household. They are on the street to arn money to contribute to the household income (Ebrahim 1984; Martins 1993). In some studics, these children are contributing as much as 70 per cent of the total fambly income. These children spend their time on the streets selling woodcarwings, snacks, paper bags and other wares to the public. Significant feature of these children is that, they usually return to the family house to sleep at night. In our study, these claildren were in two categories: the hawkers and beggars. Hawkers were sent to sell items for their families/beneficiaries, thus some were like small traders. The youngest children in this group were still going to school. This group was no different from other children who assist in doing domestic work, farm work, like looking after catele and harvesting crops. The beggars are young ragged looking children who spend the day begging, scavenging, and will steal if opportunities arise, e.g. from unlocked cars and unatended luggage, etc. These children are secn in the 
streets sniffing glue and smoking cigarette butts. Most of the "on" the street children come from single parent households and they have come to the street to earn money to support their families" daily needs.

Children "of" the street are children who, for whatever reason, fully participate in street life at an economic and social level. In some cases, these childrem thave a home too and a family available to them, but they do not go home with any degree of regularity or consistency. A large number of these children have come to Eldoret to earn money, some of them take their saving to their families once in a while. Others have no functional family ties; in some cases these children have decided to severe all ties with their families. These children beg, steal, scavenge, work in informal sector, and abuse drugs. They are completely on their own, although some may have peer (gang) support. They face stark realities of life day after day, being hemmed in by exploitative older street children and adults.

On the other hand, "school children" as a control group come from the same neighbourhood as street children. Most of the school children's parents are employed in the informal sector. Others come from single parent households (mainly headed by women), with their mothers selling farm produce in the market. In addition to school and street children, "shelter children", as one of the control groups have no home to go to, even if they wished to do so. They are in the shelter because of the death of their parents and the unavailability of appropriate extended family to take them in. Others have been rejected/abandoned by their parents. Thus, sheiter children are orphans, former street children, abandoned children, and children who have been brought to the shelter by their parents because they are unable to feed and educate them.

\section{Measurement of Social Nerworks}

In this study, we used the Revised Version of the Maastricht Social Networks Analysis (MSNA) instrument to measure the structural social network characteristics of the street children and the control groups (Baars and Kaplan, 1996). The social network refers to the available personal network (Erickson, 1976). The MSNA has been used for research and diagnostic purposes in diverse populations such as chronic psycho-geriatric patients, alcohol and drug abuse patients, and arsonists. In the case of street children, we modified the instrument to fit the situation in Eldoret. The instrument passed through various revisions dealing with language, sequencing, topic covered and its relevance to the children. We pre-tested this instrument with school children that did not participate in the study before we agreed on the final semi-structured guide. 
It should be emphasised here that the concept of a social network typically refers to network of social relationships from which individuals draw support (Bolwijn, 1996). This does not mean that its constituent relationships ane to be viewed as only supportive for they are also likely to be sources of stress. Therefore, social network can be defined as all persons and groups, expressed in terms of actual persons, with whom one maintains direct and more or less lasting ties that satisfy the daily requirements of life (Wassermann et al. 1993). The structure of a social network consists of the actual people and ties that give shape and substance to the fulfilment of an individual's basic psychosocial needs (figure 1)

Therefore, the structure of a social nework is made up of:

a. The key person of the social network, referred to as the "focal person" and,

b. The group of other persons subdivided into sector and clusters:

1. The family sector

2. The friendly relations sector

3. The social services sector

These three groups are subdivided into different dusters:

a. The variety of social characteristics of the focal person's network members, as well as the accessibility of network nembers to the focal person and;

b. The ties between the focal person and the network member can be measured in tems of:

1. The frequency of contact

2. Who initiates contact

3. The length of contact

4. The basis or origin of contact and

5. The importance of "weight" of contact

The "weight" of the contact between the focal person and the network members indicates the degree to which that contact satisfies the focal person's basic psychosocial needs and operationalises the function of a social network scored on a 5 point scale: 1 indicating a low weight of the tie and 5 high weight of the tie.

Moreover, four categoves of needs are identified and are as follows:

1. The affective need, for example the need to be loved, to be apprecinted as person, to be trusted, and the need for emotional support;

2. The need for connection, example the need to belong and to be safe, to connect with and be supported by others based on common interests, values and background. 
3. The need for stability, meaning that the ties with others endure, and are evenly distributed between people for whom one has an explicit preference and people with whom one's ties are maintained more or less out of habit and;

4. The need for material and instrumental resources, ranging from housing, food and practical help/assistance.

\begin{tabular}{|c|c|c|}
\hline Size & In terms of: & affective needs \\
\hline Family & - initiatrwe & \\
\hline Fricndy relations & - frequency & need for connection \\
\hline \multirow[t]{2}{*}{ Social serwices } & - wisight & \\
\hline & - length & need for material and instrumental resources \\
\hline Variery & & need for stability \\
\hline Accessibility & & \\
\hline
\end{tabular}

Figure 1. Model of a Personal Social Network

This analytic model of a social network can be used as a guide for social network interventions. The approach to interventions of the Mastricht Social Network Analysis (MSNA) involves a systematic step-wise strategy. MSNA interventions consist of the following steps:

a. Diagnosis of the structure of the focal person"s social newwork;

b. Interpretation of the diagnosis in order to provide an understanding of both the existing social network structure;

c. Creation of an intervention plan intended to build up a structurally vital social network;

d. Implementation of the planned social network intervention in phases and;

e. Evaluation of the progress and outcomes.

Therefore the diagnosis of the structure of a person"s social network in (a) means that intomation about this social network must be obtained from the street chidren. We obtained this information using the MSNA instrument, a semi- 
structured interview in which systematically one's personal social networks are described.

\section{Size and Composition of Social Networks}

The total number of network members constitutes the size of a personal social network. The size encompasses all those persons and groups (expressed in terms of actual persons) whom the focal person can call on due to his or her direct and more less lasting ties with them. Such network members consist of the following persons:

a. Those with whom the focal person has a more or less lasting tie;

b. Those with whom the focal person is in direct contact;

c. Those with whom the focal person has been in contact during the past year;

d. The focal person at the very least knows their names and occupation;

e. Those with whom the focal person is no longer in contact (but once was) and who exercised a lasting influence on the experience of the focal person (either positively or negatively).

The size of a social network consists of genuine living persons specifically mentioned by the focal person. This also holds true for the focal person's contacts with groups and organisations such as non-governmental organisations, social services, and police or health care institution. The focal person makes these contacts in terms of actual persons (Baars et al. 1996).

\section{ANALYSIS}

We aggregated the network file into a new data file using the SPSS software in which the focal person becomes the unit of analysis. Thus we aggregated the size composition of the network, family sector, frequency of contact with parents, clusters (father and mother) and the variable for affective needs, connection needs, preference needs and the need for help.

\section{RESUIT}

The respondents were recruited through multiple methods including targeted snowball sampling, mapping, spot observation and focus groups. Consequently, the four groups compared in our sample totalled 400 children - the "on" the street were 87 males, 13 females; "of" the street children were 89 males, 11 females; children living in the shelter were 77 males, 23 females and school chil 
dren were 72 males and 28 females. Their mean age was 13.34 years. As shown in Table 1, rnajority "of" the street based-children did not go beyond lower primary school and their current work situation involved multiple categories changing daily. Forty-six percent of the "on" the street children live with one parent while $97 \%$ "of" the street children had lost all contact with their parents. On the other hand, school children still have strong family ties (see Table 1 for summary and overview on the social characteristics of children).

Furthermore, the mean size of the social network of the "on" the street children was 10.92 (SD 3.46), "of" the street 11.70 (SD 3.91), shelter children 17.60 (SD 3.99 ) and the school children was 16.17 (SD 3.41). Oneway analysis indicated that these differences were significant $(F=78.831 ; \mathrm{df}=3 ;$ sig. $=.000)$ as shown in table 2. The Scheffe test showed that this significant difference was accounted for by the relatively larger size of the network of our control groups compared to our case groups.

But Table 2 also presents the results of aggregating the network members and cross-tabulating the distribution of ego network members across network sectors by groups. The Pearson Chi. Square test showed that there were significant differences between groups and sectors $\left(\chi^{2}=279.4 ; 6 ;\right.$ sig. $\left.=.000\right)$. The "on" the street group had the largest percentage of the network in the family sector (53.7) followed by the "of" the street group (47.9). Our case groups therefore have a relatively larger percentage of family members in their networks compared to the control groups (shelter $=40.1 ;$ school $=42.2$ ).

Moreover, for the friends sector, a similar result was observed. The case groups had a relatively larger percentage of their social network members in the friends sector ("on" the street $=36.5$; "of" the street $=41.5$ ) compared to the control (shelter $=30.8$; school $=30.3$ ). For the helping sector an inverse pattern was observed. The case groups had relatively lower percentage of helpers in their networks (on street $=9.8$; of street $=10.6$ ) compared to the control groups (shelter $=29.1$ and school children $=27.5$ ). In summary, the control groups seem to have a more balanced network between family, friends and helpers, while the street children groups have a noticeably lack of helpers in their social networks. This deficit in helpers in our case group seems to be compensated for by family - for the "on" the street group - and friends - for the "ol" the street group.

Table 3a presents the results of frequency of contact with the father. Based on the Pearson Chi. Square test we found that, there were significant differences 
Table 1. Social Characteristics of the "on" the Street, "of" the Stree, shelter and School Chidren in Eldoret

\begin{tabular}{|c|c|c|c|c|}
\hline \multicolumn{5}{|l|}{ Gender $* *$} \\
\hline Male & 87 & 89 & 77 & 72 \\
\hline$\%$ Female & 13 & 1.1 & 23 & 28 \\
\hline Mean age (SD)t & $13.3(2.6)$ & $13.6(2.3)$ & $12 .(3.0)$ & $13.8(2.5)$ \\
\hline \multicolumn{5}{|c|}{ Highest educational level*** } \\
\hline$\%$ no education & 21 & 16 & 0 & 0 \\
\hline$\%$ numsery lowwer primary & 53 & 71 & 87 & 10 \\
\hline$\%$ upper prinary & 24 & 13 & 13 & 59 \\
\hline 9 lower secondary & 1 & 0 & 0 & 22 \\
\hline \% upper secondary & 1 & 0 & 0 & 9 \\
\hline \multicolumn{5}{|l|}{ Current work situation ${ }^{\star \star \star}$} \\
\hline$\%$ in school & 0 & 0 & 100 & 100 \\
\hline$\%$ scavenging & 78 & 98 & 0 & 0 \\
\hline os self enployed & 6 & 1 & 9 & 0 \\
\hline$\%$ at home & 2 & 0 & 0 & 0 \\
\hline Yo Multiple & 14 & 1 & 0 & 0 \\
\hline \multicolumn{5}{|l|}{ Current liwing situation ${ }^{\star * *}$} \\
\hline Wit with 2 parents & 25 & 1 & 3 & 57 \\
\hline$\%$ with 1 parent & 46 & 0 & 4 & 28 \\
\hline$\%$ with other relanves & 17 & 1 & 0 & 12 \\
\hline$\%$ with others & 10 & 1 & 0 & 1 \\
\hline 86 on streat & 2 & 97 & 0 & 0 \\
\hline \%helter & 0 & a & 93 & 0 \\
\hline \multicolumn{5}{|l|}{ Neighbounhood * * } \\
\hline$\%$ ciry center & 3 & 89 & 2 & 9 \\
\hline \% slum & 89 & y & 75 & 158 \\
\hline$\%$ outskirts & 7 & 2 & 19 & 31 \\
\hline$\% / \%$ ramal & 1 & $n$ & 4 & 1 \\
\hline \multicolumn{5}{|l|}{ Neighbourhood SES ** } \\
\hline$\%$ high & 0 & 0 & 0 & 10 \\
\hline iis medinam & 2 & (1) & 21 & 21 \\
\hline low & 97 & 9 & 79 & 60 \\
\hline$y \operatorname{sects}$ & 1 & 91 & 0 & 0 \\
\hline
\end{tabular}

$\star \star \star p<001, * p<05,+N=393$ 
Table 2. Composition of the Networks by Size, Sector and Group

\begin{tabular}{|c|c|c|c|c|c|}
\hline "On" the street children & 10.92 & $53.7 \%$ & $36.5 \%$ & $9.8 \%$ & 100 \\
\hline "Of" the stree chidtren & 1.71 & $47.9 \%$ & $415 \%$ & $10.6 \%$ & 100 \\
\hline Shether chilutren. & 17.60 & $40.1 \%$ & $30.8 \%$ & $29.1 \%$ & 100 \\
\hline School children & 16.17 & $422 \%$ & $30.3 \%$ & $27,5 \%$ & 100 \\
\hline
\end{tabular}

Table 3a. Frequency of Contact with Fathers in Percent

\begin{tabular}{|c|c|c|c|c|}
\hline "On" whe stroet children & $66.7 \%$ & $16.7^{\% \%}$ & $16.7 \%$ & 100 \\
\hline "Of due steet dridren & $21.2 \%$ & $42.3 \%$ & $36.5 \%$ & 100 \\
\hline Shelter childrats & $33.9 \%$ & $32.1 \%$ & $33.9 \%$ & 100 \\
\hline Sclnool children & $77.4 \%$ & $16.7 \%$ & $6.0 \%$ & 100 \\
\hline
\end{tabular}

Table 3b. Frequency of Contact with Mothers in Percent

\begin{tabular}{|c|c|c|c|c|}
\hline "On" the stree children & $78.6 \%$ & $14.3 \%$ & $7.1 \%$ & 100 \\
\hline "Of" the street clvildren & $35.1 \%$ & $37.8 \%$ & $27.0 \%$ & 100 \\
\hline Shelter children & $38.4 \%$ & $45.2 \%$ & $16.4 \%$ & 100 \\
\hline School children & $83.7 \%$ & $13.0 \%$ & $3.3 \%$ & 100 \\
\hline
\end{tabular}

Table 4. Quality of Affective Needs Fulfilment from the Father, Axerage

\begin{tabular}{|c|c|c|c|c|}
\hline PAP & & m & & \\
\hline "On" the street children & 3.27 & 3.33 & 1.67 & 3.01 \\
\hline "Of" he street children & 2.91 & 2.91 & 1.28 & 2.33 \\
\hline Sheter chuldren & 3.58 & 2.94 & 2.13 & 2.94 \\
\hline School children & 3.94 & 3.36 & 2.80 & 3.77 \\
\hline
\end{tabular}

Table 5. Quality of Comection Need from the Father, Average

\begin{tabular}{|c|c|c|c|c|}
\hline "On" the street children & 2.73 & 2.50 & 1.50 & 2.49 \\
\hline "Of" "he street childten & 282 & 2.45 & 1.50 & 2.20 \\
\hline Sholwew wildren & 2.84 & 2.82 & 1.87 & 2.55 \\
\hline Sohool childnen & 3.47 & 286 & 200 & 3.28 \\
\hline
\end{tabular}


Table 6a. Quality of Affective Need from the Mother, Average

\begin{tabular}{|c|c|c|c|c|}
\hline "On" the stree" children & 3.88 & 3.08 & 2.17 & 3.64 \\
\hline "Of" the street children & 3.23 & 3.50 & 1.63 & 2.92 \\
\hline Shelerer children & 3.43 & 3.15 & 282 & 3.21 \\
\hline School children & 4.21 & 3.75 & 2.67 & 4.10 \\
\hline
\end{tabular}

Table 6b. Quality of the Connection Need with the Mother in Mean.

\begin{tabular}{lllll}
\hline "On" the stret children & 3.15 & 2.42 & 2.00 & 2.96 \\
\hline "Of" the street children & 2.62 & 2.82 & 1.37 & 2.37 \\
Shelter children & 2.96 & 2.64 & 2.55 & 2.75 \\
School children & 3.63 & 3.25 & 4.00 & 3.59 \\
\hline
\end{tabular}

Table 6c. Quality of Help Need Fulfilment from the Mother by Group and Frequency of Contact in Mean

\begin{tabular}{|c|c|c|c|c|}
\hline "On" the street children & 3.64 & 2.25 & 2.50 & 3.36 \\
\hline "Of" the stree children & 2.85 & 2.96 & 1.42 & 2.52 \\
\hline Shelter children & 3.46 & 3.30 & 1.82 & 3.1 .4 \\
\hline School children & 4.33 & 3.92 & 4.00 & 4.26 \\
\hline
\end{tabular}

Group $\mathrm{F}=15.11 \mathrm{P}<01 ; \mathrm{F}=10.57, \mathrm{P}<.01 ; \mathrm{F}=2.28, \mathrm{P}<.04$

Table 7. General Quality of Afective and Material Needs Fulfihment by Group to Mother

\begin{tabular}{|c|c|c|}
\hline "On" the street children & 2.86 & 2.37 \\
\hline "Or" the stribe children & 2.57 & 2.14 \\
\hline Shelter children & 2.72 & 2.28 \\
\hline School childtren. & 3.30 & 2.28 \\
\hline
\end{tabular}


between groups $\left(\alpha^{2}=57,1, \mathrm{~d} 6 . \mathrm{p}<.000\right)$. The patterns of frequency of contact with the wather for "of" the street children and shelter children was - daily $21.1 \%$ and $33.9 \%$, occasional $42.3 \%$ and $32.1 \%$, and no contact $36.5 \%$ and $33.9 \%$ respectively. Whereas the "on" the street and school children meet their fathers regularly - daily $66.7 \%$ and $77.4 \%$, occasional $16.7 \%$ and $16.7 \%$, and no contact $16.7 \%$ and 6.0 respectively. Thus, the shelter and "of" the street children have characteristic pattern of occasional or no contact with their fathers.

Table 36 presents the results of the frequency of contact with the mother. The Pearson Chi. Square test showed that there were significant differences between groups $\left(\chi^{2}=71.957, \mathrm{~d} 66 . \mathrm{p}<.000\right)$. The patterns of frequency of contact with the mother tor "of:" the street children and the shelter children were: daily $35.1 \%$ and $38.4 \%$, occasional $37.8 \%$ and $45.2 \%$, and no contact $27.0 \%$ and $16.4 \%$ respectively. The "on" the street and school children meet their mothers more regularly - dailly $78.6 \%$ and $83.7 \%$, occasional $14.3 \%$ and $13.0 \%$, and no contact $7.1 \%$ and $3.3 \%$ respectively.

Table 4 presents the results of quality average of affective needs fulfilment from the father by group and frequency of contact. We found that, there were significant differences between groups and the frequency of contact was $F=16.378$ $p<.000$. The group and the frequency of contact influence the affective needs fulfilment from the father. The school children who have a daily contact with their fathers have high affective need fulfiment (3.94), while the "of "the street children who have characteristic pattern of occasional or no contact with their fathers have less affective need fulfiment. Shelter children and "on" the streer children's affective need fulfilment characteristic is quite similar (shelter $=3.58$ and "or" the street $=3.27$ ).

Table 5 presents the results of quality of connection need fulfilment by the father. The Levene rest and analysis of varance showed that there were significant differences in frequency of contact $(F=13.53$ p 5.000$)$. The school children have a high frequency of contact with their fathers, 3.47 ) and their need of commection fulfiment is better of than the rest of the groups.

Table 6 a presents the results of quality of affective need fulfilment from the mother by group and frequency of contact. The andysis of variance shows that there are significant differences in frequency of contact $(F=10.9, p<.000)$. Affection need fulfilment by the mother is influcnced by frequency of contact rather than the group one belongs to. 
Table $6 b$ presents the results of the quality of connection need fulfiment to the mother by group and frequency of contact. The analysis of watiance showed that there were significant differences between groups $(F=10.28, p<000)$ and frequency of contact $(F=5.29, p<.04)$. The school children and the "on" the street children have a higher connection need fulfilment by their mothers because of higher frequency of contact (school 3.63 and on street $=3.15$ ). The "of" the street and shelter children have a characteristic pattern of occasional on no contact with their mothers and have less connection need fulfilment met.

Table $6 c$ presents the resuls of quality of help need fulfilment from the mother by group and frequency of contact. The analysis of variance showed that there were significant differences between groups and frequency of contact. The school children and the "on" the street children have a higher help need fulfilment by their mothers because of their higher frequency of contact. While shelter children have higher help need fulfiment, it is both daily and occasional contact with their mothers. The "of" the street children have less frequency of contact and less help need fulfilment by their mothers.

Table 7 presents the results of general quality of affective and material need fulfilment by group. The analysis of variance indicated significant differences berween groups (affective needs. $F=3.88 p<.01$; material needs $F=3.06$ $p<03)$. Group influences the affective and material needs fulfilments but not gender of the child. The school children have a higher affective and material needs met compared to "of" the street children. However, the other children's material and affective needs fulfilment were met by their social network.

\section{DISCUSSION}

On the whole, the findings indicate that the control groups (shelter children and school children) seem to have a more balanced network between family, friends and helpers, while the street children groups have a noticeably lack of helpers in their social networks. However, this deficit in the helpers in our case groups "on" the street and "of" the street children), seems to be compensated for by larger family in the case of the "on" the street children and friends for the "of" the street children. Interactions between children in these groups are not to be characterised by egoism, short-term needs satisfaction and inability to form lasting bonds. Each child has a role to play in the group activities, including playing with friends and begging for food. This responsibility for others, together with what has been described as the "stable and fixed" modes of interaction between members of a gang (Connolly, 1990), tends to indicate that 
interrelationships and network between street children do exist at the affective and normative level as well as in terms of direct sociomeconomic relationships. As Maria Cattell (1997) writing about the Samia a sub ethnic group of Luhya describes a pattern common in runal areas in Kenya; where mothers are usually assisted in the care of their infants and children by abundant household members, including young caretakers who care for a younger sibling. For this reason, a special bond often prevails between a child caretaker and her sibling. If there is no gin avallable, a boy will also take care of siblings. Typically, chidren slept with a variecy of relatives and friends during childhood and adolescence. Fostering of children also encouraged shifts of residence contributing to the notion that mobility was expected during childhood. Family networks in Kenya can be thought of as "sibling care taking societies where reciprocal family ties, especially sibling ones, serve to assist individuals when in need" (Weisner, 1982). One factor in the misunderstanding of relationships between street children is that, to an observer, these urban nomads appear to be fast-moving dependent on the satisfaction of immediate needs and unable to concentrate. If this superficial observation is carried over to the possibility of forming enduring and healthy emotional attachment, then the prospect looks very negative indeed for the street children.

Therefore, it is this type of consideration that has lead other writers such as Jill. Swart (Swart, 1990) to point out that such an attitude goes along with the nature of the social supports available in the street. This apparent lack of forward planning, the inability to defer gratification to which Agnelli (Agnelli, 1986) has referred to, is in fact a survival strategy and consistence with indigenous child raring. It is not that street children do not have medium and long-term plans, but they also have a sense of reality and recognise that such plans are not congruent with their present resources. Swart writing of the grouping of malunde (Malunde is one of several terms street children use to refer to themselves in South Africa. "The Zulu word connotes "those of the street" and provides the children with a specific identity apart from other children) in Johannesburg notes that, they are often described as "pseudo-families" (Swart, 1988). The groups provide all the functions that sociologists expect of the family: economic support, protection, emotional and affective relationships, healch care and so forth. These findings also support the view that, adults do not exclusively moderate the form and integrity of relationships among children. Children form relationships among themselves independent of adult gudance and outside the adult norms and models avalable to them. 
Furthermone, street-based and institutionalised youth have occasional or no contact with their parents. The majority of the street children have lost ties with their fathers, of those "on" the street who still have some contact with their fathers it is not on a regular basis. The "of" the street children and those in the shelter have the most critical problem because they are completely detached from their families. In particular, "of" the street childen are developing without any adult guidance. These youngsters are completely dependent on their peers for their daily living. The "on" the street children have links with their parents especially their mothers. However, they spent over 10 hours a day hawking/begging, which does not leave much time for quality relationships. with parents.

It is also important to note that about 60 percent of street children have parents and yet their relationships and contact is frail without emotional atachment. Of course the quality of contact between these children and their parents differ within groups. The worst off are the "of" the street children. The psychosocial needs fulfilment (affective needs, need for connection, need for stability, and need for material and instrumental resources) to the parent is mainly determined by the frequency of contact. In this case, school children that have a regular frequency of contact with parents had more of their psychosocial needs fulfilled than street children did. In fact, street children can be understood as one consequence of the rising culture of capialism and the declining significance of African indigenous values, under which children were reared in strong family kinship units. In such extended families, both fathers and mothers were indispensable for the social and spiritual development of children.

Moreower, our findings suggest that street children organise their psychosocial attributes primarily within the framework of the realities avalable to them and the supports existing in those realities. They tend to seck constructive adaptive patterns even though, their own lives have been marred by loss, abuse and exploitation. The street children have formed strong supportive ties and caring relationships and they cope actively with their lives on the streets nather than homes or institutional environments. Emotionally, the greatest risk to which most street children are exposed is the loss or lack of an adequate relationstup with an adult caregiver. In terms of attachment theory (Bowlby, 1988) and the developmental effects on basic emorional security, trust, identification and psychological nurturance, this loss/lack has profound implications. Ironically, what street children frequently report is that the loss/lack of such a relationship in their pre-street existence was an mportant precipitating factor in their choice or forced acceptance of street life. The example below is illustrative. 
Moses Odeke is a 12 years old boy who came on the street at age 6 after running away from thome. He has one older brother who is currently held in a juvenile institution. He has never met his parents although they live in Langas slum in Eldoret town. He mainly begs outside Sparkles (a disco hall) in Eldoret. Sometimes he begs for food from eating-places in town. Odeke smokes cigarettes and snifs glue Besides, in the streets he has his own play mates and once in a while they share whatever little food they have. At times, police harasses them for loitering or pick pocketing and some end up in the juvenile institution. Odeke would like to become a mason when he grows up. He would also like to go to school, even if it means in the children's home.

Street chidren typically repont that their homes of origin were punitive, rejecting, hostile and lacking in adult emotional support (Cockburn, 1988; Keen, 1990; Richter, 1988; 1991; Scharf, et al. 1986). Further to this, Cockburn (Cockburn, 1991) has reported on similar high levels of assault within families $(40 \%)$. He has also recorded that $95 \%$ of the mothers in this sample were unmarried and most lived in temporarily constituted relationships; that $72 \%$ of these were teenagers when their first child was born; and that alcohol abuse was almost unwersal in these familles. In addition, Bwibo (1982) and Suda (1997) states that modern Kenyan socicty, when compared to its indigenous past, has witnessed a dramatic increase in social circumstances unfavourable to children. In $1980 / 8121$ children with battered syndrome were admitted to Kenyatta National Hospital of whom 5 died states Bwibo (1982), a paediatrician at the hospital. Of significance to our discussion, Bwibo notes that victims of child abuse frequently included babies of single mothers thrown along the road, dropped in pit latrines or dustbins and others had their hands burnt because they stole from their homes. These latter three factors have been commonly observed in other samples (Cockburn, 1991, Keen, 1990; Richter, 1991) and it appears likely that the presence of these factors creates a context of high level for both abuse and the lack of an adequate caregiver relationship.

\section{CONCLUSION}

The study looked into the structure of the social networks of street children ties and how their psychosocial needs are fulfilled. The street children have a larger fanily network but lacked social services support compared with the control groups, which have a more balanced network between family, friends and helpers. We concluded that, the children who have a regular contact with their parents had their psychosocial needs fulfilled. 


\section{REFERENCES}

Agnelli, S. (1986) Street children: A growing urban tragedy. London: Weidenfeld \& Nicolson.

Baars, H.M., Kaplan, C.D. (1996), Manual for the Maastricht Social Network Analysis; Analysis and description of personal social nework, Mastricht.

Bolwin, P.H. van Santen-Hoeten, H.M.S., Bars, H.MJ., Kaplan, C.D., van der Linden, S. (1996) The Social Network Characteristics of Fibronyalgia Patients Compared with Healn Controls. Arthrits Care and Research. Annerican College of Rheumatology.

Bolwinn, PH, wan Santen-Hoeuff, H.M.S., Bars, H.M.J., Kaplan, C.D., van der Linden, S. (1996) The social network characteristics of fbromyalgia parents: a controlled comparison, Arthritis Care and Research, 9 (1) (pp 18-26).

Bowlby J. (1988). Clinical applications of attachment: in secure base. London Routledge.

13wibo, M. (1982). Batrered child syndrome. In P. Onyango \& D. Kayongromale (eds.), Child labour and health (pp 2-13). Nairobi: Acme Press.

Cattell, M. (1997). The disconrse of neglect: Fanily support for the elderly in Samia In T. Weisner, C. Bradley, and P. Kilbride (Eds.) African families and the crisis of social change (pp. 157-184). Westport, C.T. Bergin and Garvey.

Connolly, M. (1990). Adrift in the city: A comparative study of street children in Bogota, Colonbia and Guatemala City. In N.A.Boxill (Ed). Homeless children: The watchers and waiters: New York \& London: The Haworth Press.

Cockburn, A. (1988). From concem to concrete action the story of the Homestead. In b. Gannon (Ed), Today's child: Tomorrow's adult (pp. 145-149). Cape Town: National association of Child Care Workers.

Cockburn, A. (1991). Street children: an overview of the extent, causes, chanacteristics and dynamics of the problem. The Child Care Worker 9,1213 .

Erickson, G.D. (1996): Personal networks and mental illness (thesis). University of York, UK.

Human Rights Watch / Africa's report: Divide and Rule (1993). State Sponsered Ethnic Violence in Kenya. New York.

Human Rjghts Watch/Africa (1997). Juvenile Injustice Police abuse and Detention of Street Children in. Kenya

Keen, J. (1990). A window on the inner world of street children. The Child Care Worker 8 , $11-12$

Kilbride, P., Kilbrida, J. (1997). Stigma, role overload, and delowalization among contemponery Kenyan women. In T Weiner, C. Bridley, \& P. Killbride (Eds), African fimilles in the crisin of social change (Pp. 208-227). Westport, CT: Bergin and Garvey.

Kilonzo, O (1997) Daily Nation, Friday, Feb.7. Specinl Report (A festeringmenace with power to rock development: Urgent action alled for on strect children) Nisirobi.

Richter, L. (1988). A psychological study of street children in Johannesturg, (IBS report 89-01). Pretoria: Institute for Behavioural Sciences, Uniwersity of Sonth Africa.

Richter, I. (1990). South Africa sreet children: comparisons with Anglo-American runway. In N bleichrodi \& P. Drenth (Ed), Contemponary issues in cross-eultural psychology (pp.96- 109 ) Amsterdam: Swets \& Zeitlinger.

Suda, C. (1997). Street children in Narobiand the African cultural ideology of kin-based support system: Change and challenge. Child Abuse Review, 6, 199-217.

Swart. I. (1990). Malunde: the street chidren of Hillbow: Johannesbutg: Witwatersand Universicy Press.

Swart, J. (1988). An anthropological study of street thiddren in Hillbrow Johannesburg, with special reference to their monal walues. Pretoria: University of South Africa. 
Veale, A. (1992). Towards a conceptualistion of steet-children the case from Sudan and lreland. Trocaire Devel Rev 107.

Wascemian, S, Faust, K. (1993). Social Nework Andysis: methods and applications. Cambridge Universicy Press, Cambridge, ENG and New York.

Weisner, T. (1982), Sibling interdependence and child caretaking: A coss-cultural wiew. In $M$. Lamb \& B. Sutton-Smith (Eds.) Sibling relationships: Their nature and significance across the life span (pp. 305-327). Hillsdale, NJ: Lawrence Erlbaum. 


\section{CHAPTER 6}

PSYCHO-SOCIAL AND NUTRITIONAL STATUS OF STREET CHILDREN IN-COMPARISON TO SCHOOL CHILDREN: A CASE OF ELDORET TOWN

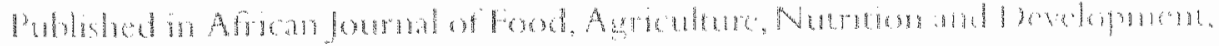
(1) $14: 1-4$ 


\section{ABSTRACT}

In most developing countries the number of children growing up on the streets of the world's cities is rising at an alarming rate. There is scanty research on the effect of such a life style on the psychosocial and nutritional status of these children. The goal of this study was therefore to examine the social networks, temperament and nutritional status of street based children compared to schoolchildren with a poor housing background. Our psychosocial research methods included qualitative and ethnographic techniques combined with standardised socio-metric and psychometric tests. Snowball sampling was used to identify the study groups. Four distinct groups of 100 children each were randomly selected. The street children were grouped as either living "on" or "of" the street. The school children comprised of those either living at home with a family or those living in a shelter under the care of social services. The Maastricht Social Network Analysis (MSNA) and psychometric Revised Dimensions of Temperament Survey (DOTS-R) tests were used to determine the social networking capacity and temperament of the children. Nutritional status was based on weight and height. Skinfold measurement was used to determine $\%$ body fat $(\% \mathrm{BF}$ ) and fat free mass (FFM). Our results show a mean age of 13.34 years for all the four groups of children. Both the "on" the street and "of" the street children did not go beyond lower primary school and they lived by scavenging. The children living at home and at the shetter had a balanced network between family, friends and social service providers. Both the "on" and "of" the street children had a significantly higher level of underweight $(p<0.05)$ and stunting $(p<0.05)$ as well as highly significant $(p<0.1)$ lower body mass index (BMI), \%BF and FFM. Our findings indicate that homelessness and absence of family support do not necessarily have adverse implication for psychological and physical development of children in especially difficult circumstances. However, efforts should be directed towards improving the home enviroment and household food security so that these children stop scavenging for food in the streets. 


\section{INTRODUCTION}

More than a decade ago, the United Nations International Children's Fund (UNICEF) estimated approximately 100 million children and adolescents are growing up on the streets of the world's cities (UNICEF, 1989). Increasing poverty, war, famine and disease occurring over the past decade have substantially increased this number. The phenomenon of street children is prevalent throughout Africa; in Kenya an estimated one million children are AIDS orphan with most of them ending up in the streets (World Bank, 1995). The lack of a stable parental figure has been linked to a variety of negative outcomes (Krazler, 1990, Damon, 1983). Children's ties to their families and their compensatory relationships with significant others are of developmental significance (Kimchi and Schaffner, 1990). Evidence pertaining to the vulnerability and coping of street children, for example, is contradictory; peer relationships are reported as erratic and unstable in some publications and mutual caring in others (Donald and Swart-Kruger, 1994). UNICEF (UNICEF, 1986) defines the "on" the street children as usually engaged in some sort of child labour while maintaining strong family ties expressed by sleeping and basing themselves in the family home; and "of" the street children as having their ties in the street with little or no social support from the family. Abandoned children may be on the streets because of the death or rejection by their parents. Such children may end up in a shelter run with help from the government or NGOs. The purpose of this study was to examine the social network, temperament and nutritional status of street based and school children in Eldoret.

\section{METHODS}

The study was a cross-sectional design. The study site was Eldoret, a Kenyan town with an estimated population of 300,000 people. An adaptive snowball sampling strategy was applied to recruit representative "on" and "of" the street children samples (Spreen, 1992, Kaplan, 1987, Thompson, 1997). This sampling strategy was employed because of non-existence of a sampling frame for the "on" the street and "of" the street children samples. Since these stret children constituted the "experimental" group in our research design, we wanted to go beyond a convenience sample to draw the most representative sample that was possible. We allowed the street children to "drive" the sampling process offering ideal and material incentives for their participation (Heckathorn, 1997). One hundred children in each group representing "on" the street, "of" the street children, shelter children and a control group of primary school children from poor Eldoret neighbourhoods were recruited for the study. In each group, a 
random sample of 51 children were selected making four sub-samples of 204 boys from the cohort of 400 children. This group of children was further assessed with psychometric test, the Revised Dimensions of Temperament Survey (DOTS-R) a 54-item, factor-analytically developed selfureport instrument that measures nine temperament dimensions. A standardised psychometric instrument for cross-cultural assessment of children's temperament validated for Kenyan samples was also used (Windle, 1986, DeVries, 1984). A Salter stand on validated weighing scale was used to take weight. A height metre was used to take height (Gibson, 1990). Body mass index (BMI) was calculated as weightheight $\left(\mathrm{m}^{2}\right)$. The prediction formulas developed by Deurenberg (1991) was used to determine \% body fat (\%BF) and fat free mass (FFM) where $\% \mathrm{BF}=1.51 \times \mathrm{BMI}-0.70 \times \mathrm{age}-3.6 \times 1+1.4\left(\mathrm{R}^{2} 0.38\right)$ for children aged $<15$ years and $\% B F=1.20 X \mathrm{BMI}+0.23 \mathrm{X}$ age $-10.8 \times 1-5.4$ $\left(R^{2} 0.79\right)$ for children aged $>16$ years. Total body fat $(T B F)$ was callculated as $\operatorname{TBF}(\mathrm{kg})=\% \mathrm{BF} \times$ weight $(\mathrm{kg})$.

Fat free mass was calculated as FFM $(\mathrm{kg})=$ weight $(\mathrm{kg})-$ TBF $(\mathrm{kg})$. Levels of underweight, stunting, and wasting were determined based on the NCHS reference standards. A flexible tape measure was used to measure mid-upper-arm circumference (MUAC). A holtain skinfold thickness calliper (UK) was used to measure in quadruple biceps, suprailiac and subscapular skinfold thickness (Gibson, 1990). One investigator made all the measurements. The mid-upper-arm muscle area (M) results from the nid upper-arm circumference (MUAC) and the triceps skinfold thickness (TSK) and is used widely as an indicator of the total body muscle mass. The following equation was used: $\mathrm{M}$ ( $\mathrm{mm} 2$ ) $=[\mathrm{MUAC}-(\mathrm{p} \times \mathrm{TSK}] 2 / 4 \mathrm{p}$ (Gibson, 1990).

\section{RESULTS}

All the children were boys with a mean age across the groups of 13.34 with no significant differences. The "on" the street and "of" the street children scavenged for a living and the "on" street children came from single parent home, while the school children came from two parent home "on" the street $46 \%$ single parents and school $57 \%$ two parents). Of the children "on" and "of "street $16 \%$ and $21 \%$ had not attended any schooling respectively.

Table 2 illustrates aggregating the network members and cross tabulating the distribution of the boys network members across sectors by groups. The Pearson Chi. Square test showed that there were significant differences between groups and sectors $\left(X^{2}=279,4 ; 6 ; p<0.000\right)$. The "on" the street group had the largest 
Table 1. Socio-Demographic Characteristics of the Children

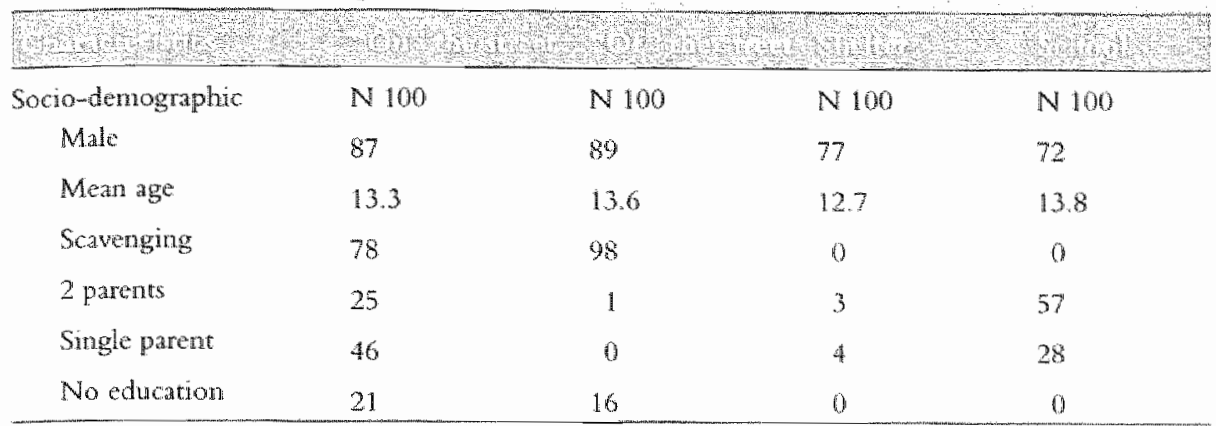

Table 2. Social Networks Type by Study Group

\begin{tabular}{|c|c|c|c|c|c|}
\hline "On" the street & 10.9 & $53.7 \%$ & $36.5 \%$ & $9.8 \%$ & 100 \\
\hline "Of" the street & 11.7 & $47.9 \%$ & $41.5 \%$ & $10.6 \%$ & 100 \\
\hline Shelter & 17.6 & $40.1 \%$ & $30.8 \%$ & $29.1 \%$ & 100 \\
\hline School & 16.1 & $42.2 \%$ & $30.3 \%$ & $27.5 \%$ & 100 \\
\hline
\end{tabular}

Table 3. DOTS-R Dimensions Scores for Eldoret Children Groups, Average $(N=204$ boys)

\begin{tabular}{|c|c|c|c|c|c|c|c|c|}
\hline & Mean & $S D$ & Mean & $S D$ & Mean & $\mathrm{SD}$ & Meara & Sid \\
\hline Activity lewel-Comeral* & 15.5 & 4.4 & 16.5 & 4.7 & 17.0 & 3.7 & 179 & 3.5 \\
\hline Activity level-sleep & 8.2 & 2.7 & 8.4 & 2.9 & 9.5 & 2.8 & 9.68 & 2.2 \\
\hline Approach/Withdrawa * * & 15.7 & 3.5 & 197 & 3.9 & 17.7 & 2.7 & 17.3 & 20 \\
\hline Aexibility/Rigidiryt+ & 11.6 & 3.4 & $\| 1.3$ & 3.3 & 12.2 & 2.3 & 12.7 & 2.6 \\
\hline Mood & 168 & 3.8 & 16.7 & 3.8 & 17.1 & 2.1 & 17.8 & 3.7 \\
\hline Rhythmicity-Sleep & 132 & 42 & 12.5 & 3.6 & 13.8 & 3.2 & 13.2 & 3.5 \\
\hline Rhythmicity-Eating & 10.2 & 3.6 & 11.6 & 3.3 & 11.4 & 2.9 & 11.3 & 3.0 \\
\hline Rhythmicity-Daily habies. & 9.8 & 2.6 & 99 & 2.6 & 10.7 & 2.5 & 10.7 & 2.3 \\
\hline Task Orientation * & 20.7 & 4.3 & 21.9 & 4.1 & 19.7 & 4.2 & 19.5 & 3.6 \\
\hline
\end{tabular}

$* 0<011 * 0<01 * p<0.05+p<10$ 
percentage of the network in the family sector (53.7) followed by the "of "the street group (47.9); and the "on" and "of" the street children have a relatively larger percentage of family members in their networks compared to the control groups (shelter $=40.1$; school $=42.2$ ).

Similar results were observed for the friends sector. The "on" and "of" the street children had a relatively larger percentage of their social network members in the friends sector "on" the street $=36.5$; "of" the street $=41.5$ ) compared to the control (shelter $=30.8 ;$ school $=30.3$ ). An inverse pattern of relationship was observed for the social service sector. The "on" and "of" the street groups had relatively lower percentage of social service in their networks "on" the street $=9.8 ;$ " of " the street $=10.6$ ) compared to the shelter and school children groups (sheler $=29.1$ and school children $=27.5$ ).

As shown in Table 3 (on page 109) the statistical analysis for the DOTS-R dimensions showed statistically significant differences on the approach/withdrawal dimension $(F=12.384, p<0.001)$. The activity level-sleep $(F=4.196$, $p<0.01)$ and the task orientation $(F=3.616, p<0.01)$ dimensions were next in rank in terms of significance level. The difference on the activity level-general dimension ( $F=3.006, p<0.05$ ) was also found to be statistically significant. Statistical trends could be seen in the flexibility/rigidity $(F=2.034, p<10)$ and thythmicity-daily habits $(F=2.166, p<0.10)$. No other significant differences between the groups were detected.

Over all the prevalence of severe underweight $(z<-2.00)$ and stunting $(z<-2.00)$ was $30.7 \%$ and $25.9 \%$ respectively. Severe underweight and stunting was $35.3 \%$ and $35.3 \%$ for "on" the street, $23.5 \%$ and $21.6 \%$ for "of" the street, $45.1 \%$; and $27.5 \%$ for sheter, $19.6 \%$ and $19.6 \%$ for school children respectively. Body Mass index was highly correlated with measures of leanness i.e. Fat Free Mass (FMM, $r=0.78, p<0.01)$. A Body Mass Index (BMI) of $<17.5$ indicative of severe malnutrition and chonic energy deficiency (CED) was found in $64.9 \%$ of the children. Children with a MBI <17.5 and living at home with a family, in a shelter, "on" the street and "of" the street were $68.6 \%, 62.5 \%, 80.4 \%$ and $49.0 \%$ respectively. The mean ( $(S D)$ MUC, underweight, levels of stunting, BMI, \%BF and FFM statistics are shown in Table 4. The mean ( 1 SH) BMI for children in school, shelter, "on" and "of" the street was $16.9(1.8), 16.9(2.2), 15.7(2.1)$ and $17.7(2.2)$ respectively.

The significance of the differences in nutritional status among the groups is shown in Table 5. Compared to the "of" the street children, the "on" the street 
Table 4. Nutritional Status of Boys by Study Groups

\begin{tabular}{|c|c|c|c|c|c|c|c|c|c|}
\hline & $N$ & Mean & $5 D$ & Mean & $\mathrm{SD}$ & Mean & $\mathrm{SO}$ & Mata & 50 \\
\hline $\mathrm{MUC}^{\mathrm{I}}$ & 51 & 19.9 & 2.2 & 21.1 & 3.1 & 19.4 & 2.7 & 21.8 & 3.0 \\
\hline Underweight ${ }^{2}$ & 51 & -1.20 & 0.75 & -1.72 & 0.88 & -1.80 & 0.95 & -11.22 & 0.94 \\
\hline Stumeing & 51 & -1.14 & 0.94 & -1.46 & 1.14 & -1.72 & 1.20 & -1.01 & 1.19 \\
\hline $\mathrm{BMI}^{+}$ & 51 & 16.9 & 1.8 & 16.9 & 2.2 & 15.7 & 2.1 & 17.7 & 2.2 \\
\hline $\mathscr{B B F}$ & 51 & $\mathbb{3} .8$ & 2.6 & 13.0 & 3.9 & 11.9 & 3.2 & 14.7 & 3.1 \\
\hline$F F M^{5}$ & 51 & 32.4 & 6.5 & 310 & 5.9 & 27.8 & 6.6 & 36.7 & 7.6 \\
\hline
\end{tabular}

${ }^{7}$ MUC-Mid upper arm circumference $(\mathrm{cm}):^{2}$ Weight/Age $Z$ scores based on NCHS reference standards; ${ }^{3}$ Height /Age Z scores based on NCHS reference standards; "Body Mass Index (Woighn/Hoight $\left.\mathrm{m}^{2}\right):^{5}$ Far Free Mass $(\mathrm{kg})$

Table 5. Statistics for Differentials in Nutritional Status Among "on" and "of" the Streets Study Group Boys

\begin{tabular}{|c|c|c|c|c|c|c|c|c|}
\hline & $\mathbb{N}$ & Mean & 50 & Mean & $\mathrm{SD}$ & Meran & $\$ \mathrm{D}$ & Valne \\
\hline Underweight: & 51 & -1.48 & 0.92 & -1.80 & 0.95 & -1.22 & 0.94 & $<0.65$ \\
\hline Stunting & 51 & $-1,33$ & 1.15 & -1.72 & 1.20 & -1.01 & 1.19 & $<0.95$ \\
\hline $\mathrm{BMI}^{-1}$ & 51 & 16.5 & 2.2 & 15.7 & 2.1 & 17.7 & 2.2 & $<0.0$ \\
\hline$\% \mathrm{BF}^{\circ}$ & 51 & 13.4 & 3.1 & 11.9 & 3.2 & 14.7 & 3.1 & $<0.01$ \\
\hline $\mathrm{FFM}^{5}$ & 51 & 32.7 & 10.3 & 27.8 & 6.6 & 36.7 & 7.6 & $<0.01$ \\
\hline
\end{tabular}

${ }^{1}$ Mean values for all the four groups; ${ }^{2}$ Weight/Age $Z$ scores based on NCHS reference standiards;

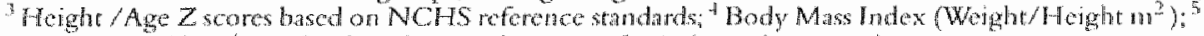
Fat Free Mass $(\mathrm{kg}) ; " \mathrm{p}$ Value based on student $t$ tese for independent samples

children's nutritional status shows a significantly higher level of underweight $(P<0.05)$ and stunting $(p<0.05)$. Very highly significant $(p<0.01)$ are at lower BMI, \%BF and FFM. A different picture images (results not shown) when similar comparisons are made between "on" the street, "of" the street and school children. Compared to school children "on" the street children have highly significantly $(\mathrm{p}<0.01)$ higher levels of under weight and stunting "Of" the street children have a highly significantly $(\mathrm{p}<0.01)$ higher mean $\mathrm{MUC}$ and BMI.

One-way analysis of variance showed that there were significant differences between and within the four study groups. The mean statistics were BMI (F 
$7.735 \mathrm{df}=3 \mathrm{p}<0.01), \mathrm{FFM}(\mathrm{F} 15.9, \mathrm{df}=3 \mathrm{p}<0.01)$, underweight $(\mathrm{F} 6.60, \mathrm{df}=$ $3 \mathrm{p}<0.01)$ and stunting $(\mathrm{F} 4.11, \mathrm{df}=3 \mathrm{p}<0.01)$. The difference was in favour of the "of" the street children with a mean $( \pm S D)$ BMI of 17.7,2.2. A similar pattern in the prevalence of underweight and stunting was also observed.

\section{DISCUSSION}

Our primary aim was to provide a description and interpretation of a representative sample of Eldoret's street children population that can be compared to school children as a control group. Consistent with the Eastern African literature, street children are, for the great majority, a male population (Beyene and Berhane, 1997, Ayaya and Esamai 2001). The school control group also had a large majority of males, though the gender difference is not statistically significant. Almost all of the "of" the street children are scavenging for a living, but somewhat surprisingly, the majority of "on" the street children is also engaged in this activity. While more than half of the school children live with two parents, only a quarter of the "on" the street children is based in intact families. Issues relating to female-headed households are definitely pertinent to this group, as has been found by other Kenyan studies (Wainaina, 1981). With respect to nutritional well being, a stable socio-economic environment is imperative for the cognitive development of the children (Nabarro et al, 1988). Surprisingly, the prevalence of wasted children was relatively low. This becomes more obvious by comparing the levels of stunting in the "on" and "of" the street with the shelter and school children. We also observed a difference in the average weight, which favours the "of" street children when comparing them with their siblings at the shelter. Furthermore, their astute begging might actually enhance the nutritional intake (Aptekar, 1988).

According to the causal model of malnutrition proposed by UNICEF (UNICEF, 1990) and accepted internationally by FAO/WHO (FAO/WHO, 1992), caring capacity plays a central role. Children particularly rely on the physical and emotional support of others (Weisner, 1997). Several studies have shown that an inappropriate caring capacity leads to under-nutrition (Longhurst and Tompkins, 1995). Following this rationale, the lower prevalence of underweight and stunting in "of" street children may be due to the support received from their peers on the streets. The prevalence of underweight and stunting are significantly lower in "of" the street children and may indicate their ability to survive in a very hostile environment. But the disadvantaged life led by these street children is reflected in the levels of body mass index. A person with a low BMI is most certainly physiologically and physically disadvantaged (James, 
1994., Desai, 1989). The primary social network deficiencies of street children seem to be related to size and imbalance in sector composition. The low percentages of service providers in both the "of" and "on" the street groups contradicts the view presented by Campos al (Campos et al 1994), that the street-based children have more contact with service providers than their home-based counterparts as it is the case in Brazl. In our study the shelter and school groups seem to have a more balanced network of family, friends and social service. We also note that the "on" and "of" the street children have a noticeable lack of social service in their social networks. This deficit in social service in the "on" and "of" the street groups seems to be compensated for by" family for the "on" the street group and friends for the "of" the street group.

The psychological measures findings supported the research suggesting that the majority of street children do not present with mental health problens (Aptekar, 1988). Based on the findings of the psychological test analysis, "of" the street and shelter children temperament stylistic trait seems to have a good fit with their lifestyle and institutional demands. The religiously oriented shelter programs, in their local and international fund-raising activities, actively employ these children. They are encouraged to approach prospective donors and assigned highly supervised tasks of singing, acting and/or proselytising to obtain support for the programs as well as the household chores in the shelter. The paradoxical easy temperament style of street children may be an expression of a continuous childhood developmental struggle to find a niche in a hostile and dangerous world constituted by especially difficulc circumstances. Although not statistically significantly different than the control group, the "on" the street children's relatively higher score on the mood dimension indicates perhaps a conditioned contextual pathway formed by the cumulative reactions of others. Expressions of good mood and friendliness to most people in the strect by street children fits well with their dependence on strangers for donations and other favours. However, to maintain this temperament style, as other African studics have documented, they sniff glue and take other drugs to cope with the hunger, cold and hostility (Jansen at, 1992). However, such a process-oriented theory to explain the paradoxical temperament of street children, as has also been suggested by the American adolescent research, can only be tested with longitudinall research. Contrary to the situation observed among homeless families in the West, street children in Elldoret are not necessarily at the botrom of the heap (in terms of growth and physical health) and adoption of strcet-life may, for some at least, represent both a rational and successful response to their prior circumstances. Others who have studied children in developing countries (Ayaya, 2001, Aptekar, 1988, Ennew 1994, UNICEF, 1986) have expressed 
similar views. Although, our data are cross-sectional rather than longitudinal, this suggests that the "of "the street children are able to maintain growth despite a lack of permanent shelter and parental care.

\section{CONCLUSIONS}

The linking of the MSNA methodology to a snowball sampling proved to be an afficient way of obtaining a relatively large and representative sample for the study. Quallitative field observations, key informant interviews and focus groups supplemented the MSNA and psychosocial and mutritional data. These findings indicate that, at least in Eldoret, homelessness and absence of family support may not necessarily have adverse implication for psychological and physical health development of street based children. However, the finding of this study suggests that efforts should be directed coward improving the home enviromment and household food security so that these children stop scavenging for food in the streets.

\section{REFERENCES}

Ayaya, 5.O. And Esamai, F.O. (2001) Health proplems of street children inEldoret, Kenya. East Africa Medical Joumal, $78: 624-629$.

Aptekar, L. (1989) street children of Cali. Duke University Press, Durhan, NC.

Beyene, Y. and Berhane, Y. (1997). Characteristics of street chiddren in Nazareth, Ethiopia, East Afric Medial Jommal, 74: 85-88.

Campos, R. Antunes, C.M., Raffaeli, M. et al (1994) Socinl networks and daily activities of stree youth in Belo Horizonte, Brizill. Child Dewelopment, 67:319-330.

Damon, W. (1983) Socal and Personality Development. Norton. New York.

de Vres, M. W. (1984) Femperanent and infane mortality among the Masai of East Africa. Anke.J. Psyituary 1:1189-1194.

Deurenberg, D:, Westrstrate, J.A. and Seidel, J.C. (1991) Body Mass lndex as a Measure Of Body Fatness Age and Sex Specific Prediction Formulary. Br. J. Nut, 65: 105-114.

Desai, ID. (I989) Nutricional status and physical work performance of agricultural Migrants in Southern Brazil. Proceding of XIVth Interantional congress of Nutrition Seoul Korean Nutrition Society, 297-301.

Donald, D. and Swart-Kruger, I. (1994) The South Africa stree chid: Developmental implication. S. Afriat. Ps Phology 24: $169-174$

Enucw J. (1994) street and working children: A guide to planning. Development Manual 4, Sawe the Children, London.

FAO/WHO (1992) Food and agriculture orgmisation of the United Nations/ World Health Onganization. Major issues for nutritional strategies. International conference on nutrition. FAO/WHO, Rome.

Gibson, R. (1990) Principles of nutritional status assesment. Oxford Oxford University press.

Heckathorn, D. (1997) Respondent-driven sampling: A new approach to the study of Hidden populations, soral puthers, 44: 174-199. 
James, W.P. (1995) The functional significance of low body mas index. (1DECG 1992) Enmow Jonnal of Clinical Nutrition, $48: 3$.

Jansen, L. Richter, R., and Griesel, R. (1992) Glue snifting A comparison study of sniffers and non sniffers, foumal of Adolesches, $15: 29-37$.

Kaplan, C. D. Korf, D and Sterk, C. (1987) Temporal and social contexts of heroin-using populaw tions: An illustration of the snowball sampling technique. Jomimal of Nenons and Mental Disotders, $175: 566-574$.

Kimchi, J and Schaffiner, B. (1990) Childhood protective factors and stress risk h: Childhood Stress. Arnold L E (Ed), Wiley, New York, 475-500.

Krazler, E.M. (1990) Parent death in chilchood [n: Childhood Stress. Arnold $\mathbb{L} \mathbb{E}$ (Ed). Wiley, New York, 405-421.

Longhurst, $\mathbb{R}$, and Tompkins, $\mathbb{R}$. (1995) The role of care in mutrition a neglected Essential ingredient. SCN News, 12:1.

Nabarro, D., Howard, P. Cassels, C., Pant, M., Wijgg, A, and Padfeld, N. (1988) The importance of infections and environmental factors as possible determinants of growth retardation in children in: Linear growth Retardation in Less developed countries. Waterlow J C (Eds). Raven press, New York.

Spreen, M. (1992) Rare population, hidden populations, and link-tracing Design: what and why? Bullecin de Methodologie Socioloque, 36: $59-70$.

Thompson, S.K. (1997) Adaptive sampling in behavioural survey in the validity Of self-reported drug use Improving the accuracy of survey estmates, voll 167 (Eds, Harrison, L. and Hughes

A) USGPO, Washington, D. C. 296-319.

UNICEF (1989) United Nations Children's Fund Annual Report, UNICEE, New York.

UNICEE (1886) United Nation Children's Fund. Children in especially difficult Circunstances. UNICEF, New York.

UNICEE (1990) United Nation Children's Fund. Strategy for improwing nutrition of children and women in: Developing countries. UNICEF; New York.

Wainaina, $\}$. (1981). The parking boys of Narobi. African Journat of Sonchlogy, 1: 7-45.

Weisner, T.S. (1997) Support for children and the African family crisis, African Families and the crisis of social change. Bergin \& Garvey Westport Comnecticut.

Windle, M. (1986). Reasseing the Dimensions of Temperamental individualty across Life span:

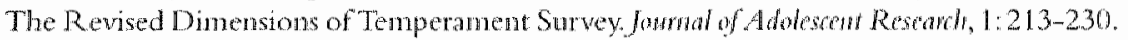

World Bank, (1995) Kenya Povery Assessment Report. World Bank Washington. 
$\ldots$ 


\section{CHAPTER 7}

\section{COMPARING TEMPERAMENT CHARACTERISTICS} OF STREET CHILDREN AND NON-STREET CHILDREN IN ELDORET 


\section{ABSTRACT}

Objectwe: The study examined the interaction of temperamentenvironment and how they impact on the psychological functioning of a street children and non-street children.

Methot: The study was a cross-sectional design conducted in Eldoret town. 204 males were selected for the study with a mean age of $13.97(S D=1.63)$. A Revised Dimensions of Temperament Survey (DOTS-R) a 54 item, factor-analytically-developed self-report instrument that measures nine temperament dimensions was used.

Resuls: The statistical analysis showed that the largest significant level was on the approach/withdrawal dimemsion $(F=12.384, p<.001)$ the activity level-sleep $(F=4.196, p<.01)$ and the task orientation $(F=3.616, p<.01)$ dimensions were next in rank in terms of significant. The highest mean score on activity level-general (1.7.88) and the activity level-sleep (9.65) were in the "of" the street children that is consistent with there scavenging lifestyle and their sleeping patterns they have to be vigilant when sleeping on shop verandas, run down buildings, and trash-bins.

Condwion: Our results clearly support much of the earlier research on street children, counter to public opinion and hostility, we found them highly resilient displaying a high degree of adaptability and flexibility in the face of adversity and, because of their special psychological characteristics, remaiming remarkably well adjusted as individuals. 


\section{INTRODUCTION}

The study of temperament as a stylistic component of behaviour has been a focal point for developmental psychologists, educators and clinicians investigating individual-social context relations (Plomin, R. and Dunn, J. 1986, Wibdle, M. and Lerner, R.M. 1886, Carter, et al, 2001). Models have been formulated which suggest that individual differences in temperament may moderate the quantity and quality of interactions with significant others and may, therefore, influence psychosocial development and behavioural adjustment (Lerner, R.M. and Lerner, J.V. 1983, Thomas, A. and Chess, S. 1977, Wills, T.A. et al, 2001). According to this conceptualisation, temperament refers to stylistic and dispositional features of behaviour with an emphasis on how people behave rather than on how well they perform on tasks (i.e., ability levels), or on the underlying motivational dynamics. It has been viewed as the outward manifestation of internal bio-psychological events related to arousal, vigilance, and generation of effect, social bonding and motility and was developed in order to balance a psychological "environmentalism run wild" (deVries M.W. 1994, Moffitt, et al, 2002, Ying-Chiao L. et al, 2000). For example, the temperament dimension approach-withdrawal refers to initial response tendencies to approach or withdraw when encountering new persons or novel situations, and sleep rhythmicity refers to the regularity of the daily sleep-wake cycle. Virtually all people manifest the behavioural responses associated with temperament attributes. On the other hand, we propose that individual differences in the systematic expression of these attributes are significant with regard to interpersonal interactions with significant others such as parents, peers, and teachers in their response to their daily demands of living (Windle, M. 1992).

While temperament is conceived as a key intrinsic factor in child development, social environmental factors have also been identified with child behavioural outcomes such as social adjustment, mental health and resilience to stress (Werner, E.E. and Smith, R.S. 1982, Garmezy, N. and Rutter, M. 1983, Chess, S. and Thomas, A. 1984, Moffit, 2002). The reviews of childhood stresses indicate that three factors temperament; family support and external support are the most consistent predictors of child and adolescent adjustment in response to stressful life events (Garmezy, N. 1983). Children with a difficult temperanent profile (i.e., biological arhythmicity, and withdrawal from novel stimuli, low adaptability or inflexibility to changes in the environment, high-intensity responses, and negative mood quality) have been reported more likely to have negative social interactions with significant others such as parents, teachers and peers with resultant increased risk for adverse psychosociall development and 
maladjustment (Thomas and Chess, 1977, Ying-Chiao et al, 2000). Similarly, based on longitudinall data, affectionate infant temperament style elicited positive responses from the primary care givers of children of alcoholics and that such positive parent-infant relations differentiated children of alcoholics who did not and did develop maladjustment problems in late adolescence (Werner, E.E. 1986).

In this chapter, we will contribute to this research need by assessing the temperament in samples representing four groups of children "on" the street, are those children who spend most of their time in the streets or markets, usually as child workers. A significant feature of these children is that they generally retain strong family links, usually returning to the family home to sleep at night. The "of" the street children are for whatever reason fully participate in street life at an economic and social level. These children, although they have a home to go to, do not go home with any degree of regularity or consistence. The "shelter" chidren are either abandoned or orphans, these children have no home to go to, even if they wished. They are in the shelter because of the death of a parents or rejection by their parents and unavalability of appropriate extended family (Veale, 1992). The "school" children came from disadvantaged neighbourhood schools in Eldoret town.

\section{METHODS}

The study was a cross-sectional design. The study site was Eldoret, a town of about 300,000 people in Kenya. One hundred children in each group representing "on" the street children, "of" the street children, abandoned (shelter) children and a control group of primary school children from poor Eldoret neighbourhoods were recruited for the study. However, sub-samples of 204 boys from the cohort of 400 children were conveniently selected and further assessed with psychometric test, Revised Dimensions of Temperament Survey (DOTS-R). The socio-demographic and social network characteristics of the total sample are reported in another publication (Ayuku, et al, 2004).

\section{Motsuroment}

The difficulty of using standardised psychometric tests in cross-cultural research has been long documented, but the accepted opinion is that they are of some value especially when making group comparisons (Hollzman 1980). We used the Revised Dimensions of Temperament Survey (DOTS-R). A 54-item, factor-analytically developed self-report instrument that measures nine temperament dimensions, for our measure of temperament (Windle and Lerner, 1986). 
Table 1. DOTS-R Dimensions Mean Scores, Standard Deviations and Significance Levels for Eldoret Children Groups ( $N=204$ boys).

\begin{tabular}{|c|c|c|c|c|c|c|c|c|}
\hline & Mean & $\mathrm{SD}$ & Men & $\mathrm{SD}$ & Mean & $\mathrm{SD}$ & Mean & $\mathrm{SD}$ \\
\hline Acrivity level-Gencral" & 15.51 & 4.43 & 16.49 & 4.67 & 17.00 & $3.7 \|$ & 17.88 & 3.51 \\
\hline Activity level-Slecp & 8.16 & 2.69 & 8.39 & 291 & 9.49 & 276 & 9.65 & 2.23 \\
\hline Approach/Withetrawal * & 15.75 & 3.52 & 19.69 & 3.87 & 17.67 & 2.70 & 17.29 & 2.44 \\
\hline Flexibility/Rigidityt & 11.59 & 3.45 & 11.35 & 3.34 & 12.18 & 2.35 & 12.67 & 2.57 \\
\hline Mood & 16.80 & 3.85 & 16.73 & 3.78 & 17.14 & 2.10 & 17.84 & 3.70 \\
\hline Rhythmicicy-sleep & 13.18 & 4.20 & 12.51 & 3.64 & 13.80 & 3.22 & $13.8 \mathrm{~s}$ & 3.50 \\
\hline Rlyythmicity-Eating & 10.22 & 3.64 & 11.02 & 3.28 & 11.39 & 2.86 & 11.33 & 3,02 \\
\hline Rhytumiciry-Daty habitst & 9.76 & 2.57 & 9.86 & 2.62 & 10.69 & 2,53 & 10.73 & 2.30 \\
\hline Task Orientation * * & 20.73 & 4.35 & 21.80 & 4.06 & 19.69 & 4.25 & 19.51 & 3.61 \\
\hline
\end{tabular}

$* \star * p<001 ; * * p<01 ; * p<05 ;+p<10$

Two different translators translated the DOTS-R into Kiswahili then back into English. The accuracy of the translation was compared with the original version. No major differences were found between the original and the translated questionnaire. We then piloted the instrument with some of our school children sample and found no major difficulties in comprehension among the school children sample.

Table 1 presents the DOTS-R dimensions mean scores, standard deviations and significance levels for the Eldoret children"s groups. The statistical analysis showed that the largest significant level was on the approach/withdrawal dimension $(F=12.384, p<.001)$. The activity level-sleep $(F=4.196, p<.01)$ and the task orientation ( $\mathrm{F}=3.616, \mathrm{p}<.01)$ dimensions were next in rank in terms of significance level. The activity level-general dimension $(F=3.006, p<.05)$ wats also found to be significant.

The highest mean scores on the activity level-general (17.88) and the activity level-sleep $(9.65)$ were in the "of" the street children that is consistent with their scavenging lifestyle and their sleeping patterns (they have to be vigilant when sleeping on shop verandas, run down buildings, and trash-bins). On the other hand, the shelter children recorded the highest scores on approach/withdrawal (19.69) and task-orientation (21.86) dimensions. Like the "of" the street children, this temperament stylistic trait seems to have a good fit with their lifestyle 
and institutional demands. The religiously oriented shelter programs, in their local and international fund-raising activities, actively employ these children. They are encouraged to approach prospective donors and assigned highly supervised tasks of singing, acting and/or proselytising to obtain support for the programs as well as the household chores in the shelter.

Although not significantly different from the other groups, they also reported the highest negative mood quality indicating, perhaps, that they are not so happy in this situation although it provides a good fit with their other traits of approach/avoidance and task-orientation.

The trend data also suggest that both "of" and "on" the street children tend to differ from their more socially controlled age-cohorts in the shelters and schools on the dimensions of flexibility/rigidity and thythmicity-daily habits. The "of" the street children have the same habits of waking up, looking for food, begging, scavenging and sniffing glue each and every day with no variation for weekends as do the control group. The "on" the street children also have the same activities each day of waking up (at home) and then out in the streets begging, hawking and carrying things for people until well after dark. Thus, the street based children higher scores on these dimensions, support the interpretation that in order to survive street children have had to develop a more flexible behavioural style and higher degree of regularity in their daily life. These children have to actively minimize the many risks that they are exposed to compared to the shelter and school children that must fit into social controlled programs of planned and organized diversity.

Figure 1 is partitioned at the mean to define the easy and difficult child categories. Interestingly, both street children groups ("on" the street, "of" the street) have about the same degree of "easiness" while, the shelter children, classified, as difficult children are somewhat less so than the extreme school children. On the face of it these results secm comnterintuitive as street children are publicly recognised as the "problem" group and, therefore, common sense might assume that they have temperaments that are more difficult. However, the goodness of fit criteria in temperament theory needs to be kept in mind. The school children, originating from impoverished economic and therefore difficult backgrounds express a good fit with their difficult temperament styles. As mentioned in the introduction, the issue here is that stressful situations can provide developmental challenges promoting self-growth. 


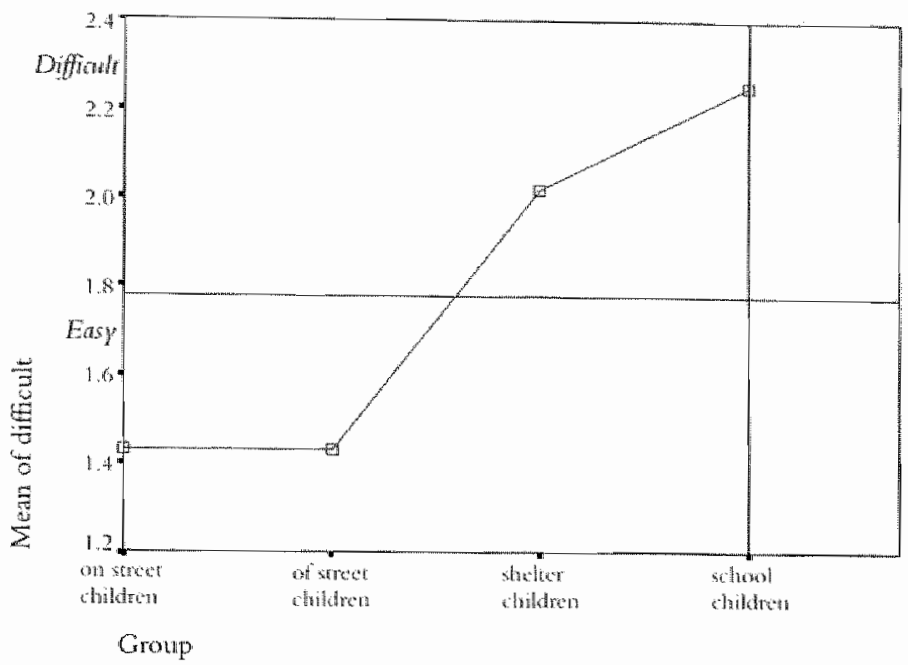

Figure 1. Easy and Difficult Child

A difficult child temperament style can become a successful coping strategy to meet with the demands of changing difficult circumstances and improving oneself. In traditional Kenyan child-rearing practice, children are often left with their siblings to be cared for by their parents under the watchful eye of the community. With schooling, now parents look to the schools to provide care for their children. These children have gradually mastered the school environment and they are coping with their new expectations of competition. The school environment does not demand a spontaneous response to unfamiliar situations, but rather a controlled and predictable reaction to routines.

While moving school children to a new school normally takes then quite some time to adapt, coping with the especially difficult circumstances provides a wholly different set of demands on the street child. In especially difficult circumstances, the expression of an easy temperament seems to represent a "paradoxical" fit with the demands of the emvironment that cannot easily be judged in the simple terms of goodness or badness of fit. The "of" the street children, by their temperament style, seem to have adapted easily to their environment with the support of their "brothers" in peer groups and gangs to which they owe high degrees of loyalty and conformity. 
Also, this form of sockal support resembles mone closely the traditional Kenyan sibling centred care than the highly adult controlled environment found in the schools and shelters. These children can also casily use drugs, eat whatever they can find, have a capacity to approach anyone to beg or ask for help regardless of their position in society. The "on" the street children present another patern of the easy child temperament style. These children owe loyalty to their femalemeaded families, which maintain some modicum of stability in their lives. They go to the street to earn money, which they share with their families. The tamily keeps some sense of order in their lives without the high degrees of social control that would conflict with the demands of the street that require quickness in adaptation and response. The family reduces the stress of street life for these "on" the street children in an analogous way to how the peer group and gang does it for the "of" the street children.

\section{DISCUSSION}

Our results are not easy to explain by the existing theories of temperament developed for the most part in American white middle class social environments. They especially highlight the need to see the children in context and to apply the concept of temperament "to illustrate and understand the complex environment-person interaction that had previously remained undetected" (deVries 1994). Our results clearly support much of the earlier research on street childrem that counter to public opinion and hostility. We found them to be highly resilient displaying a high degree of adaptability and flexibility in the face of adversity and, because of their special psychological characteristics, remaining remarkably well adjusted as individuals (Rutter, 1983, Dawes and Donald, 1994, Aptekar, 1988, Martin, et al, 2000). In fact, our results stggest that the "complex" interaction might not be best modeled as a statistical interaction at all, but rather a circular function feedback process in which individual differences in temperament elicit differential reactions from others that, in turn, create a contextual pathway for child development. Such an explanation has been offered co revise some of the conceptual weaknesses in the goodness of fit model in explaiming American adolescent psychosocial functioning (Windle and Lemer, 1986). Street children's paradoxical easy temperannent style may be an expression of a continuous childhood developmental struggle to find a wiche in a hostile and dangerous world constituted by especially difficult circumstances. Although not statistically significantly different than the control group, the "of" the street children's relatively higher score on the mood dimension indicates perhaps a conditioned contextual pathway formed by the cumulative reactions of others. Expressions of good mood and friendliness to most people in the 
street by street children fits well with their dependence on strangers for donations and other favors. However, to maintain this temperament style, as other African studies have documented, requires that they sniff glue and take other drugs to cope with the hunger, cold and hostily (lansen et al, 1992). However, such a process-oriented theory to explain the paradoxical temperament of street children, as has also been suggested by the American adolescent research, can only be tested with longitudinal research. With our study's cross-sectional research design, it is neither possible to conclusively support the theory nor to specify the precise causal linkage between temperament and the social environment. A priority for future research in this area as well as others pertaining to street children should be on longitudinal cohort studies (Martins and Ebrahim, 1993).

Given this methodological limitation, there nonetheless exists ample support in the literature for our interpretation of the "of" the street children temperament. As a correlate of a process characterized by high energy, vigour and overt motor activity in a routine and constant struggle to get food (Aptekar, 1988, Aptekar, 1989, Ennew, 1994, Felsman, 1979, Luna, 1991, Swart, 1990). Street based children are among some of the numerous groups of urban homeless and poor, working like adults and being excluded from normal adult organizations of social control (Glasser, 1994). As mentioned above, this daily process is diametrically in contrast with our control group who participate in daly, adult-supervised and organized activities at school or at home. This process continues and spreads out into the sleeping time characterized by high level of motor activity during sleep (e.g., tossing and turning). Even in sleep, these children are vigilant for their survival on the streets where the school children can rest in their own beds after the demands of the day. In one study on victimization of street children in neighbouring countries in East Africa, the authors reported theft, beatings and safety problems as a characteristic feature of their daily lives (Lalor, ct al, 1993). They describe how street children must develop a variety of coping strategies to avoid the theft and beatings that they must be constantly vigilant against. Street based children must be able to sustan a balanced approach/withdrawal style in order for them to adapt to their extremely difficult circumstances. For example, their survival process involves the selection of persons or places that are safe to beg from sell or congregate.

Our other results pertaining to the "easy" child and "difficult" child temperament clusters emphasize the fact that children are born with individual differences in terms of their temperament styles. Some children are born in the average range, but others come into the world with extremely positive on 
extremely negative, socially undesirable temperament traits. The "difficult" children phenomenology is more withdrawing from novelty, less adaptable, and secondarily or as a reaction, with a more negative mood and high emotional intensity. Ultimately, this child is predisposed to externalising behawioural disorders (such as violence) when the parental/teacher attitudes to discipline are dysfunctional (Maziade et al, 1990, Kangethe and Dhadphale, 1991). The school children had a lower scone on mood, and approach/withdrawal dimensions, which is consistent with their difficult behavioural style. The "easy" children are reported to be more approach oriented, sociable, less intense, and to have higher levels of positive mood quality. Our results differ from the benchmark American adolescent study that reported several temperament attributes correlating significantly with family support, suggesting that high levels of familial emotional support are associated with tlexibility of biological functioning such as eating and daly habits like bowel movements (Windle, 1992). However, our results are similar for temperament attributes associated with friends" emotional support. The street based children who rely on friends for material and emotional support are more sensitive to the social environment. They are beginning or about to begin going through the stomy period of puberty and individuation transitions without any family support. Their "easy" temperamental style may enhance these children's adjustment processes on the streets, but it also places them at risk for adapting quickly to antisocial behaviours from gangs and others on the streets. On the other hand, their temperament may evoke from the environment certain interpersonal or other forces that might not otherwise be noticeable or prominent. For example, the irritable (difficult) child may evoke physical abuse from an overstressed parent with insufficient self-control. Either being victimized or exposed violent acts perpetrated on siblings in early childhood might be a reason for street children having an easy temperament later on in childhood. A contextual pathway has been created based on a coping strategy to avoid beatings and to obtain money and material support on the mercy of the public. Furthermore, children's temperaments shape their responses to the people and things in their daily live; especially those that induce stress (Carey and McDevitt, 1995).

The overt behavioural components of a child's reactions are what the parents or members of the public see. The concept of the "goodness of fit" is useful but it has limitation in the school or streets setring. We must recognize that in the streets as well as in schools there are limits to the application of the goodness-of-fit concept. Some behavioural characteristics and some environmental properties make a healthy consonance between child and street/school extremely difficult to achieve. 


\section{CONCLUSION}

Our results provide confidence that the DOTS-R has a high potential for: research and clinical assessment in African children in extremely difficult circumstances. The recommended research design for such studies should be longitudinal incorporating mulciple case and control groups. Becouse of the rapidly changing socio-cultural context in Africa, this future research should try to involve a combination of testing procedures with the collection of collateral qualitative data using Anthropological techniques.

\section{REFERENCE}

Aptekar, L. (1988) Street children of Cali, Duke Uniwersity Press, London.

Aptekat, L. (1989) Colombian street children: Their thealth and how they can be served, Journal of Mental Health, 17:81-104.

Ayuku, D. Kaplan, Ch., Herman, B. and deVries, M. (2004) Characteristics and personall social networks of the on-the-street, of-the-street, shelter and school children in Eldoret, Kenyat. International Social Work, 41 (3): $293-311$.

Carter, J.D., Joyce, P.R., Mulder, R.T., Luty, S.E. (2001) The contribution of Temperament, childhood neglect, and abuse to the development of personality dysfunction: A comparison of three models. I of Personality Disorders, 15 (2) $123-135$.

Cary, W.B and McDevitt, S.C. (1994) Copnig with children's Temperament: A Duide for Professionals, Basic Books, New York.

Chess, S. and Thomas "A. (1984) Origins and evolution of behaviour disorders from infancy to early adult life, Bruner/Mazel, New York.

Dawes, A and Donald, D. (1994) Understanding the psychological consequences of adversity, In childhood and adversity: Psychological perspectives from South African Research (Eds, Dawes $A$ and Donald D) Dawid Phillip, Cape Town, 1-27.

deVries, M.W. (1994) Kids in context: temperament in cross-cultural perspective In prewention and Early Intervention (Eds. Carey W 13 and MCDewit S. C.) Brumer/Mazel. New York. $126-139$.

Ennew, J. (1994) Parentess friends: A cross-cultural examination of networks anonget street ahi].dren and stree youth, in Social Networks and Social Support in Childhout and Adolosedence Eds, Nestman $F$ and Huselman K) De Giruyter, Amsterdan, 40?-426.

Fedsman, K. (1979) Inwulnerability: On risk, resiliency and adaptation in childhood, Cambridge, MA. Harward University Press.

Garmezy, N, and Rutrer, M. (1983) Tress, coping and development in children, McGimw-Hill, New York.

Garmezy, N. (1983) Strssors in childhood, In Strec, coping and development in Children (Eds. Garmezy $\mathrm{N}$ and Ruter M) McGraw-Hill, New York.

Glasser, I. (1994) Homelessness in a global perspective, G. K. Hall, New York.

Holtzman, W. (1980) Projective techniques, In handbook of cross-cultural methodology (Eds. Triandis, $H$. and Berry, I) Allyn \& Becon, New York, 2: 245-278.

Jansen, L., Richter, R and Griesel, R. (1992) Glue snifing: A comparison study of sniffers and nonsniffers, foumal of Adolesemen 15:29-37. 
Kangethe, $\mathrm{K}$, add Dhadplale, M. (1991) Prevaltence of psychiatric illness among Kenyan children, Eas African Medial Journal, 68: 526-531.

Lalor. K., Taylor, M. Veal, A., Hessein A.l and Elbushra, M.E. (1993) Victimisation anong street chidren in sudan and Ethiopia: A Preliminary Andysis, in Understanding crime: Experiences of crime and crime Control (Eds, delFrate, A. A. Zvekic U. and van Dijk J. J) United Nation, New York.

Lerner, R.M. and Lerner, J. V. (1983) Temperament and adaptation across life: Theoretical and cmpirical issuas. In life-span development and behaviour, (Eds, Baltes, B. B. and Brim, O. G) Academic Press, New York, 5:197-231.

Luna, G. (1991) Street youth: Adaptation and survival in the AIDS decade, Joumal of Adolescent Health, 12:511-514.

Maziade, M., Caron, C., Cote, R., Boutin, P. and Thivierge, J. (1990) Extreme temperament and diagnosis: A study in Psychatrica sample of consecutive children. Archives of general psychiatry, 47: 477-487.

Martin, G.C, Werthem, E.H., Prior, M., Smart, D, Sanson, A and Oberklaid, F (2000) A longitudinat study of the Role of childhood temperament in The later development of eating concerns, John Wily \& Sons, Irce int. Joumal Eating Disond. 27: 150-162.

Martins, S and Ebrahim, G.J. (1993) Street chiddren, Joumal of Tropical Pediatrcs, 39:265-268.

Mofier, "T.E., Caspi, A., Harrington, H. and Milne, B.J. (2002) Males on the life-course-persistent and adolescence-limited antisocial patways: Followm at 26 years. Develoment and psychopathology, 14:179-207.

Plonin, R, and Dunn, I. (1986) The study of temperament: Changes, continuties And challenges, (Eds) Erlbaum, Hillsdade, NJ.

Rutter, M. (1983) Stress, coping and developnent in children, In Stress, coping and Development: Sone issues (Eds, Garmezy Nand Rutter M) McGraw,Hill, New York, 1-41.

Thomas, A and Chess, S. (1977) Temperament and dewelopment, New York.

Werner, E. E and Snith, R.S. (1982) Vulnerable but imwincible: A Longitudinal Study of resilient children and youth, McGraw-Hill, New York.

Werner, E.E.(1886) Resilient Offspring of alcoholics: A Longitudinal study from birth to age 18 , Journal of studies of Alcolnol, $47: 34-40$.

Windle, M. and Lemer, R.M. (1986) Reasessing the Dimension of Temperamental individuality across the life span. The Revised Dimensions of Tempermant Survey Joumal of Adolescent Research, 1:213-230.

Windle, M. (1992) Temparenent and social support in adolescence: Interrelations with depressive symptoms and delinguent behavours, fournal of youth and Adolescence, 21:1-21.

Will, T.A., Cleary, S, Filer, M. Shmar, O, Mariani, Jand Spera, K. (2001) Jemperament related to carly-onset substance use: Test of A Developmental Model Prewention Science, 2:145-163.

Wolk, A. (1992) Towands a conceptualisation of street chidren the case from Sudan and lreland. Trocaire Derslopment Rev. 107.

Ying-Chia, L., Ying-Sheve, C, Chon-Hong, Y and Shih-jen, T. (2000) the correlation between the diffenle Tenperanent and Subjectives Psychatric symptoms in Chines Early Adolescents. Child Psychamy and Human development, 31, (2): 129-137. 
CHAPTER 8

DISCUSSION AND CONCLUSIONS 
Street children are a worldwide phenomenon with common characteristics such as food scavenging, substance abuse, commercial sex and other forms of illegal and anti-social activities. Kenyan street children share these with other street children around the world. The street children of Eldoret and their families are by and large products of massive urban migration because of poverty, family discord and displacement from their land by the 1991-1993 ethnic clashes (Human Rights Watch/Africa, 1993).

Street children, although often making a strong visual impression are largely a "hidden population" when it comes to our knowledge. The study applied a biopsychosocial theoretical approach with a field intensive methodology to obtain knowledge of this hidden population. Our findings alter the contours of the current picture we have of street children. In contrast to the public view that the "of" the street group that are full participants in street life, are socially isolated, physically wasted children with troublesome temperaments and negative social attitudes, we and that they exhibit positive mood and easy temperaments, have relatively good health and nutrition and sometimes extensive alternative social networks. Similar results were found in studies in Latin America (Aptekar, 1994) with mixed positive and negative results found elsewhere (Veale, 1997, Campos et al, 1994, Ennew, 1994).

The implication of these multiple results is truly radical. Street children as a special group of children in difficult circumstances are not essentially a social defaced and misfits, but a potential social benefit to the development of society. Despite the social problems with violence and substance abuse, compared to school and institutionalized children, they have an added value in terms of their human capital; a value obtained in struggling to survive and sustain their links with their families. They provide an untapped service for the entrepreneurial spirit that is necessary for the development of Kenyan society. Their motivation to be recognized as full citizens, which is their legal right is grounded on their ambiguous status in the social structure (Giddens, 1999, DeSoto, 2000). What they are in need of is not charity, but a special kind of help and investment that will stimulate their value as social capital. The strong bonds that they have developed among themselves to cope with the separation from their families as well as the bridges they provide between the street's informal economy and the legal economy makes them a good investment as at group for future development. This investment will recognize the "success" that these children have already had in bridging and bonding. 
As shown in this study, street children in Eldoret could also be categorized using UNICEF nomenclature into "on" the street, "of" "the street, and sheltered children. The "on" the street children were children who spent most of their time on the street begging, working, scavenging for food and sniffing glue. Significant features of these whildren were their strong family hinks, usually returning to the family house to sleep at night and contributing to the family household income. In contrast, "of" the street children were fully participating in street life at an economic and sociallevel. While some had migrated alone others had a house in the slums of the town or family members nearby, but they had cut all links and preferred the streets and their freedom. On the other hand, shelter children were former street children, abandoned children and orphans or were brought to the shelters by parents who were unable to care for them. In contrast, the reference group comprised of school children who lived with their families and came from the same slum areas of Eldoret as the street children.

At the outset and throughout the study, we used qualitative measures such an focus groups and participant observer interviews with street children, service providers and the public, in order to gather a range of social, personal and public perspectives and opinion about the causes and facts of life on the streets. Street children reported a wide range of factors as to why they were living on the streets. Poverty, lack of food, school fee, and love, physical abuse from parents and relatives, and a desire to be independent, earn money for one self and to assist the family were all endorsed in the study. The school children endorsed the same factors as service providers with a few exceptions such as peer pressure, single motherhood and rural urban migration that were not mentioned by street children. Street children endorsed solutions to their problems that were policy measures geared to fulfill their basic needs such as shelter, food and clothing; followed by policies providing them with the opportunity for schooling and training. Street children recognized poverty, lack of food, school fees and "love problems" as main causes that lead to their present situation. However, they do not blame their parents for being unable to provide for their physical and emotional needs; instead they were sympathetic to their parents" circunstances. Once on the street, the children were able to fend well for thenselves as reflected by their good objective nutritional status. However, they still maned the provision of food as a necessary policy prionity as well as adding shelter and security to the list.

Along with the wish for a basic need policy expressed by the strect children was the important demand for an identity card. This indicted that the chiddren were very much aware of their normal exclusion from full Kenyan citizenship. Such 
tions and the literature. When comparing the levels of growth stunting between the "on" and "of" the street children with the shelter and school children a low level of "wasted children" were found on the streets. Average weight, of the "of" the street children was also better. The prevalence of underweight and stunting are siguificantly lower in "of" the street children and may indicate their ability to surwive in a very hostile enviromment. It is surmised that astute begging, scavenging and the physical and enotional support they get from others in the strees may have actually enhanced their nutritional status. This lower prevalence of underweight and stunting in "of" the street children has been seen in other studies that point to the positive effect of support received from their peers on the streets (Longhurst and Tompkins, 1995). Better nutrition was found among Indonesian and Nepalese "on" the street children using similar methods (Gross et al, 1996). However, the costs of the disadvantaged life style led by these "of" the street children is reflected in their low levels of body mass index (BMI). That street children exhibit a low level of wasting in these studies, suggests that the key problem for these children is not only nutritional but instead the need for a policy that adds to physical assistance, an emphasizes on mental and social health.

Since children are born with individual differences in terms of their temperament styles, we included the study of individual temperamentad characteristics. This study uncovered the street children's paradoxical easy temperament style. This may be an expression of a continuous childhood developmental struggle to find a niche in a hostile and dangerous world. The "on" the street children's relatively higher score on the mood dimension indicates perhaps a conditioned contextual pathway formed by their cumulative reactions of others under especially dificult circumstances. Expressions of cheerfulness and friendliness to people on the street fits well with their dependence or exploitation of strangers for donations and other favors. However, they maintain this temperament style at high cost, as other African studies have documented, seemingly requiring. self-abusive behaviours like sniff glue and taking drugs in order to cope with the hunger, cold and hostility (Richter, 1990, Wamaina, 1981).

Given the documented existence of individual difterences in temperament (Thomas and Chess, 1994, Sameroff and Mackanzie, 2003), most chidren are bon in the average range, but others come into the world with extremely positive or extremely negative, socially undesirable temperament traits. The interaction of these traits with the enviromment is an important predictor of developmental outcome. We assumed that temperament may have played a role in the selection of children who live on the street. The "difficult" child for 
example, is more withdrawn, less adaptable, and as a reaction more negative in mood and with high emotional intemsity. The school children had a lower score on mood, and approach/withdrawal dimensions, which is consistent with a more difficul behavioural style. The "easy" children are more approach oriented. The street based children in this study, who rely on friends for material and emotional support were more sensitive to the social environment than school children. Their differences suggest that temperament measured in this study is not simply a mater of genetics and individual difterences but is also a continue outcome of the transaction of an individual with the enviromment.

The street children "easy" temperamental style may enhance their adjustment processes on the streets, but it also places them at risk for adapting quickly to antisocial behaviours from gangs and other antisocial group on the streets. On the other hand, their temperament may evoke from the environment certain interpersonal or other forces that might not otherwise be noticeable or prominent. For example, the irritable (difficult) child may evoke physical abuse from an over stressed parent with insufficient self-control. Either being victimized or exposed to violent acts perpetrated on siblings in early childhood might be a reason for street children having an easy temperament later on in childhood. $\mathrm{A}$ pathway has been created based on a coping strategy to avoid beatings and to obtain money and material support on the mercy of the public. Furthermore, children's temperaments shape their responses to people and aspects in their daily life, especially those that induce stress.

As mentioned in the beginning of this chapter the street children in this study have relatively good mood, social support and physical and mental health providing a fresh perspective on these children. In addition and contrary to popular expectation, the number of abandoned children among the street child population was relatively small. If we consider the relative distribution of chilldren between these categories: "on" the street, "of" the street, and shelter and the mobility of the street child, we begin to see some of the comploxity of analyzing the street child population. The evidence avalable suggests that children with families move back and forth between the street and family. Such fuctuating levels of family involvement might suggest the operation of a dynamic process, experienced by the child as an aray of forces and attractions between the street and family. Positive features such as family protection, perer support, anse of personal empowement, and so on are thought to be set against negative features, such as risk of victimization, poverty, fanily dysfunction and parental violence, and mental health problems. Given this scenario, we can best conceptualize the child as having made, or having had forced upon him 
or her, a range of choices about lifestyle and links with the family. For example, remaining with the family, earning a marginal income on the streets to support household income, mowing to the streets and cutting all family links; resulting in a matrix of choices positive and negative.

By "choices" we mean something like what is proposed by Simon (1978) and Maslow (1943). According to them the forces impinging on the child can be conceptualized as primarily situational in character, reflecting on and interacting with the varying environmental, economic, and cultural experiences of the child. Early in life, children are expected to control or schedule their needs for eating, eliminating, being active, and resting. Also, certain safety regulations, which must be adhered to, are prescribed. In satisfying other needs, such as needs for love and belonging, esteem, and self-actualization, children have somewhat more freedom - if they are not confined within a particular school $/ \mathrm{classroom}$ situation - than within the larger environment, including play field, neighbourhood, streets, and home. The desires to know and understand can be met successfully in the school situation; but here, too, the child is not given complete freedom to decide what is most worthwhile to know and understand. In this study, various degrees of integration of personal needs with social demands were found in street children. One important dimension in this integration was rebellious-independence-conformity. This way of thinking about the processes underlying the movement of children to street life is more helpful than conceptualizing those processes simply in terms of inadequacy or pathology on the part of the child, or in terms of overwhelming economic or social processes. A further aspect of Simon's approach which was mentioned above is the drawing of a critical distinction between those factors leading the child to move to the street and those factors sustaining and directing life on the street, once the child has become engaged in street life. For instance, it follows from drawing such a distinction that policies directed toward stopping movement to the street may have little if any relevance to the child already engaged in street life.

Scavenging and working for a living are necessary elements of survival for many urban poor in Eldoret, for whom the child is the most effective earner. In this context, it is naive and inappropriate to cast street life in a negative light without recognizing the role that street scavenging plays in lives of the urban poor. Most of the parents interviewed felt that, they had no alternative open to them other then to send their children to scavenge, even though they disliked that alternative. Furthermore, the focus groups discussions reveal that at no time are parents happy when they cannot provide for their children. Generally, street children earn a living through scavenging, begging, stealing, and exchanging sex for 
money (especially girls). As far as work is concerned, street children are involved in shoe shining, car washing and hawking of small items such as sweets, groundnuts and cigarettes. The children emphasized that what they acquire from the above-mentioned activities is not enough to sustain them in their already poor living conditions. Unsatisfied needs, with their resulting tension within, serve as a motivation to arouse and direct behaviour toward goals which the individual perceives as satisfying the need and, thereby, reducing the tension (Maslow, 1943). The majority of street children reported that, as a survival mechanism, they scavenged for food in dustbins. The issue to focus on is not the angagement of children in scavenging and working (which undoubtedly can have negative conseguences), but why some children progress away from the family while involved in street work. Maslow's hierarchies of needs were also reflected in the MSNA analysis, where the weight of ties operationalized such basic social needs of connectiveness, material support and affection. Furthemore, street life is tough and harsh for many street children interviewed.

The children reported sexual victimization, theft, and beatings from other older street gangs and the public, and other safety issues if they are not in a group. This violence seems to be one of the main constants in street children throughout the world. For instance, a recent study of the life trajectories of street children utilizing shelter services in Sao Paulo, Brazil, found that the children's most meaningful experiences could be grouped into discrete thematic categories of family, the street, friends, drugs, the police, shelters and the future. A synthesis of these categories showed the life trajectories of these children to be driven by violence that had the consequence of jiming their full development (Ribeiro, 2001).

In Eldoret. Kenya, as in Sao Paulo, Brazil, fear of victimization wes a radity to all of the respondents. Indeed, for younger street children of Eldoret, attempted theft of the little money they eamed was an almost daily occurrence, resulting in developing a variety of strategies to avoid carrying money by thenselves, including having group/gang protection. Beatings and assaults was another feature of most children's lives. The beatings were sometimes too severe that the affected child sustained visible and permanent damage. The net result of the extensive victimization experienced by the street children is a pervasive loss of a sense of security.

This lack of a sense of physical security contributes to tho street child's vulncrability and thus victimization, in turn underscores the absence of adult or family protection. As a result of this physical neglect, a potential psychopathology of 
street life becomes a possibility (Valdez, et al, 2000). A fundamental requirement for developing a sense of security and psychological wellbeing is protection, especially with respect to the safety of the child's sleeping place. Sleep is a state of profound potential vulnerability, which is increased by the inherent risk of victimization in the night. In Eldoret the "of" the street children feit that their place of sleeping was unsafe.

\section{CONCLUSION}

The methodological approaches to the investigation of street children in Eldoret were based on the proposition that, analysis must be comparative to move beyond description to the conceptual level of science, in order to generate causal explanations, and suggest evidence based modes of social action This comparative approach was built upon the foundation of intensive medical Anthropological fieldwork, that builds knowledge through an iterative process of constant comparison of analytical categories, such as what was found in the UNICEF classification of street children. We were inspired by the comparative research conducted some years earlier on South African street children by Linda Richter (1993) and her associates. Their studies were the first to built a program of research results combining Psychology and Anthropology in comparative research designs. Specifically, defined subgroups of street children (Western sociecy "runaways" vs. African street children; glue using street children vs non-glue using) were compared and contrasted to yield an understanding of the causes of street children. Our focus group discussion technique followed similar procedures to that of Richter (1993) and her associates. The comparative methodological approach required not only multiple group designs, but also the use of mulcimethods that were "cascaded" to render a comprehensive understanding of the phenomenon of street children as well as to generate specific explanations of street children's behaviour, biology and environment. Such an approach had to systematically integrate qualitative and quantitative strategies. It was a cornerstone of the social psychiatric approach developed in Maastricht over the last two decades (deVries, 1996, deVries and Kaplan, 1997). This "cascade" approach was related to the proven methodology developed by Aptekar (1991) and his associates for investigating street children, with the aim of intervention in Colombia. We, as Aptekar and associates had done, applied qualitative ethographic techniques together with standardised sociometric and psychometric assessment protocols, to yield specific results that can be used to define target intervention strategies. 
Along with the focus groups that were also used in South Africa, spot observations and key informant interviews were employed as they had been in Colombia, in order to provide contextual data from which the validation and interpretations of the metric data were evaluated. Using the "best" research practices developed in Africa and South America for the street children problem, we have not only gained confidence in the validicy and generalisability of our results, but, see this multi-method and comparative approach as a model for transfer to other settings in Africa, where causal knowledge of the emerging street children phenomenon is vitally needed. We also realize that a serious limitation of the methodological design for generating causal explanations is its cross-sectional nature. Stronger results will be possible with longitudinal designs. Our future plans in Eldoret start with the construction of a registry and database of the cohort used in this study, for the purpose of planning longitudinal studies of family relations and related social and psychological pathologies as the children mature.

Solutions to the problems of street children in Kenya abound in government and numerous non-governmental organizations (NGOs), churches and other private programs, specifically concerned with relabilitation and prevention of street children. Still, in spite of goodwill and expensive programs, the street children population continues to grow along with an increasing consensus that rehabilitation programs have not proven to be effective. Jnstead, programs are now addressing preventive strategies designed, for example, to intervene not directly with street children, but instead at the family level, to enhance the family's capacities to better cope with the social and economic factors. Family factors are well known contributors to the movement of children from homes to the streets in the first place (Sudn, 1999). Current interventions stress both rehabilitation and prevention with a focus on community based organizations (CBOs). Empowered with resources to provide money not directly to the child, but rather support for schooling, training for employment, and recreational activities such as sports, art, and music. The child is by and large nowadays understood as an active agent, one who must be motivated to participate willingly in his/her own rehabilitation. Attempts, for example, to forcibly relocate street children into rehabilitation centers (homes) have not worked. Instead, street children overall flee from such institutions, where disciplinary regimes and required labor are emphasized. Nevertheless, programs that do conform to a concept of family and child reciprocal interactions frequently are less effective than one might hope. This is understandable given the limited resources and sheer numbers of available programs. There is much owerlap and duplication of effort, which is further, exacerbated by distinct levels of social organization, 
often with incompatible assumptions and knowledge base about street children and their aspirations. International, national, and local programs of intervention and prevention are often active without vertical linkages, and sometimes without any shared cultural assumptions about causes, solutions, and other ideas pertaining to the overall sociall environment, within which the street child and his family operates in. Interventions comprising juvenile courts, dealing out custodial care for rehabilitation and institutionalization have only resulted in brutality being inflicted on the children. It is apparent from our study that the only public service reaching the street children is the police. However, instead of protection they are dealing out physical punishment, banishment, and even extermination. At the same time, the existence of rehabilitation centres and juvenile courts creates the fallse impression that something is being done.

In constructing programs for street children, we should base our approaches on their strength and capacity for self-empowerment as well as for pro-social empowerment. Social workers can recognize the coping capabilities of intact families and work to support and strengthen them so that their integrity can be maintained. In the absence of intact famillies, social service agencies can work to strengthen the relationships between street children and their primary caretakers, even if those caretakers are often street children. They can also reinforce the structural resources of these prinary care givers with a good social diagnosis provided by the Maastrcht Social Network Analysis (MSNA). This diagnosis can reveal contacts with family relations that can be mobilized by the social workers. Program approaches need to avoid equating pro-social behaviour with conformity to adult control and expectations.

Appreciation of the normative diversity of street children and respect for their survival strategies that often involve inconsistent normative behaviour needs to be instilled in the policy making process as social work research has emphasized (Cosgrove, 1990). The imposition of institutional values is counter productive to the extent that they devalue children's ability, lead them to devalue themselves, and make them dependent. Instead of devaluing their capabilities, institutions and homes can build on the strength of children and be responsive to their input and ideas when planning, implementing and evaluating programs. Street children have found (or formed) constructive mini-communities to obtain the sense of belonging that their families or society have not provided. Programs that build on these capabilities in strengthening their self-empowerment and being sensitive to traumatic nature of their experiences on the streets are most welcome. 
A number of innovative intervention strategies can be formulated on the basis of our research results. The first priority is an outreach project: family reunification intervention. Whereby the street children and their families that were included in the present study project will be reunited, tracked and followed up in a longitudinal cohort study, that will allow for the direct observation of the vulnerable families and provide outreach service by helping them to cope. After studying the situation, the families will be helped to plan a course of action that not only helps them to earn a living, but also strengthens family solidarity. This outreach project should also apply to the resettled ethnic clash victims.

Another strategy involves the application and training of street educators. Who will work in public space with some regularity, promoting increased awareness of the dangers of substance abuse, sexually transmitted diseases, and about life on the streets in general to the street children. They will also teach about nutrition and health care, as well as citizenship and children's rights. Street education should help develop social values and teach the rudiments of literacy and numeric.

Although the emphasis of interventions are to work with the children in the streets, rescue centres are apparent. 'These will provide temporary shelter and care where children stay on average of 3-6 months, while social workers help to establish links with their families. Such centres should provide temporary shelter, care and protection, as well as immediate social services. There are opportunities for counselling and developing useful skills, and for weaning the child from substance abuse, while awaiting return to the family. The main difference between these institution and the existing rehabilitation centres is the forms on temporary work to effect the transition to the family. Religious indoctrination and hash discipline are counter productive to this aim.

Yet another intervention is the way forward. Here emphasis should shift from residential care to community and home-based care, by all stakeholders including government, NGOs, religious organizations and development partners. Enhanced collaboration between the government, community-based organizations, NGOs and other stakeholders, involved in community programs, through advisory councils; sensitizing the community and child service providers is the core of the "way forward" strategy. Also this strategy recognizes that the especially targeted are those children in need of special protection within the community environment. The strategy aims at enhancing children and youth participation in all care and support initiatives. Empowering communicies to develop and use avalable resources in the care of children in need of 
special protection is another part of the strategy. Continuous surveys to get up to date and reliable data on the street children in need of special protection and those under residential and community based care is required, in order to facilitate proper planning of the "way forward".

The stark psychological and physical poverty that marks the lives of street children and their families requires substantial social and health policy change, if their lives are to be significandly improved. Such substantial social change requires demonstrating the destructive impact of the conditions that characterize the lives of street children and recognizing that these conditions are not self-induced. The format and results of this research support the conclusion that street children do not bring their fate on themselves. Providing pro-social options to such children can benefit society, while meeting their needs as well. Such an approach to public policy needs to acknowledge that the rolle and skills of street children are valued and used by at least some segments of society. We may be distressed when street children are involved in antisocial and corrupting activities, but to change that situation we must provide them with more appropriate legal ways to survive (e.g. identity cards), and we must protect them from adult exploitation. Unless we can provide street children with a sense of worth within organized society, they will continue to survive as best as they can, even though some of their activities will be demeaning, self-destructive, antisocial, and may benefit those in society who exploit them.

Therefore, the most persistent policy-relevant finding of this study is that thinking must go beyond one-dimensional conception of street children. The research in this study has elaborated UNICEF milestone report classification of street children, that was the first international policy attempt to provide a science-based classification, that reflected the essential diversity of the population. Street children in Eldoret were found to vary considerably across dimensions of their social networks, psychological temperament, and health status, and future orientations. The research has struggled not only to confirm the existing knowledge of street children diversity, but also to provide a critical reflection on the heterogeneity of this vulnerable population. Also, through reflecting upon the fundamental causes, evidence was provided that street children are in actuality the "tip of the iceberg". Street children belong on the continuum with other high-risk children, such as those in families with substance abuse, mental health problems and family violence. This finding has also been found in a study of street children in Central and Eastern Europe, that was part of the World Bank Street Children Initiative (Penton, 2000). The aim of the initiative was to examine the phenomenon of the growth of street children in the region. The 
stimulation for this initiative was deterioration of the circumstances for many children in the region, since the fall of communism. The report concluded that the existence of street children is only the most visible part of the problem of children at risk, and children from socially vulnetable families. As the report emphasizes, the street children phenomenon is the end product of a complicated negative process. The factors determining this process are relevant for many others. The report, like the work done in Eldoret, concludes that in Central and Eastern Europe, poverty is obviously a core factor. But also along with poverty are numerous contributing factors, inchding public attitudes institutionalized in policy. These involves a dominant public attitude that has been the legacy from the old governmental regimes in Central and Eastern Europe as it is in Kenya; an exclusive reliance on a strategy of institutional care. Thus, as was found in our focus groups and key informant interview analysis, the core categrory of solving the problems through policy measures subsumes poverty and other causes under a wide array of options, that may be effective in changing the situation ance polices of the past are transformed.

This study has been a modest attempt to move towards a science-based approach to street children social welfare problems, their health and families. The limitations are obvious. The design of the study has been cross-sectional and thereforc was restricted to a descriptive and correlation level of scientific evidence. The next step in the hierarchy of evidence-based studies would be a non-experimental intervention study that targets some of the specific causal variables that have been suggested by our descriptive and correlation study. As mentioned above, family reunification interventions are the direction that seens warranted by our limited results. A strategy for implementing such as targeted intervention is currently being formulated as part of a pilot study. The full study will improve upon the cross-sectional design of this dissertation. The street children and their families will be followed up in a longitudinal cohort design that will allow for the direct observation of the causal linkages we inferred from our cross sectional design. Successful result derived from the implementation of this fanily ranification intervention would provide a basis for the next step, the development of controlled, randomized trial of a specific practice that would be addressed to change the social networks and psychopathologies associated with street children and their families. The objective of such a randomized study most likely will have to do with correcting the imbalance in the social networks of street children. For instance, community trials manipulating and influcncing core risk factors such as the absence of service providers, male care providers in the family sector and deficits in task orientation temperament could be forescen from the results of the present research. Such interventions would provide evidence in 
order to base a future "best" practice that effectively influences some of the fundanental causes that move the high-risk children onto the streets and keep them there.

It needs to be also seen that, there still will remain structural limitations even if a true best practice is used in future. Therefore, a constant reconsideration of the macroeconomic factors such as persistent poverty and drug abuse, should accompany any local community based analysis of interventions that target street children and their families. On the other hand, there is an inextricable link between the macro-level factors and the local micro-level, where street children struggle with their daily survival. The critical significance of this link was eloquently recognized by Nelson Mandela who said, "We must move children to the center of the world's agenda. We must rewrite strategies to reduce poverty so that investments in children are given priority". In this way, a good practice tangeting street children and their families could reciprocally fight back on the process that sustains persistent poverty.

The United Nations Children's Fund is well aware of these links and puts a dynamic spin on the process. The problems in the developing world interact with one another in what has been termed the "PPE (poverty, population and environment)-spiral" (Bellamy, 2002). However, an "upward spilal" is also described with the key components include health and nutrition, education and family planning. These three areas for potential improwement are all inextricably tied to the tip of the iceberg represented by the street children. A best practice in the field of street childran can have an impact far beyond the continum of high-risk groups, creating a synergism on the problems of the PPE spiral. Future research needs to be done and the objective of this study will have been mer if it makes a small, but significant contribution to building the capacity of African societies to implement evidence-based services and policy through the following three projects:

- Reunification of street children with their families followed up in a longitudinal cohort study.

- To contact national baseline survey to establish a reliable data on street children and other children in reed of special protection.

- Evaluate children residential programs in western Kenya to establish their strengths and weaknesses. 


\section{REFERENCES}

Aptekar, $\mathbb{L}$. (1994) Street children in the developing world: A review of their condicion, Cross-Cultural Research, 28, 195-224.

Ayuku, D. Kaplan, Ch., Herman, B. and deVries, M. (2004) Chancteristics and persond social networks of the on-themstreet, of-the-street, shelter and school children in Edoret, Kenym. International Sicial Work, 47 (3):293-311

Bellamy, C. (2002). The Sate of the World's Children 2002. Geneva, UNICEF

Bowlby, J. (1980) Attachment and loss (vol, 3) New York: Basic Books.

Cosgrove, J.G. (1990). "Towards a working definition of street children". Intemationsal Socid Work 33: $185-192$.

Campos, R., Antunes, C.M., Raffaeli, M. Halsey, N., Ude, W. Greco, M. et al. (1994) Social networks and daily activities of street youth in Belo Horizonte, brazil, Child Dewelopment, 65: 319-330.

DeSoto, H. 2000) The nystery of capital: Why capitalism triumphs in the west and hils everywhere else, New York. Banie Book.

Ennew, J. (1994) parentless friends: A cross-cultural examination of networks amongst Street children and street youth in Sockal Networks and Support in Chilhood and Adolesencence (Eds, Nestman, F and Husselmam, KK.) De Gruyter, Amsterdam, pp. 406-426.

Giddens, A. (1999) Runaway world how globalization is reshaping lives, London.

Giel, R. Arango, M.V., Climent, C.E., Harding, T.W., Ibrahim, H.A., Ladrido, I.L. and Yunis, Y. (1981) Childhood mental disonders in primary healel Care in 4 developing counutries, pediate rics, 68,677 .

Gross, R., Landfried, B. and Herman, S. (1996) Height and weight as a reflection of the nutritional situation of school-aged children working and living in the strects of Jakarta Soc Sci. Mod. Vol. 43: 453-458.

Human Rights Watch/Africa (1993) Divide and rule, state sponsored ethonic violence In Kenya, New York.

Human Rights Watch/Africa (197) Juvenile injustice police abuse and detencion of Stret children in Kenya, New York.

Kangethe, R. and Dhadphale. M. (1991). Prevalence of psychatric illucss among Kenyen Children, East African Mediral Jownual, 68, 526-531.

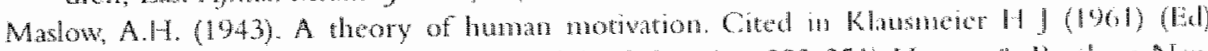

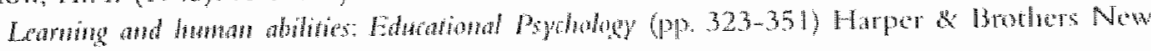
York.

Medina-Mora, M.E., Gutierrez, R. and Vega, L. 1997. What happened to street kids? An analysis of Mexicar experience. Substance Use \& Misuse, 32, 293-316.

Penton, R, (2000). Street Childiren in Ten Countries in Central and Enstern Europe - An Overview Addressing the World Bank Initiative. Stockholn, Stockholn University, Department of Social Work.

Ribeiro, M.O. and Trench Ciampone, M.H. (20n1). "Homeless thildren the lives of a group of

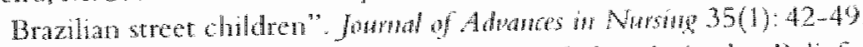

Richter, L.M. and Swart-Kruger, J (1993) Knowledge. Articudes, Beliefs and Beliaviour Patterns of street children in South Africa with regard to AlDS. Department of National Healdh and Population Development, Pretoria.

Rubin, D.H. Erickson, C.J, San Augustin, M. Cleary, S.D., Allen, J.K. and Coluen, P. (1990) Cognitive and academic functioning of homeless children compared with housed drildren, Pediaturic, $97,289-294$ 
Samerof, A.J. and Mackenzic, M.J. (2003) Reseatch strategies for capturing transactional models of development: the limits of the possible, Development And Psychopathology, $15 \mathrm{pp}$. $613+640$

Simon, H.A. (1978). Rationality ats process and product of thought. Cited In Carr S C. and Schumaker I F* (1996) (Ed) Psychology and the developing world (Pp 90-99) Praeger, Wesport.

Suda, C. (1999) African family and child welfare: Tradition in transition. Intematowal jowmat of contismpotary sociology 36 (1) $56-65$

Veali, A. (1997) Towards a conceptualization of street children: The case from Sudan and Ireland. Troaire Development Review, Dublin, $107-128$.

Valdez, A. Kaplan, Ch, and Codina, E. (2000) Psychopathology among Mexicar American gang members. A comparative study, International Jowmal of Offenders Therapy and Comparative Crinunology $44(1): 46-58$

Wainaina, J. (1981) The parking boys of Nairobi, Africa Journal of Sociology, 1: 7-45.

World Bank, (1995) Kenya Poverty Assessment, Washington. 


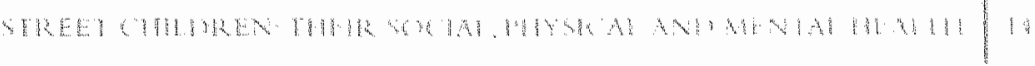

SUMMARY 
Street children in Africa are a recent development but frequently reflect patterns of urbanisation and capical economy introduced in the early $20^{\text {th }}$ century. In Kenya, the phenomenon of street chidren is emanating from the Europan experience between 1890 and 1963 . With the emergence of new towns, Nairobi, Mombassa, Eldoret, Nakuru and Kisumu among others, street children become part of the new development. At independence, street children had increased in number and ever since have become a problem not only for the Kenyan government, but also for voluntary and non-governmental organisations (NGOs). For instance, in 1997 the Child. Welfare Society of Kenya (CWSK) estinated that there were abour 625,000 chidren in especially difficult circumstances in the country. In the following year, the total number of street children in Kenya was estimated at 135,000.

In Kenya, street children mainly reside in urban areas, for example Eldoret, the study area. As shown in this study, street children in Eldoret can also be categorized into "on" the street, "of" the street, and shelter children. The "on" the street children were children who spend most of their time in the street pavements begging, working, scavenging for food and sniffing glue. $A$ significant feature of these children was their strong family links and usually returning to the family house to s]eep at night and contributing to the family household income. In contrast, "of" the street children were filly participating in street life at an economic and social level. Some of these children had family members in the slums of the town, but they had cut all links and preferred the streets and their freedom. Others had migrated alone from other towns. On the other hand, shelter children were former street children, abandoned, orphans, and others brought in the shelter by parents, who were unable to fulfil their physical needs, such as provide food and school fee. The reference group was the school chil dren that come from the same slum areas of town like the street chidren. Generally, street children in Eldoret and their families are by and large products of massive urbin migration, due to rural poverty, family discond, and displacement from their land by the 1991-1993 ethnic clashes.

Chapter 1 introduces the reader to the Kenyan socio-economic situation and the ghobal and locil perspective of street children. The majority of world's street children are boys, Kenya included. The objectives of this study were to: (1) describe street children's own perspectives on the causes of becoming a street child, activities on the streets, and rehabilitation possibitities; (2) describe public perspectives of the causes of becoming a street child and rehabilitation of street children: (3) describe the personal social networks of street children, their case profiles, and compare the social network of street children with the reference 
group; (4) evaluate the nutritional status of the street children with the reference group and (5) measure the temperament of the street children with the reference group.

Chapter 2 describes research methodology. Multiple assesment approaches we used, relaying heavily on the use of qualitative ethographic techniques combined with standardized sociometric and psychometrics tests. The research design was cross-sectional study, site and recruiment of subjects, modifoations of the study instruments and data analysis.

Chapter 3 reported range of factors to why the children were living onto the streets: poverty, lack of food at home, school fee, and love, physical abuse from parents and relatives, and desire to be independent, earn money for self and assist the family. The school children and service providers endorsed these same factors with a few additions such as peer pressure, single motherhood and rural urban migration. The children's activities on the street are centred on scavenging, begging, stealing, sniffing glue, sexually acting and in same instances fighting among themselves, or being beaten by the public. The public supported the above factors in addition to ethric clashes and single motherhood. Besides, gender differences were noted, where females endorsed dysfunctional families and alcoholic parents; and males endorsed child abuse and prostitution. The public advocated for physical removal of street children to rehabilitation centres and returning the ethnic clash victims back to their land. While street children advocated for their present needs fulfiment such as food, clothing and shelter.

Chapter 4 the MSNA provided a social network diagnosis of "on" the street and "of" the street children. Using fimmy as a case study, he is on the stree to support his family as breadwinner. Instead of going to school he has opted for short-term economic survival strategies. On the other hand, the necessicy of considering gender differences in the protiles of street children is evidenced by the case of Jimmy and Turu. For example, the case of Turu shows how dinerent social support functions and size of the nework can be between strect ginls and boys. Thus, despite the high level of social support indicated in this case, the relatively snaller network size of street grits makes them mone vulnemble. One or two friends lost could have disastrous effects on the social support of these girls. The case of Turu also points to the ambiguous, gender-related issue of connercial sexual work.

Chapter 5 describes the characteristics and personal social network of "on" the street, "of" the street, shelter and school children. The streec children have larger 
family networks but lacked social services support compared with the control groups, which have a more balanced network between family, friends and helpers.

Chapter 6 describes the nutritional status of the compared groups. Contrary to popular expectations, the "of" the street children showed fewer signs of malnutrition, indicating their ability to cope under hostile conditions. Difference in the average weight, also favoured the "of" the street children when compared to children at the shelter. Their Body Mass Index (BMI) levels, however, were lower, indicating that this group is suffering under the constant stresses of street life.

Chapter 7 describes the temperament of each group of children in the study. The results clearly support much of the earlier research on the street children, that counter to pablic opinion and hostility towards them, they are a highly resilient group. Displaying a high degree of adaptability and flexibility in the face of adversity and, because of their special psychological characteristics, remaining remarkably well adjusted as individuals with an extraordinary positive mood.

Chapter 8 deals with discussion and conclusions of the study. Conclusions and recommendations are based on the findings that provide a picture of street children that runs counter to current stigmatised beliefs. These findings alter the contours of the current picture we have of street children. In contrast to the public view that street children are socially isolated, physically wasted, with troublesome temperaments and negative social attitudes; we find that they exhibit positive mood and easy temperaments. Besides, they have relatively good health and nutrition, and sometimes extensive alternative social networks. The implication of these multiple results is truly radical. Despite the social problems with violence and substance abuse, street children as a special group of children in difficult circumstances, are not essentially social defaced and misfits, but a potential social benefit to the development of society. 


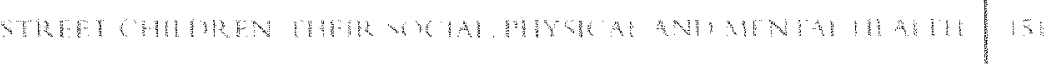

SAMENVATTING 
Stratkinderen in Afrika vormen een betrekkelijk recent verschijnsel dat evenwel voor een belangrijk deel is terug te voeren op factoren als verstedelijking en het ontstaan van staatseconomieën in het begin van de $20^{*}$ eeuw. In Kenia komt het probleem van de stratkinderen dan ook voort uit de koloniale periode tussen 1890 en 1963. Met de opkomst van nieuwe steden zoals Nairobi, Mombassa, Eldoret, Nakuru en Kisumu, is het aantal straatkinderen navenant toegenomen en sindsdien niet alleen het probleem van de Keniaanse overheid, maar ook van vrijwilligersorganisaties en NGOs geworden. In 1997 schatte de Child Welfare Society van Kenia dat er ongeveer 625,000 kinderen in het land waren die in buitengewoon zware omstandigheden verkeerden. Het aantal straatkinderen werd, een jaar later, geschat op 135,000.

De stratkinderen van Kenia verblijven voornamelijk in de steden, zoals dat ook geldt voor het studiedomein: Eldoret. In het algemeen gesproken komt het probleem van de straatkinderen van Eldoret voort uit omvangrijke stedelijke migraties, gevoed door armoede, familietwisten en de etnische conflicten tussen 1991 en 1993.

Zoals het onderzoek laat zien zijn de stratkinderen van Eldoret in te delen in "on the street" en "of the street" en kinderen die een vorm van opvang kennen. "On the street" kinderen brengen de meeste tijd door met afval doorzoeken, bedelen, werken, en lijm snuiven. Zij hebben wel een sterke gezinsband, dragen bij aan het gezinsinkomen, en keren dan ook gewoonlijk naar huis terug om te slapen. De "of the street" kinderen daarentegen, nemen volledig deel aan het straatleven, zowel in sociaal als in economisch opzicht. Sommigen van deze kinderen woonden vroeger in de krottenwijken van Eldoret bij hun fanilie, maar hebben alle banden met hun verleden verbroken en de voorkeur gegeven aan de vrijheid van de straat, anderen zijn uit andere steden gemigreerd. De kinderen in opvang zijn doorgaans ex-stratkinderen, verlaten wezen, terwijl anderen door de ouders in opvang gegeven zijn ondat zij niet in staat waren voor eten, school en schoolgeld te zorgen. De referentiegroep in het onderzoek wordt gevormd door schoolgaande kinderen uit dezeltde sloppenwijken watruit ook de stratkinderen komen.

Hoofdstuk 1 geeft een inleiding in de Keniananse sociaal-economische situatie en het globalle en locale perspectief op het probleem wan stratkinderen. Het doel van het onderzoek is het leven op straat, de carrière van een straatkind en mogelijke oplossingen, vooral te beschrijven vanuit het perspectief van de kinderen zelf en dat te contrasteren met opvattingen van hulpverleners en het algemene publick. Een tweede doel van het onderzoek is het in kaart brengen 
van de sociale newwerken van de stratkinderen en deze te vergelijken met die van de kinderen uit de referentiegroep. De volgende doelstelling is het vaststellen van de voedings- en gezondheidssituatie van de stratkindenern en deze te vergelijken met de referentiegroep. Tenslotte besteedt het onderzock aandacht aan de temperament of de prikkelbarheid van de kinderen, wederom in vergelijkend perspectief.

Hoofdstuk 2 gaat in op de onderzoeksmethoden. Er zijn verscheidene methoden toegepast die de gewenste combinatie vormden van kwalitatieve, etnografische techmieken an de ene kant en gestandardiseerde socio- en psychometrische testen aan de andere kant.

Hoofdstuk 3 beschrijt de bevindingen van de focusgroepen van stratkinderen, schoolkinderen, hulpverleners en leden van het algemene publiek. In het algemeen bestaat er overeenstemming over de oorzaken van het probleem straatkinderen: armoede, gebrek an voedsel thuis, mishandeling door ouders en familieleden en de wens onahankelijk geld te verdienen. Schoolkinderen, hulpverleners en leden van het publiek geven daabij nog druk van de peergroep, het hebben van een alleenstaande moeder, alcoholisme van de ouders, misbruik en prostitutie, als oorzaken aan. De belangrijkste bezigheden van de straatkinderem zijn het doorzoeken wan afval, bedelen, stelen, lim snuiven, seksuele activiteiten en soms deelname aan onderlinge vechtpartijen. Het publiek stat vooral het verwijderen van de kinderen van de straat voor door hen op te nemen in rehabilitatie instellingen of door slachtoffers van de etnische conflicten te doen terugkeren nar hun oorspronkelijke woonplats. De straatkinderen zelf daarentegen hebben vooral behoefte aan het opheffen van de acute behoeften zoals honger, kleding en opvang.

In Hoofdstuk 4 worden de resultaten van de diagnostische warde van de Maastricht Social Metwork Analysis (MSNA) voor stratkinderen besclurevent. In het geval van Jimmy met zijn alleenstaande moeder kon een sociall netwerk mechanisme worden gespecificeerd wardoor armoede als oorzak fungeert voor het stratkinderen verschijnsel. De weinige inkomsten van zijn moeder in de informelle economische sector zijn onvoldoende om fimmy te onderstem in zijn rol als kostwinner. In plats van voor de school kiest hij voor korte termijn economische overlevingstrategieen. De casus van Turu illustreert het gendemaspect van de sociale netwerken van stratkinderen. In hatr geval is sprake van een hoge mate wan sociale steun, maer door haar relatief kleine notwerk is toch sprake wan kwetsbarheid. Jongens hebben vaker een groter netwerk w zijn in dit opzicht minder kwetsbatr. 
Hoofdstuk 5 handelt over de algemene kenmerken van de kinderen van de vier onderzoeksgroepen. De straatkinderen hebben, in vergelijking met de referentiegroep, een groter familienetwerk, maar hebben minder contacten met de sociale instellingen. Kinderen van de referentiegroep hebben een meer evenwichtig samengesteld netwerk naar familie, wrienden en hulpverleners.

Hoofdstuk 6 geeft een overzicht van de voedingsstatus en gezondheid. Straatkinderen lijken geen groeiachterstand te hebben in vergelijking met de schoolgaande kinderen. De "of the street" kinderen hebben wel vergelijkenderwijs een slechtere gezondheid en lagere BMI met daarnaast meer drugsen alcoholmisbruik. De prevalentie van "wasted" kinderen is desondanks relatief laag voor stratkinderen.

De resultaten in Hoofdstuk 7 betreffende de assessment van het temperament van de straatkinderen ondersteunen de conclusies uit eerder onderzoek dat in tegenstelling tot de eenvormige negatieve publieke opinie, de groep een grote diversiteit in temperament laat zien en hoge mate van veerkracht en positieve stemming tentoon spreiden. Ondanks de vijandige omgeving blijven ze flexibel en kunnen ze zich goed aanpassen aan hun omgeving.

In Hoofdstuk 8 worden de discussie en conclusies voor beleid gepresenteerd. Deze conclusies zijn gebaseerd op de bevinding dat stratkinderen in tegenstelling tot de negatieve publieke opinie een groep is met een relatief goede voedingsstatus, positieve sociale relaties en een flexibel temperament. Een groep die ondanks veel sociale tegenslagen in staat is om zichzelf in stand te houden. Suggesties voor interventies zijn gebaseerd op het mogelijke sociale kapitaal dat deze groep vertegenwoordigt voor de samenleving in ontwikkelingslanden. 


\section{ADDENDUM}

Table 1. Reliability of DOTS-R Dimensions for US-Elenentary, Kenyan Puinary School Children, Compared With the "on" the Street, "of" the Street and Shelter Chidren

\begin{tabular}{|c|c|c|c|c|c|c|}
\hline Activity level General & 7 & .75 & .59 & .57 & .23 & .42 \\
\hline Activity level Sleep & 4 & .81 & .34 & .38 & .22 & .03 \\
\hline Approach/Withdrawal & 7 & .77 & .34 & .27 & .06 & .06 \\
\hline Flexibility/Rigidity & 5 & .62 & .47 & 41 & .15 & .23 \\
\hline Mood & 7 & 80 & .47 & .38 & .83 & .26 \\
\hline Rhythmicity-Sleep & 6 & .69 & .63 & .51 & .21 & .51 \\
\hline $\mathbb{R}$ hythmicity-Eating & 5 & .75 & .65 & .39 & .18 & .30 \\
\hline Rhythmicity-Daily habits & 5 & .54 & .13 & .13 & .12 & .31 \\
\hline Task Orientation & 8 & .70 & .58 & 44 & .08 & 40 \\
\hline
\end{tabular}

Note: Cronbach"s alpha was used to assess reliability The Ns for ref. US-Elcnentary, children, Kenyan School, Shelter." On" the street, and "Of" the street children samples for calculation of alpha ane 224,51, 51,5 land 51 respectively.

Table 2. Socio-demographic, Social Network, Psychological and Health Status Characteristics of Eldoret Children

Socio-demographic

\begin{tabular}{|c|c|c|c|c|}
\hline Male & 87 & 89 & 77 & 72 \\
\hline Fernale & 13 & 11 & 23 & 28 \\
\hline Mean age & 13.3 & 3.6 & 12.7 & 13.8 \\
\hline Soavenging & 78 & 98 & $i$ & 0 \\
\hline 2 parcents & 25 & 1 & 3 & 57 \\
\hline Sungle paront & 46 & () & 4 & 28 \\
\hline No education & 21 & 16 & 0 & a \\
\hline \multicolumn{5}{|l|}{ Social Nerwork } \\
\hline Mean size & 109 & 11.7 & 17.6 & 16.2 \\
\hline ytamily & 54 & 48 & 40 & 42 \\
\hline "y mriendly relations & 36 & 41 & 31 & 30 \\
\hline WService providors & 10 & 11 & 20 & 27 \\
\hline \multicolumn{5}{|l|}{ Psychological } \\
\hline Mean DOTSun & 13.4 & 13.8 & 130 & 12.8 \\
\hline \multicolumn{5}{|l|}{ Healch Stattus } \\
\hline Skm diseases & 10 & 3 & 5 & 3 \\
\hline Orher distases & 8 & 13 & 3 & 12 \\
\hline Drug misusc & 26 & $70)$ & 27 & 2 \\
\hline
\end{tabular}

$t=N$ of $400 ;=N$ of 204 
$m$ 


\section{CURRICULUM VITAE}

David O. Ayuku was born on 2 September 1956 in Kakamega, Kenya. Ayuku completed primary and high school education in Kenya. The sort for Kenya Certificate of Education in 1971 and East Africa Certificate of Education in 1975. Proceeded to the United States of America (USA) where he undertook both his undergraduate and graduate studies. He obtained a Bachelor of Science (BSc) in Psychology in 1980 from Mid-American Bible College (formerly Gulf-Coast Bible College, Houston, Texas); and Master of Arts (MA) in Clinical Psychology in 1985 from Texas Southern University, Houston, Texas.

While undertaking graduate studies and after graduation (MA in Clinical Psychology), Ayuku worked as an Associate Clinical Psychologist If at the Richmond State School (for mentally retarded children in the USA). Thereafter, he left the USA to join the Faculty of Health Sciences, Moi University (in Eldoret, Kenya), in March 1990. Since March 1990, Ayuku has worked as a Lecturer in the Department of Behavioural Sciences. He also works as a clinical psychologist, providing psychotherapy and counselling services at Moi Teaching and Referral Hospital and other private hospitals within Eldoret. He is married with four children (ages, 22, 21, 17 and 11).

Ayuku's study and research interest on child health and development (with special interest on street children) has been ongoing for over a decade. Based on this research interest, he has published and co-authored a number of publications. 


\section{PUBLICATIONS}

Ayuku, D.O et al (1991) Interviewng: A mannal on intervieuring for Healh Professionals, Moi University.

Moss, W., Bentley, M., Ayuku, D.O., Egesah, O. Sweat, M., Narango, P. Zeniman, J., Chemtai, A., Halsey, N. (1999) Foundations for effective strategies to control sexually transwitted infections: Votces from Rural Kenya. AIDS CARE. VOT. 11, 1, pp.95-113.

Nangulu-Ayuku, A., Ayuku, D.O. (2000) (Book Review in: Journal of Third World Studies, Fall 2000 pp 265-268) Weisner, Thomas S. Candice Bradley, and L. Kolbride (Eds). African fonilies and the Crisis of Sorial Change. Westport, CT \& London: Bergin \& Garvey, Pp. 369.

Ayuku, D. O (2001) A case study of street children in Kenya: In Unwersities and the Health of The Disadvantaged (Eds), Blumenthal, D. S. and Boelen, World Health Organization, Geneva, pp. 81-82.

Ayuku, D.O. Kaplan, C.D., Baars, H.M.). and deVries, M.W. (2004) Characteristics and personal social networks of the "on" the street. "of" the street, shelter and school children in Eldoret, Kenya, Intemational Social Work, 47 (3): 293-311, Sage Publication.

Ayuku, D.O., Odero, W., Kaplan, C.D., deBruyn, R. and deVries, M. W. (2003) Social Network Analysis for Health and Social Interventions among Kenyan Street Children. Healh Policy and Planning; 18 (1): 109-118. Oxford University Press.

Odero, W. and Ayuku, D.O. (2003) Violence and Alcohol: A study of injury presentations to emergency departments in Eldoret, Kenya. African Safety Promotion, A foumd of Injwy and Violence Prevention, 1 (2):38-42.

Ayuku, D.O., DeVries, M.W., Arap Mengech, H.N.K., Kaplan, C.D. (2004) Temperament Characteristics of street and non-street children in Eldoret, Kenya. African Health Scienos Joumal, 4(1):24-30.

Ayuku, D.O., Ettyang, G., Odero, W. (2004) Psycho-social and Nutritional Status of Street Children In-comparison to School Children: A Case of Eldoret Town, African Joumal of Food, Agricultute, Nutrition and Development. 4(1): $1-11$ 